\title{
Klein: Proceso de desarrollo de software con trazabilidad de requerimientos, documentación mínima y aplicable con equipos pequeños y distribuidos
}
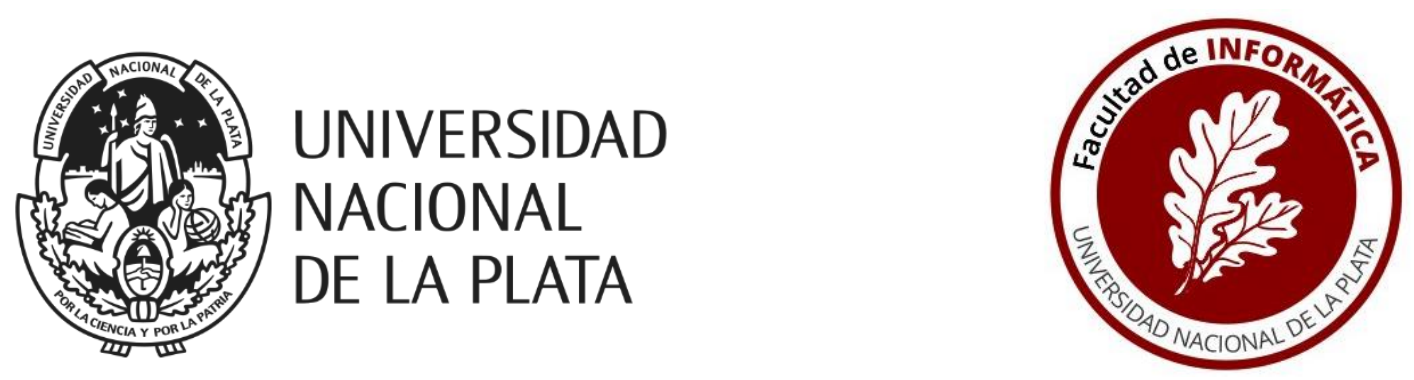

\author{
Pablo Claus \\ Director: Leandro Antonelli \\ Codirectora: Alejandra Beatriz Lliteras \\ Tesis presentada para obtener el grado de \\ Magíster en Ingeniería de Software
}

Facultad de Informática

Universidad Nacional de La Plata 


\section{Resumen}

El desarrollo de software es complejo por naturaleza, tanto por el proceso, como por el conocimiento que debe plasmar y finalmente porque requiere satisfacer las necesidades del cliente. Cada vez más empresas les exigen a sus proveedores de software una certificación de calidad, para lo cual se tienen que contar con un proceso estándar que tenga trazabilidad de los requerimientos desde el punto de vista del cliente. Por otro lado, contar con documentación sencilla y puntual contribuye a que tanto los clientes como el equipo de desarrollo puedan mitigar el impacto de la tendencia a leer de manera superficial fomentado por Internet, los teléfonos, los relojes inteligentes y las redes sociales. Además, si el desarrollo tiene que ser realizado por un equipo pequeño, de menos de 5 integrantes, y con alguno de sus miembros distribuido geográficamente, la tarea puede ser abrumadora.

Este trabajo propone un proceso de desarrollo que enfatiza los siguientes pilares: 1) Lograr la trazabilidad de los requerimientos, 2) haciendo foco en la documentación mínima, 3) que pueda ser utilizado por equipos pequeños y 4) con al menos uno de sus integrantes distribuido geográficamente. Si bien hay varias propuestas para desarrollar software, desde el desarrollo clásico hasta el ágil, ninguna cumple con los 4 pilares de manera simultánea. El proceso propuesto fue validado a través de un caso de estudio que duró 18 meses. El mismo consistió en un desarrollo de un producto de software para un cliente comercial. Para analizar los resultados del caso de estudio se utilizaron datos cuantitativos y cualitativos. Finalmente, como un aporte sustancial, en 2019 la empresa en la que se aplicó el proceso propuesto en esta tesis certificó la norma de calidad ISO 9001.2015 para desarrollo de software utilizando Klein como estándar.

Palabras claves: Desarrollo de Software, Ingeniería de Software, Trazabilidad de Requerimientos, Equipos Pequeños, Equipos Distribuidos, Documentación Mínima. 


\section{Agradecimientos}

Este trabajo fue el producto de varios años de investigación y trabajo. Por supuesto, solo es posible gracias al ánimo y los consejos de muchas personas. En primer lugar, quiero agradecer a mi mujer Laura por su apoyo durante toda la carrera que implicó dedicarle menos tiempo a ella por tener que investigar, estudiar y viajar a La Plata. A Daniel, Carolina, Paula y mi tía Tere por su interés sincero en mi progreso como profesional. Por otro lado, quiero dar gracias a todos los participantes que hicieron posible la realización de este trabajo: Gonzalo, Luis, Franco, Alberto, Jorge, Adolfo y Marcelo. Una mención especial para Luis Barrientos y Alberto Vázquez por permitirme hacer la maestría y por darme luz verde para poner en práctica lo que aprendí en la empresa. Por supuesto muchas gracias a Leandro Antonelli y a Alejandra Literas por aceptar ser mis directores. Fueron muy pacientes conmigo y sus aportes significativos permitieron darle a este trabajo la formalidad y el nivel requerido. 


\section{Índice}

Capítulo 1. Introducción 1 Capítulo 2. Background

Desarrollo de software ágil

Lectura superficial

9

Capítulo 3. Trabajos Relacionados

\begin{tabular}{ll}
\hline & 18 \\
\hline 1
\end{tabular}

Resumen de los trabajos relacionados 31

\begin{tabular}{ll}
\hline Tabla comparativa & 44 \\
\hline
\end{tabular}

Capítulo 4. Klein: Proceso de desarrollo propuesto

Principios del proces 46

\begin{tabular}{|c|c|c|}
\hline & Principios del proceso & 46 \\
\hline & Proceso de desarrollo propuesto & 48 \\
\hline & Otras consideraciones & 58 \\
\hline & Ciclo de entrega: un ejemplo de aplicación & 59 \\
\hline Capítulo 5. Caso de estudio & & 61 \\
\hline & Objetivos y preguntas de investigación & 61 \\
\hline & Diseño del caso de estudio & $\overline{62}$ \\
\hline & Ejecución & 65 \\
\hline & Resultados & 70 \\
\hline & Evaluación de validez & 76 \\
\hline & Limitaciones y conclusiones & 76 \\
\hline Capítulo 6. Conclusiones & & 79 \\
\hline Referencias & & 82 \\
\hline Apéndice & & 88 \\
\hline & Encuesta para obtener información cualitativa & 88 \\
\hline & Respuestas a las encuestas cualitativas & 89 \\
\hline & Red de códigos cualitativos & 95 \\
\hline & System Usability Scale & 96 \\
\hline & Estándar certificado con la norma ISO 9001.2015 & 97 \\
\hline
\end{tabular}




\section{Índice de Figuras}

Capítulo 2. Background

\begin{tabular}{lll} 
FIGURA 2.1 & Ejemplo de tablero Kanban & 18 \\
\hline FIGURA 2.2 & Ejemplo de lectura en forma de "F" & 20 \\
\hline FIGURA 2.3 & Teorema de Valor Marginal & 27 \\
\hline FIGURA 2.4 & MTV influenciado por el aburrimiento y la ansiedad & 28 \\
\hline FIGURA 2.5 & MVT incluyendo la accesibilidad de información & 30
\end{tabular}

Capítulo 4. Klein: Proceso de desarrollo propuesto

\begin{tabular}{lll} 
FIGURA 4.1 & Proceso de desarrollo Klein & 47 \\
\hline FIGURA 4.2 & Tablero Kanban con los requerimientos como tareas & 52 \\
\hline FIGURA 4.3 & Tablero Kanban con las tareas en ejecución & 54 \\
\hline FIGURA 4.4 & Ejemplo de dos ciclos de entrega & 60 \\
\hline & & 63 \\
\hline FIGURA 5.1 & Arquitectura de la solución & 68 \\
\hline FIGURA 5.2 & Arquitectura de microservicios
\end{tabular}




\section{Índice de Tablas}

Capítulo 3. Trabajos Relacionados

TABLA 3.1 Comparación entre los trabajos relacionados

Capítulo 4. Klein: Proceso de desarrollo

propuesto

\begin{tabular}{lll} 
TABLA 4.1 & Documento “Iniciación" & 49 \\
\hline TABLA 4.2 & Documento "Definición Preliminar" & 51 \\
\hline TABLA 4.3 & Documento “Revisión" & 57 \\
\hline TABLA 4.4 & Resumen del proceso & 57 \\
\hline
\end{tabular}

Capítulo 5. Caso de estudio

TABLA 5.1 $\quad$ Detalle de iteraciones proyecto "Interfaz" 66

\begin{tabular}{lll}
\hline TABLA 5.2 & Detalle de iteraciones proyecto "Microservicios" & 67
\end{tabular}

\begin{tabular}{lll}
\hline TABLA 5.3 & Códigos cualitativos & 70 \\
\hline
\end{tabular}

\begin{tabular}{lll}
\hline TABLA 5.4 & Ocurrencia de códigos cualitativos & 71 \\
\hline
\end{tabular}

\begin{tabular}{lll}
\hline TABLA 5.5 & Ocurrencia binaria de códigos cualitativos & 72 \\
\hline
\end{tabular}

\begin{tabular}{lll} 
TABLA 5.6 & Rating SUS & 72 \\
\hline
\end{tabular}

\begin{tabular}{lll} 
TABLA 5.7 & Resultados de la encuesta SUS & 73 \\
\hline
\end{tabular} 


\section{Capítulo 1 Introducción}

$\mathrm{E}$ N LAS DÉCADAS anteriores al año 2000 el desarrollo de software consistía en grandes equipos trabajando juntos con roles específicos y gran cantidad de documentación. Por ejemplo, en 1970 Winston Royce presentó el modelo Waterfall (Royce, 1970) como una manera de reducir los costos en el desarrollo de software. El modelo original contaba con seis etapas: requerimientos de software, diseño, codificación, pruebas, operación y mantenimiento. Las etapas se realizaban en secuencia y el énfasis estaba en la documentación extensa para evitar olvidos en etapas posteriores. En 1985 el Departamento de Defensa de Estados Unidos adoptó este enfoque como estándar de desarrollo para todas las empresas que desarrollaran software militar (Department of Defense, 1988). Dicho estándar requería que se incluyan las etapas de análisis de requerimientos, diseño preliminar, diseño detallado, codificación y pruebas de unidad, integración y pruebas. Aunque ya pasaron muchos años, todavía hay variantes del modelo Waterfall que en la actualidad continúan utilizándose en proyectos de desarrollo de software.

A principios de los años 90 el enfoque de muchos equipos de desarrollo pasó de la programación estructurada a la orientada a objetos. Ante esta situación, en 1996, Jacobson estableció las bases del Proceso Unificado Rational (RUP) descrito en 1999 (Jacobson, 1999). Este es un proceso de desarrollo de software que junto con el Lenguaje Unificado de Modelado (UML), constituyó una metodología estándar para el análisis, implementación y documentación de sistemas orientados a objetos. Las principales características de RUP son desarrollo iterativo, administración de requisitos, uso de arquitectura basada en componentes, control de cambios, modelado visual del software y verificación de la calidad del software. Este proceso, al igual que Waterfall, demanda gran cantidad de documentación. El objetivo es que cada equipo decida, dependiendo del proyecto, los elementos del proceso que sean adecuados. RUP está pensado para equipos grandes de desarrollo.

A finales de la década de los 90 muchos proyectos de desarrollo fracasaban, ya sea por no cumplir con lo solicitado por el cliente o porque los tiempos de desarrollo se extendían tanto, que las empresas y sus necesidades no eran las mismas al inicio que al final del proyecto. Como reacción a esta situación, tomaron mucha fuerza las metodologías ágiles (Agile Alliance, 2001), que buscaban reducir la cantidad de documentación de los proyectos de desarrollo y focalizarse en la entrega de valor hacia el cliente. $\mathrm{Mu}$ chos desarrolladores se dieron cuenta de que la manera de crear software no estaba funcionando y era necesario pensar algo distinto. Estos desarrolladores comenzaron a mezclar ideas antiguas y nuevas y cuando encontraron una combinación que funcionó, crearon una metodología para su equipo. Estas metodologías enfatizaron la estrecha colaboración entre el equipo de desarrollo y las partes interesadas del negocio, la entrega frecuente de valor comercial, equipos compactos y autoorganizados y formas inteligentes de crear, confirmar y entregar código. La retroalimentación rápida y la 
voluntad de cambio resultaron ser las características clave del movimiento ágil. Si el equipo de desarrollo no estaba seguro de lo que el usuario necesitaba, le ofrecía una primera aproximación y luego escuchaba los comentarios. Algunas propuestas ágiles son Scrum (Sutherland, 2017), Extreme Programming (Beck, 2004) y Kanban (Anderson, 2016). Para utilizarlos es necesario contar con equipos que trabajen juntos, en el mismo lugar físico. Sin embargo, cada vez es más común que los equipos de desarrollo tengan integrantes multidisciplinarios y distribuidos geográficamente (Robinson, 2019).

En las últimas décadas, se ha visto un aumento significativo de la complejidad inherente a los proyectos de desarrollo de software. Esta complejidad se debe a la evolución natural de las características que ofrecen las innumerables tecnologías y sistemas de software disponibles y al mayor grado de sofisticación de los proyectos (Johnsson \& Magnusson, 2019) (Zhi-peng \& Guiming, 2019). Por otro lado, la gran cantidad de información sensible que almacenan las empresas, la cantidad de usuarios y la necesidad de garantizar la compatibilidad entre diferentes plataformas han aumentado la dificultad de los proyectos al requerir mecanismos de seguridad avanzados (Venson \& Guo, 2019). La necesidad cada vez mayor de reducir el tiempo de comercialización disminuye los márgenes de error, lo que aumenta la presión aplicada a los equipos para entregar un mejor software en menos tiempo. Para reaccionar ante este escenario, las grandes corporaciones han respondido estableciendo asociaciones con fábricas de software y, en algunos casos, creando sus propios centros de desarrollo en el extranjero. Éstos podrían ser una buena solución para empresas y proyectos a gran escala. Sin embargo, son inadecuados para algunas pequeñas y medianas empresas (PyMES) dada la naturaleza corta de sus proyectos (Monteiro \& Borges, 2012). Como consecuencia de los problemas anteriores, las PyMES requieren metodologías con el potencial de ayudarlas a hacer frente a los desafíos que enfrentan. Por ejemplo, utilizar un proceso con un equipo de menos de cinco personas es un desafío para muchas empresas, aun utilizando metodologías ágiles (Cerqueira \& Magalhães, 2018).

Algunas empresas requieren hacer una asignación de trabajo para su equipo eficiente y para reducir costos buscan desarrollar y mantener los sistemas con pocas personas distribuidas geográficamente, trabajando desde su casa, para no requerir espacio físico (Wang \& Luo, 2017). Por otro lado, si sus clientes son empresas grandes que requieren que sus proveedores tengan una certificación de calidad, las empresas tienen la obligación de contar con un proceso estándar que tenga la trazabilidad de los requerimientos. Finalmente, contar con documentación sencilla y puntual contribuye a que tanto los clientes como el equipo de desarrollo puedan mitigar el impacto de la tendencia a leer de manera superficial (Carr, 2011). Por lo tanto, este tipo de empresas necesitan que sus proyectos puedan ser aplicados a equipos pequeños y distribuidos geográficamente, cuya documentación sea mínima y con trazabilidad de los requerimientos. A continuación, una explicación de lo que abarca cada uno de los puntos mencionados.

Un "equipo pequeño" es aquel formado por menos de 5 integrantes. Hay equipos de desarrollo que, buscando estandarizar su proceso, se han inclinado hacia las metodologías ágiles utilizando Scrum en todos sus proyectos. Quizás en un proyecto donde todo el equipo participa se puede aplicar Scrum cumpliendo con los roles y las exigencias del framework, pero ¿qué sucedería si, en alguna iteración particular, solo deberían 
intervenir 2 o 3 integrantes? Forzar la aplicación de Scrum, haciendo que un desarrollador cumpla varios roles a la vez y con un equipo menor al requerido no puede tener buenos resultados (Sutherland \& Schwaber, 2017). En ese caso no quedaría otra que utilizar otro framework. Pero eso haría que, en un mismo proyecto, se utilicen metodologías diferentes, con estándares diferentes. Podría suceder que en la versión 1 se utilice Scrum, en la versión $2 X P$, en la versión 3 nuevamente Scrum y quizás en la versión 4 otra metodología. Esta situación podría dificultar el mantenimiento. Por ejemplo ¿qué pasaría si un desarrollador tiene que mantener una versión hecha aplicando XP cuando no tiene experiencia en el mismo? Así que un requisito importante es contar con un proceso de desarrollo que sirva de estándar y que pueda aplicarse independientemente de la cantidad de integrantes del equipo.

Es cada vez más común contar con uno o más miembros del equipo distribuidos geográficamente. La pandemia de COVID-19 ha forzado esta situación en muchos casos. ¿Qué sucede si el proceso de desarrollo que el equipo utiliza requiere interacción personal en el mismo lugar físico? No es aplicable si alguno o todos están distribuidos. Por ejemplo, si se utilizara un tablero Kanban físico ¿cómo se podría utilizar si no se puede estar físicamente en la oficina? Situaciones como estas han obligado a las empresas a adaptarse invirtiendo tiempo y recursos para que el equipo pueda trabajar remotamente. Por lo tanto, contar con un proceso estándar que pueda utilizarse tanto en la oficina de manera presencial como de manera remota es una ventaja importante. Esto incluye tableros en la nube, código fuente distribuido, VPN, herramientas de mensajería instantánea y videoconferencias y otras herramientas de colaboración en línea.

La tendencia a leer de manera superficial es cada vez más común en la era de la tecnología. Sin duda que esto afecta tanto a los integrantes del equipo como a los clientes. Quizás en otra época era normal leer libros para capacitarse o grandes manuales de usuario, sin embargo, en muchos casos la tendencia apunta hacia exactamente lo contrario. Muchas personas prefieren textos cortos, de lectura fácil y con imágenes y resúmenes a textos largos y densos. En este contexto, quizás pedirle al equipo de desarrollo que, para aplicar XP, deba leer algunos libros en inglés sobre Test-Driven Development ${ }^{1}$ no tenga la mejor recepción. Lo mismo en el caso del cliente o el usuario, requerir que lea documentación extensa y técnica quizás no sea de su agrado. Por lo tanto, es importante que los documentos que formen parte del proyecto tengan un enfoque ágil y conciso, lo que incluye las instrucciones de cómo aplicarlo.

En muchas empresas, por cuestiones de normas de calidad, se necesita tener trazabilidad de los requerimientos aprobados por el cliente de manera explícita, lo que implica que el cliente debe firmar documentos donde apruebe la idea inicial del desarrollo, los requerimientos a desarrollar y, finalmente, con el producto funcionando, dar su consentimiento de haber recibido lo que solicitó. Sin embargo, como sucede en varias partes del mundo, quizás el equipo ha decidido utilizar Kanban como estándar de desarrollo, sin embargo, ¿cómo se le puede mostrar a un auditor de calidad que lo que se desarrolló es lo que el cliente solicitó? ¿dónde firmó el cliente lo que quería y dónde su conformidad con lo que se le entregó? Pero esto no es solo el caso de Kanban, ya que el mismo

\footnotetext{
${ }^{1}$ Práctica que involucra escribir las pruebas primero, codificar y refactorizar. El concepto está explicado en el libro Test-Driven Development con ejemplos de Beck (Beck K. , 2002)
} 
problema se presenta con otros enfoques ágiles, carentes de documentos de este tipo. Por lo tanto, se necesita un proceso de desarrollo que como estándar incluya documentos que tracen los requerimientos.

Antes de la revolución de las redes sociales, los smartphones e internet, las personas acostumbraban a leer gran cantidad de artículos impresos. Era normal leer novelas, revistas o diarios extensos. Leer libros para capacitarse era totalmente normal. Sin embargo, con la llegada de la era de la tecnología, todo cambió. Numerosos estudios muestran que hay una tendencia cada vez mayor a leer de manera superficial (Carr, 2011). Los textos largos se están cambiando por cortos y puntuales, ya que a las personas les aburre leer contenido extenso de manera sostenida (Gazzaley, 2016). Este documento de tesis aplica lo anteriormente expuesto, por lo cual los conceptos se presentan de manera concisa.

Como parte de este trabajo de tesis se analizaron diferentes propuestas de desarrollo de software que van desde las clásicas hasta las ágiles con el objetivo de identificar insuficiencias para su aplicación en: equipos pequeños, distribuidos geográficamente, en proyectos que requieran trazabilidad de los requerimientos y documentación mínima. Este aspecto de la documentación es una característica de las metodologías ágiles, pero, además, es una consecuencia del impacto de internet, las redes sociales y los smartphones en los hábitos de lectura de las personas. Finalmente, se aplicó el proceso propuesto en un caso de estudio realizado con un equipo de desarrollo profesional de la industria y con un sistema y cliente real.

Puntualmente, el trabajo experimental duró 18 meses donde el proceso fue aplicado en 28 iteraciones. El caso de estudio se realizó en una empresa argentina especializada en software y hardware para la industria de hidrocarburos y telemetría. Específicamente, se realizó con dos proyectos tecnológicos para la industria petrolera involucrando a 7 profesionales. Para analizar su efectividad se reunieron datos tanto cuantitativos como cualitativos. En el caso de la evaluación cualitativa, los métodos utilizados fueron: observación, análisis de documentación, cuestionarios y entrevistas. Toda esta información fue transcrita y analizada utilizando la codificación descriptiva para datos cualitativos recomendada por Saldaña (Saldaña, 2009). Para la evaluación cuantitativa, se utilizó una encuesta System Usability Scale (SUS) a los participantes (Lewis \& Sauro, 2009).

El objetivo de este trabajo es proponer un proceso de desarrollo de software basado en los siguientes pilares: trazabilidad de los requerimientos, documentación mínima y equipos pequeños con integrantes distribuidos geográficamente.

Cuando en este documento se utilice la expresión documentación mínima se refiere a que es clara, concisa, completa y menor en tamaño con respecto a la exigida por las metodologías clásicas de desarrollo de software.

El proceso presentado en este trabajo le permitió a la empresa que participó del caso de estudio certificar la norma ISO 9001.2015 de calidad de software en 2019. A partir de dicha certificación, Klein es el proceso estándar de todos los desarrollos de la empresa. En el apéndice 5 se incluye una versión simplificada del documento que especifica el procedimiento de diseño y desarrollo de software adoptado por la empresa.

Esta tesis está organizada de la siguiente manera: el Capítulo 2 presenta una reseña de propuestas para el desarrollo de software. Además, se analiza, en base a estudios recientes, cómo Internet, los smartphones y las redes sociales han provocado la 
tendencia a leer de manera superficial. El Capítulo 3 presenta algunos trabajos que han sido publicados en revistas prestigiosas y que se relacionan con la propuesta. El Capítulo 4 describe el proceso propuesto, sus características, etapas y principios de aplicación. En el Capítulo 5 se provee evidencia empírica que valida la aplicabilidad del proceso de desarrollo propuesto en proyectos de desarrollo de software reales, con un equipo real y con un cliente real. El Capítulo 6 brinda las conclusiones y los trabajos futuros. Finalmente se incluyen los anexos que complementan los puntos principales de este trabajo. 


\section{Capítulo 2 Background}

$\mathrm{E}$

N ESTE CAPÍTULO se analizan dos aspectos muy importantes que se relacionan con el proceso propuesto. Por un lado, los procesos de desarrollo de software y por otro la tendencia actual a leer de manera superficial. En primer lugar, se analizan algunas propuestas conocidas para gestionar un proyecto de desarrollo de software comenzando por las metodologías clásicas, como el modelo Waterfall y el Proceso Unificado Rational (RUP) y finalizando con las metodologías ágiles como Scrum, Extreme Programming $(X P)$ y Kanban. En segundo lugar, se analiza qué dicen las investigaciones actuales sobre la tendencia a leer de manera superficial y la importancia de crear documentación que tenga presente ese aspecto.

\section{DESARROLLO DE SOFTWARE CLÁSICO}

En general el desarrollo de software tradicional tiene en común seguir el "Ciclo de vida de desarrollo de software" (Langer, 2016): una serie de actividades o fases bien definidas, en secuencia, que tienen entrada y salida. Normalmente cada actividad genera un producto intermedio hasta llegar al producto final. Las fases tienen que ver con planeamiento, análisis, diseño, codificación, testing, implementación y mantenimiento. A continuación, se describen las fases del ciclo de vida de desarrollo de software tradicional de acuerdo con lo explicado por el estándar adoptado por el Departamento de Justicia de Estados Unidos (The Department of Justice, 2003):

- Iniciación. Comienza cuando el cliente identifica una necesidad u oportunidad. Se crea la propuesta.

- Desarrollo del concepto del sistema. Define el alcance y los límites. Incluye análisis de costo beneficio, factibilidad, riesgos.

- Planeamiento. Crea el plan del proyecto incluyendo los recursos necesarios para el desarrollo.

- Análisis del sistema. Analiza las necesidades del usuario y desarrolla los requerimientos del usuario. Crea un documento con los requerimientos funcionales y no funcionales del sistema.

- Diseño del Sistema. Transforma los requerimientos del sistema en documentos de diseño rigurosos. Describe las características del sistema en detalle y con rigurosidad. Genera diseños de pantalla, modelos, diagramas de proceso y actividades, pseudocódigo.

- Desarrollo. Convierte los documentos del diseño en un sistema de software completo. Incluye codificar, crear la base de datos, casos de testing, refactorización, etc.

- Testing. Evalúa si el sistema desarrollado cumple con los requerimientos a través de una serie de pruebas de unidad e integración. 
- Implementación. Incluye la preparación previa a la instalación, la puesta en producción y la corrección de problemas asociados.

- Operación y Mantenimiento. Etapa donde se realizan correcciones y nueva funcionalidad al sistema para evitar que quede obsoleto.

- Descarte. Describe las actividades cuando el sistema dejará de utilizarse, como la migración de datos a un nuevo sistema.

\subsection{MODELO WATERFALL}

En las décadas anteriores al año 2000 el desarrollo de software consistía en grandes equipos trabajando juntos con roles específicos y gran cantidad de documentación. Por ejemplo, en 1970 Winston Royce presentó el modelo Waterfall (Royce, 1970) como una manera de reducir los costos en el desarrollo de software. El modelo original contaba con seis etapas: requerimientos de software, diseño, codificación, pruebas, operación y mantenimiento. Las etapas se realizaban en secuencia y el énfasis estaba en la documentación extensa para evitar olvidos en etapas posteriores. En 1985 el Departamento de Defensa de Estados Unidos adoptó este enfoque como estándar de desarrollo para todas las empresas que desarrollaran software militar (Department of Defense, 1988). Dicho estándar requería que se incluyan las etapas de análisis de requerimientos, diseño preliminar, diseño detallado, codificación y pruebas de unidad, integración y pruebas. Aunque ya pasaron muchos años, todavía hay variantes del modelo Waterfall que en la actualidad continúan utilizándose en proyectos de desarrollo de software (Al-Maharmeh, 2010), (Elghondakly \& Moussa, 2015), (Schuh \& Rebentisch, 2017).Las etapas se recorren de manera secuencial y no debe iniciarse una nueva hasta no haber concluido la anterior.

Algunos aspectos para resaltar de Waterfall son que es un proceso estructurado y permite determinar de manera sencilla en qué etapa del desarrollo se encuentra el proyecto. Además, ayuda a los desarrolladores a delinear qué tienen que hacer en cada etapa. El foco está en corregir cualquier desvío en las etapas tempranas. Un aspecto importante es que no provee productos concretos de software hasta el final del proyecto, pero la documentación que se genera provee indicadores de progreso que pueden compartirse con el cliente o usuario. Una característica distintiva de Waterfall es que requiere definir todos los requerimientos del producto antes de comenzar a desarrollarlo, por lo que es vital conocer claramente las características al inicio del proceso.

\subsection{PROCESO UNIFICADO RATIONAL}

A principios de los años 90 el enfoque de muchos equipos de desarrollo pasó de la programación estructurada a la orientada a objetos. Ante esta situación, en 1996, Jacobson estableció las bases del Proceso Unificado Rational (RUP) descrito en 1999 (Jacobson, 1999). Este es un proceso de desarrollo de software que junto con el Lenguaje Unificado de Modelado $(U M L)$, constituyó una metodología estándar para el análisis, implementación y documentación de sistemas orientados a objetos. Las principales características de RUP son desarrollo iterativo, administración de requisitos, uso de arquitectura basada en componentes, control de cambios, modelado visual del software y verificación de la calidad del software. Este proceso, al igual que Waterfall, demanda gran cantidad de 
documentación. El objetivo es que cada equipo decida, dependiendo del proyecto, los elementos del proceso que sean adecuados. $R U P$ está pensado para equipos grandes de desarrollo y se basa en los siguientes bloques de construcción:

- Roles (quién). Un rol define un conjunto de habilidades, competencias y responsabilidades relacionadas.

- Productos (qué). Un producto representa el resultado de una tarea, incluidos todos los documentos y modelos producidos durante el proceso.

- Tareas (cómo). Una tarea describe una unidad de trabajo asignada a un rol que proporciona un resultado significativo.

En cada iteración las tareas se categorizan en nueve disciplinas, seis de ingeniería: Modelado de Negocio, Requerimientos, Análisis y Diseño, Implementación, Pruebas y Despliegue. Y tres disciplinas de soporte: Gestión de configuración y cambios, Gestión de proyecto y Entorno.

Además, RUP tiene determinados cuatro fases en si ciclo de vida:

1) Fase de Inicio. Esta fase tiene como propósito definir y acordar el alcance del proyecto con los involucrados. Se identifican los riesgos, se propone una visión general de la arquitectura de software y el plan de las iteraciones siguientes.

2) Fase de Elaboración. En esta fase se seleccionan los casos de uso que permiten definir la arquitectura del sistema, se realiza la especificación de los casos de uso seleccionados y el primer análisis del dominio.

3) Fase de Desarrollo. El propósito de esta fase es completar la funcionalidad del sistema, clarificar los requisitos pendientes y administrar los cambios de acuerdo con las evaluaciones realizadas por los usuarios.

4) Fase de Transición. El objetivo es asegurar que el software esté disponible para los usuarios finales, corregir cualquier error o defecto encontrado en las pruebas de aceptación, capacitar a los usuarios y proveer el soporte técnico necesario. Se debe verificar que el producto cumpla con las especificaciones acordadas.

El proceso tiene seis prácticas que deben aplicarse:

1) Desarrollar iterativamente. Los proyectos se entregan, aunque sea de un modo interno, en etapas iteradas. En cada iteración se analiza la opinión de los involucrados, la estabilidad y calidad del producto, y se refina la dirección del proyecto, así como también los riesgos involucrados.

2) Gestión de requerimientos. El proceso deberá adaptarse a las necesidades del cliente.

3) Uso de componentes. Este principio motiva a la reutilización de patrones de diseño, componentes de software y esquemas.

4) Modelar visualmente. Usar diagramas para representar todos los componentes principales, usuarios y su interacción.

5) Verificar la calidad. El control de calidad no debe realizarse al final de cada iteración, sino en todos los aspectos de la producción. El aseguramiento de la calidad forma parte del proceso de desarrollo. 
6) Control de cambios. Muchos proyectos son creados por muchos equipos, a veces en varias ubicaciones. Como resultado, es esencial asegurarse de que los cambios realizados en un sistema estén sincronizados y verificados constantemente.

\section{DESARROLLO DE SOFTWARE ÁGIL}

A finales de la década de los 90 muchos proyectos de desarrollo fracasaban, ya sea por no cumplir con lo solicitado por el cliente o porque los tiempos de desarrollo se extendían tanto, que las empresas y sus necesidades no eran las mismas al inicio que al final del proyecto. Como reacción a esta situación, tomaron mucha fuerza las metodologías ágiles (Agile Alliance, 2001), que buscaban reducir la cantidad de documentación de los proyectos de desarrollo y focalizarse en la entrega de valor hacia el cliente. Muchos desarrolladores se dieron cuenta de que la manera de crear software no estaba funcionando y era necesario pensar algo distinto. Estos desarrolladores comenzaron a mezclar ideas antiguas y nuevas y cuando encontraron una combinación que funcionó, crearon una metodología para su equipo. Estas metodologías enfatizaron la estrecha colaboración entre el equipo de desarrollo y las partes interesadas del negocio, la entrega frecuente de valor comercial, equipos compactos y autoorganizados y formas inteligentes de crear, confirmar y entregar código. La retroalimentación rápida y la voluntad de cambio resultaron ser las características clave del movimiento ágil. Si el equipo de desarrollo no estaba seguro de lo que el usuario necesitaba, le ofrecía una primera aproximación y luego escuchaba los comentarios. Tratando de encontrar una alternativa a las opciones disponibles de desarrollo de software que dominaban la industria, representantes de Extreme Programming (XP), Scrum, Dynamic Development Method, Adaptive Software Development, y otros se reunieron en febrero de 2001 en Utah, Estados Unidos. El resultado fue la redacción del "Manifiesto Ágil" (Agile Alliance, 2001), que contenía cuatro valores y doce principios que revelaban mejores maneras de desarrollar software. Los autores establecieron lo siguiente:

"Estamos descubriendo formas mejores de desarrollar software tanto por nuestra propia experiencia como ayudando a terceros. A través de este trabajo hemos aprendido a valorar: Individuos e interacciones sobre procesos y herramientas, Software funcionando sobre documentación extensiva, Colaboración con el cliente sobre negociación contractual, Respuesta ante el cambio sobre seguir un plan. Esto es, aunque valoramos los elementos de la derecha, valoramos más los de la izquierda.” (Agile Alliance, 2001). A continuación, se explican con más detalle qué implican cada uno de los valores mencionados en el manifiesto de acuerdo con lo explicado por Flewelling (Flewelling, 2018).

Individuos e interacciones sobre procesos y herramientas. En un entorno ágil se utilizan procesos y herramientas, pero se prefiere usarlas de la manera más liviana posible porque lo que se valora es la comunicación entre las personas. Si se desea fomentar la colaboración, es muy importante que las partes técnicas y no técnicas se entiendan bien. Las herramientas y los procesos tienden a complicar ese objetivo. Un buen ejemplo de esto son las historias de usuario, una técnica para la obtención de 
requerimientos, usualmente escritas en tarjetas que no permiten mucho detalle. El objetivo es estimular, mediante conversación, el entendimiento compartido de la tarea.

Software funcionando sobre documentación extensiva. El foco está en entregar software que satisfaga las necesidades del cliente. En el pasado se usaban documentos para comunicar al cliente lo que se estaba construyendo. Esto generaba confusión y ambigüedad. Normalmente el cliente no es un experto construyendo software por lo que encuentra la documentación difícil de entender y no logra imaginar qué es lo que se está desarrollando. La manera más fácil de comunicarse con él es a través de software funcionando con el cual pueda interactuar. Por otro lado, permitir que el usuario vea software en una etapa temprana permite descubrir si se pensó lo que el cliente pensó. De esta manera se puede desarrollar software de manera incremental mientras se valida, temprano y regularmente con el cliente, si se está construyendo lo que se debería.

Colaboración con el cliente sobre negociación contractual. El objetivo es brindar utilidad para el cliente y obtener lo mejor de él en el proceso. Los contratos pueden limitar esa meta, especialmente cuando las cosas que se asumieron al comienzo no son tan precisas con respecto a la realidad de lo que se debía hacer. Renegociar o modificar un contrato sobre la marcha del proyecto suele generar inconvenientes que afectan el desempeño del equipo y su habilidad de entregar software de calidad.

Respuesta ante el cambio sobre seguir un plan. Para un modelo de desarrollo que surge de entornos inestables, que tienen como factor inherente el cambio y la evolución rápida y continua, resulta mucho más valiosa la capacidad de respuesta que la de seguimiento y aseguramiento de planes preestablecidos. Los principales valores de la gestión ágil son la anticipación y la adaptación; diferentes a los de la gestión de proyectos ortodoxa: planificación y control para evitar desviaciones sobre el plan.

Además de los valores mencionados, el desarrollo de software ágil tiene una serie de principios, que se explican a continuación, de acuerdo con lo expuesto por Flewelling (Flewelling, 2018).

- La principal prioridad es satisfacer al cliente a través de la entrega temprana y continua de software con valor. Entregando software de manera incremental lo más pronto posible y de manera regular permite confirmar que se está desarrollando el sistema correcto. La mayoría de las personas no sabe qué es lo que realmente quiere hasta que lo ve y puede usarlo. Con esta manera de trabajar se puede obtener de manera temprana el feedback del usuario y reducir el riesgo de construir el software equivocado.

- Se acepta que los requisitos cambien, incluso en etapas tardías del desarrollo. Los procesos ágiles aprovechan el cambio para proporcionar ventaja competitiva al cliente: en vez de tener un alcance cerrado y de ignorar que las necesidades del negocio pueden evolucionar, se busca adaptarse a los nuevos descubrimientos y re priorizar el trabajo para entregar un software más valioso para el cliente.

- Se entrega software funcional frecuentemente, entre dos semanas y dos meses, con preferencia al período de tiempo más corto posible. Cuanto más rápido se entrega una versión del software, más rápido se tiene feedback. 
- Los responsables del negocio y los desarrolladores trabajan juntos de forma cotidiana durante todo el proyecto.

- Los proyectos se desarrollan en torno a individuos motivados. Hay que darles el entorno y el apoyo que necesitan, y confiarles la ejecución del trabajo.

- El método más eficiente y efectivo de comunicar información al equipo de desarrollo y entre sus miembros es la conversación cara a cara. La conversación cara a cara tiene un "ancho de banda" muy alto, porque no solo incluye palabras sino expresiones faciales y lenguaje corporal. Es la manera más rápida de obtener información de otro ser humano. Es una actividad interactiva que puede ser utilizada para resolver cualquier ambigüedad a través del cuestionamiento. No hay otra forma de comunicación que pueda igualarla.

- El software funcionando es la medida principal de progreso. Cuando se piensa en un equipo de desarrollo de software y su propósito lo cierto es que no hay otra medida más adecuada para establecer su progreso que el software funcional. El énfasis está en este punto porque no se desea dar un falso indicador de progreso. No se puede estar $100 \%$ seguros de que lo que se está construyendo es correcto hasta que el cliente no confirme que el software entregado hace lo que se supone que tienen que hacer. Todo lo demás que el equipo de desarrollo produce es solo un soporte para entregar el software desde documentos de análisis y diseño hasta guías de usuario.

- Los procesos ágiles promueven el desarrollo sostenido. Los promotores, desarrolladores y usuarios deben mantener un ritmo constante de forma indefinida: este principio apunta a evitar que el equipo, durante un periodo prolongado, sea puesto bajo presión para entregar el software. Esto compromete la calidad del producto y puede desanimar al equipo.

- La atención continua a la excelencia técnica y al buen diseño mejora la agilidad. Usando los principios $S O L I D^{2}$ y prestando atención a los detalles cuando se desarrolla software, se mejora la habilidad de perfeccionar y cambiar el software.

- La simplicidad, o el arte de maximizar la cantidad de trabajo no realizado, es esencial. Hay que construir el software más simple que cumpla con las necesidades actuales del cliente. Si no se tiene la seguridad de que el cliente necesite una funcionalidad, hay que preguntarle. Si se desarrolla algo de lo que no se está seguro se podría estar resolviendo un problema que todavía no existe. Programar una funcionalidad no solicitada requiere código, que podría introducir errores y complejizar el código.

- Las mejores arquitecturas, requisitos y diseños emergen de equipos autoorganizados.

\footnotetext{
2 SOLID: Es un acrónimo introducido por Robert C. Martin de Single responsibility, Open-closed, Liskov substitution, Interface segregation y Dependency inversion que representa los cinco principios básicos para crear un sistema que sea fácil de mantener y ampliar con el tiempo. Para más información consultar el libro del autor "Clean Code: A Handbook of Agile Software Craftsmanship” (Martin, 2008)
} 
- A intervalos regulares, el equipo reflexiona sobre cómo ser más efectivo para, a continuación, ajustar y perfeccionar su comportamiento en consecuencia. Un equipo que aparta tiempo para reflexionar en la manera de mejorar su desempeño es un equipo que entrega software cada vez con más calidad, menos errores, bajo un mejor entorno de trabajo y con clientes cada vez más conformes.

A continuación, se analizarán los métodos ágiles más importantes: Scrum, Extreme Programming $(X P)$ y Kanban y cómo se relacionan con el manifiesto ágil. Según VersionOne's $14^{\circ}$ Annual State of Agile Report (VersionOne Inc, 2020) el 76\% de los equipos utiliza Scrum puro o junto con otra metodología, el 17\% utiliza Kanban puro o junto con otra metodología, y el $9 \%$ utiliza XP puro o junto con otra metodología (Nota: la suma excede el $100 \%$ debido a que cada porcentaje individual puede incluir valores contemplados en más de una metodología).

\subsection{SCRUM}

Scrum es un framework con el cual los equipos pueden resolver problemas complejos, de manera adaptativa, creando productos con el mayor valor posible. Según los creadores del framework (Sutherland \& Schwaber, 2017), Scrum es liviano, simple de entender y difícil de dominar. Explican que Scrum no es un proceso, técnica o un método definitivo sino un framework dentro del cual se pueden usar varios procesos o técnicas. El framework Scrum está compuesto por el equipo Scrum y sus roles asociados, eventos, artefactos y reglas. Cada componente dentro del framework tiene un propósito específico y es esencial para el éxito de Scrum.

El equipo de Scrum está formado por el Product Owner, el Scrum Master y el equipo de desarrollo. El equipo es auto organizado, es decir, que decide cómo hacer el trabajo en vez de recibir instrucciones de alguien externo. A continuación, una descripción de cada uno de los integrantes del equipo, de acuerdo con lo descrito en la guía de Scrum (Sutherland \& Schwaber, 2017).

Product Owner. Es el responsable de maximizar el valor del producto resultante del trabajo del equipo de desarrollo. Es quien tiene la visión del producto, maneja el presupuesto y es el representante del negocio. Es el responsable de mantener y manejar el Backlog del producto, lo que implica expresar con claridad los ítems, ordenarlos de acuerdo con prioridades y asegurarse de que sea visible, transparente y claro para todos. Es una persona no un conjunto de personas.

Scrum Master. El Scrum Master es responsable de promover y apoyar Scrum como se define en la Guía de Scrum. Los Scrum Masters hacen esto ayudando a todos a entender la teoría, prácticas, reglas y valores de Scrum.

Equipo de Desarrollo. El Equipo de Desarrollo consiste en los profesionales que realizan el trabajo de entregar un incremento de producto terminado que potencialmente se pueda poner en producción al final de cada Sprint (iteración de tiempo fijo). El tamaño óptimo del equipo de desarrollo es lo suficientemente pequeño como para permanecer ágil y lo suficientemente grande como para completar una cantidad de trabajo significativa. Tener menos de tres miembros en el equipo de desarrollo reduce la interacción y resulta en ganancias de productividad más pequeñas. Los equipos de desarrollo 
más pequeños podrían encontrar limitaciones en cuanto a las habilidades necesarias durante un Sprint, haciendo que el equipo de desarrollo no pudiese entregar un incremento que potencialmente se pueda poner en producción. Tener más de nueve miembros en el equipo requiere demasiada coordinación. Los grandes equipos de desarrollo generan demasiada complejidad como para que un proceso empírico les sea de utilidad.

Por otro lado, la guía de Scrum define tres artefactos: Backlog del Producto, $B a-$ cklog del Sprint e Incremento. A continuación, la descripción de cada uno de ellos.

Backlog del Producto. Es el conjunto de requerimientos para el producto. Usualmente en forma de historias de usuarios, pero también puede ser en forma de tareas. Es manejado y priorizado por el Product Owner.

Backlog del Sprint. Es el conjunto de requerimientos que el equipo ha elegido del Backlog del producto para completarlos en el siguiente Sprint.

Incremento. Es el incremento del software funcional que fue creado durante el Sprint a partir de los ítems del Backlog del Sprint. Es el trabajo completo, usable y que puede estar listo para ser implementado.

Finalmente, en Scrum existen eventos predefinidos con el fin de crear regularidad y minimizar la necesidad de reuniones no definidas en Scrum. Todos los eventos tienen una duración máxima. A continuación, cada uno de los eventos, de acuerdo con lo definido en la guía de Scrum.

Sprint. El corazón de Scrum es el Sprint, son iteraciones de tiempo fijo (entre 1 y 4 semanas) durante el cual se crea un incremento de producto terminado, utilizable y potencialmente puesto en producción.

Planificación del Sprint. El trabajo por realizar durante el Sprint se planifica en la Planificación de Sprint. Este plan se crea mediante el trabajo colaborativo del equipo Scrum completo. Se busca cerrar el compromiso sobre qué puede entregarse como incremento al finalizar el Sprint y cómo se va a lograr cumplir con ese objetivo. Se seleccionan los ítems del Backlog del producto que van a completarse durante el Sprint y se crea el Backlog del Sprint.

Scrum Diario. El Scrum Diario es una reunión con un tiempo fijo de 15 minutos para el equipo de desarrollo. Se lleva a cabo cada día del Sprint. En él, se planea el trabajo para las siguientes 24 horas. Esto optimiza la colaboración y el desempeño del equipo inspeccionando el trabajo avanzado desde el último Scrum Diario y haciendo una proyección del trabajo del Sprint a realizar a continuación. El Scrum Diario se realiza a la misma hora y en el mismo lugar todos los días para reducir la complejidad. El equipo usa el Scrum Diario para evaluar el progreso hacia el objetivo del Sprint y para evaluar qué tendencia sigue este progreso hacia la finalización del trabajo contenido en la lista de pendientes del Sprint. Se responden preguntas como: ¿qué se hizo ayer? ¿qué se va a hacer hoy? ¿qué impedimentos hubo? Los Scrum Diarios mejoran la comunicación, eliminan la necesidad de realizar otras reuniones, identifican impedimentos a remover relativos al desarrollo, resaltan y promueven la toma rápida de decisiones y mejoran el nivel de conocimiento del equipo. El Scrum Diario es una reunión clave de inspección y adaptación.

Revisión del Sprint. Al final del Sprint se lleva a cabo una Revisión de Sprint para inspeccionar el incremento y adaptar el Backlog del producto si fuese necesario. 
Durante la Revisión de Sprint, el equipo y los interesados evalúan lo que se hizo durante el Sprint. El Product Owner explica qué elementos del Backlog del producto se han terminado y cuáles no. El equipo de desarrollo hace una demostración del trabajo que ha terminado y responde preguntas acerca del incremento. El resultado de la Revisión de Sprint es el Backlog del producto revisado, que define los elementos posibles para el siguiente Sprint. Es posible además que el Backlog del Producto reciba un ajuste general para enfocarse en nuevas oportunidades.

Retrospectiva. La Retrospectiva de Sprint es una oportunidad para el Equipo Scrum de inspeccionarse a sí mismo y de crear un plan de mejoras que sean abordadas durante el siguiente Sprint. La Retrospectiva de Sprint tiene lugar después de la Revisión de Sprint y antes de la siguiente Planificación de Sprint. Se responden preguntas como: ¿qué se hizo bien? y ¿qué se podría haber hecho mejor?

\subsection{EXTREME PROGRAMMING}

Extreme Programming $(X P)$ es otro framework popular entre los equipos de desarrollo. Si bien aplicado exclusivamente solo abarca el $1 \%$ de los proyectos de desarrollo, aplicado en combinación con otros frameworks alcanza el 9\% (VersionOne Inc, 2020). XP es uno de los pocos frameworks que prescribe prácticas técnicas. A continuación, una descripción de sus principales características, de acuerdo con sus autores Beck y Andres (Beck \& Andres, 2004). XP tiene cinco valores: comunicación, simplicidad, feedback, coraje y respeto. A continuación, una breve descripción de lo que implica cada uno.

1) Comunicación. El desarrollo de software es un trabajo en equipo que requiere comunicación para transferir el conocimiento de un miembro a otro. $X P$ pone énfasis en la importancia de tener el tipo de comunicación apropiada, cara a cara, con la ayuda de una pizarra.

2) Simplicidad. Se busca resolver el problema de la manera más simple posible. Hacer sólo lo que sea estrictamente necesario para mantener el diseño del sistema tan simple como sea posible, de manera que sea fácil de mantener, revisar y cambiar. Simplicidad también significa sólo incluir los requerimientos de los cuales se tiene conocimiento, y no tratar de predecir el futuro.

3) Feedback. A través de un feedback constante, el equipo puede identificar áreas para mejorar y revisar sus prácticas.

4) Coraje. Se necesita coraje para dejar de hacer algo que no funciona y probar algo diferente. También se necesita coraje para aceptar el feedback aun cuando no se esté de acuerdo o cueste aceptarlo.

5) Respeto. Los miembros del equipo necesitan respeto para comunicarse unos con otros, proveer y aceptar feedback y también trabajar juntos para identificar problemas en el diseño y corregirlos.

Por otro lado, el núcleo de XP está formado por un conjunto de prácticas de desarrollo de software relacionadas entre sí que se explican a continuación.

Sentados juntos: Como la comunicación es uno de los cinco valores de $X P$ y la mayoría de las personas concuerda en que la mejor manera de comunicarse es cara cara, el equipo debería sentarse junto en el mismo espacio físico sin barreras de comunicación. El equipo completo: Un conjunto de personas y de carácter multidisciplinario 
forma un solo equipo. Esto significa que las personas con una necesidad, como aquellas personas que pueden satisfacer esa necesidad trabajan juntos, a diario, para lograr el resultado. Marco de Trabajo Informativo: Hay que organizar el espacio de trabajo del equipo para facilitar la comunicación cara a cara, pero permitiendo también lugar para la privacidad cuando sea necesario. El trabajo tiene que ser transparente para los otros miembros del equipo. Trabajo Energizado: El equipo es más efectivo cuando se trabaja concentrado y libre de distracciones. Trabajo energizado significa asegurarse de que el equipo está física y mentalmente focalizado. Esto implica no trabajar de más y mantenerse sanos. Programación en pareja: Significa que todo el código de producción será desarrollado por dos personas sentadas enfrente de la misma máquina. La idea detrás de esta práctica es que dos cerebros y cuatro ojos son mejores que un cerebro y dos ojos. Constantemente se obtiene revisión de código y una respuesta rápida a los problemas que podrían hacer que una sola persona se estanque. Equipos que usan programación en pareja han encontrado que esto mejora la calidad y no necesariamente involucra más trabajo ya que los problemas se resuelven más rápidamente y al estar más enfocados la misma tarea se resuelve con menos código. Historias: Describen qué debería hacer el producto en términos con significado para los clientes y los usuarios. Estas historias pretenden ser descripciones breves de las cosas que los usuarios quieren hacer con el producto, pueden usarse para la planificación y como recordatorio para futuras conversaciones cuando se esté trabajando sobre ellas. Ciclo Semanal: Ciclo semanal es un sinónimo de una iteración. En el caso de $X P$, el equipo se reúne el primer día de la semana para evaluar el progreso hasta la fecha, el cliente elige las historias que quisiera que se entreguen en esa semana, y el equipo determina cómo abordarlas. El objetivo para el final de la semana es contar con la funcionalidad testeada que realice las historias seleccionadas. La intención detrás de una iteración con tiempo fijo es producir algo para mostrar al cliente para obtener feedback. Ciclo Trimestral: Es sinónimo de entrega. El propósito es tener el detalle del trabajo de cada ciclo semanal en contexto del proyecto global. Relajarse: En términos de XP la idea detrás de relajarse es agregar algunas tareas bajas en prioridad tanto en el ciclo semanal como en el trimestre, que pueden desecharse en caso de que el equipo se atrase en realizar algunas tareas importantes. Esto permite incrementar las posibilidades de cumplir con el pronóstico, sin resignar trabajo importante. Build de diez minutos: La meta es hacer un build automático del sistema completo y correr todos los test dentro del límite de 10 minutos. Esta práctica permite encontrar errores rápidamente y alienta al equipo a automatizar el proceso de hacer builds. Integración continua: Es una práctica donde el código que ha sido modificado inmediatamente se testea con el código consolidado. El objetivo de esta práctica es encontrar y arreglar cualquier problema de integración que se presente lo más pronto posible. La razón detrás de este enfoque es que, si se experimentan problemas a la hora de integrar gran cantidad de código nuevo, un enfoque mejor sería integrar de a poco de tal manera que si surgen errores serían más fáciles de encontrar. Programación “Test-First”: En vez de seguir el camino normal, es decir, escribir código $\rightarrow$ escribir casos de test $\rightarrow$ ejecutar los test, la práctica de programación "Test-First" sigue el siguiente camino: Escribir un test automático que falle $\rightarrow$ ejecutar el test que falle $\rightarrow$ escribir el código que pase el test $\rightarrow$ ejecutar el test $\rightarrow$ repetir. Diseño incremental: Esta práctica sugiere 
que sólo se debe profundizar en los detalles del diseño cuando sea estrictamente necesario, a medida que se va avanzando en el proyecto y de acuerdo con la información más reciente. Mientras tanto el diseño debe mantenerse lo más simple posible y a grandes rasgos. Está práctica también incluye la refactorización.

La principal contribución de XP al mundo del desarrollo de software es una colección interdependiente de prácticas de ingeniería que los equipos pueden usar para ser más efectivos y producir código de mayor calidad. Muchos equipos que adoptan el desarrollo ágil comienzan con un framework diferente y cuando identifican la necesidad de prácticas de ingeniería más disciplinadas, adoptan varias, si no todas, las prácticas de ingeniería alentadas por $X P$.

\subsection{KANBAN}

$K_{a n b a n^{3}}$ es un método para mejorar el proceso usado por equipos de desarrollo ágil. Permite definir, administrar y mejorar la entrega de productos de software. El foco está en "empezar desde lo que se sabe" y luego ir mejorando ese proceso. Los equipos que utilizan Kanban empiezan aplicando la manera de pensar "Lean". A continuación, una explicación breve de los puntos principales de "Lean", de acuerdo con lo explicado por Stellman (Stellman \& Greene, 2014).

A diferencia de Scrum y XP, Lean no incluye un conjunto de prácticas, pero sí una serie de valores. Eliminar el desperdicio: Encontrar el trabajo que se está haciendo y que no aporta valor al software y eliminarlo. Ampliar el aprendizaje: Usar feedback constante del proyecto para mejorar la manera en que se desarrolla el software. Decidir lo más tarde posible: Tomar las decisiones más importantes del proyecto cuando tengamos la mayor cantidad de información posible. Entregas lo más rápido posible. Energizar el equipo: Establecer un ambiente de trabajo que favorezca la concentración. Construir con integridad: Desarrollar software que tenga sentido para los usuarios y que sea coherente con el resto. Ver el cuadro completo: Implica entender el trabajo que se está llevando a cabo en el proyecto. Esto provee una base sólida que, combinada con el método Kanban, permite mejorar el proceso de desarrollo.

Por otro lado, de acuerdo con Anderson (Anderson \& Carmichael, 2016) Kanban tiene tres principios fundamentales:

1) Empezar con lo que se está haciendo ahora. Esto minimiza la resistencia al cambio respecto de lo que se hace actualmente. Por otro lado, para mejorar el proceso, primero tiene que haber un proceso, aunque sea deficiente. Además, hay que respetar los roles, responsabilidades y títulos actuales.

2) Aceptar que los cambios son progresivos y evolutivos.

3) Alentar el liderazgo a todo nivel.

Además, Anderson también explica que Kanban tiene seis prácticas fundamentales, que se describen a continuación.

1) Visualizar. Visualizar el flujo de trabajo y hacerlo visible es la base para comprender cómo avanza el trabajo. Sin comprender el flujo de trabajo, realizar los cambios adecuados es más difícil. Una forma común de visualizar el flujo

\footnotetext{
${ }^{3}$ Del japonés: "kan": visual y "ban": tarjeta
} 
de trabajo es el uso de columnas. Las columnas representan los diferentes estados o pasos en el flujo de trabajo.

2) Limitar el trabajo en curso. Introducir y respetar los límites establecidos de trabajo simultáneo cambia de un sistema donde se "introduce" a uno donde se "saca", ya que no se introduce una nueva tarea hasta que el trabajo pendiente no esté completo. Tener muchas tareas incompletas es un desperdicio y alarga los tiempos de entrega. Observar, limitar y optimizar la cantidad de trabajo en curso es esencial para el éxito con Kanban. Establecer este límite no es sencillo: Si es demasiado bajo podría haber personas sin tareas y demora en comenzar tareas. Por otro lado, un límite demasiado alto, podría llevar a comenzar muchas tareas y terminar pocas. Normalmente los límites de trabajo pueden mejorarse con el tiempo para lograr el equilibrio.

3) Gestionar el flujo. Se debe supervisar, medir y reportar el flujo de trabajo a través de cada estado. Al gestionar activamente el flujo, los cambios continuos, graduales y evolutivos del sistema pueden ser evaluados para tener efectos positivos o negativos.

4) Hacer políticas explícitas. Las políticas explícitas son una manera de articular y definir el proceso que va más allá de la definición del flujo de trabajo. Algunas políticas son límites de trabajo en curso (Work in Progress), definición de "Listo" y la manera de seleccionar nuevas tareas para realizar.

5) Implementar ciclos de feedback. Los ciclos de feedback son muy importantes para mejorar el proceso. Puede incluirse revisiones de estrategia, operación, riesgo, servicio y entrega.

6) Mejorar colaborativamente y evolucionar experimentalmente.

Kanban es usado para definir, manejar y mejorar el sistema de entrega del producto a los clientes. El primer paso para mejorar el proceso es entender cómo el equipo está trabajando actualmente y eso es lo que Kanban puede hacer por medio de un tablero, que es el elemento más representativo del framework. Un tablero Kanban es una herramienta que el equipo usa para visualizar el flujo de trabajo. Consiste en un número de columnas dibujadas en un pizarrón con notas adhesivas pegadas en cada columna. También existe la alternativa de utilizarlo en forma digital. El tablero Kanban no tienen columnas fijas. Estas pueden variar de equipo a equipo. En algunos casos puede tener tres columnas, por ejemplo, "Pendiente", "En Desarrollo" y "Listo", pero en otros, muchas más, como se ve en la Figura 2.1. Es importante entender que el tablero Kanban permite visualizar el flujo de trabajo y el proceso actual, por lo que generalmente no se debe copiar las columnas de otro tablero y adaptarlas. Lo ideal es desarrollar el tablero propio estudiando el flujo de trabajo y visualizándolo. Copiar una definición de proceso existente sería la antítesis del enfoque evolutivo de Kanban. Si el método requiere comenzar con lo que se hace actualmente, entonces no se debería comenzar copiando algo que alguien más esté haciendo.

Otra característica es que deben existir límites explícitos sobre la cantidad de ítems en progreso, llamado "Trabajo en curso" (del inglés Work in Progress (WiP)), que cada columna puede tener. Cuando se llega al límite en una columna, no se puede agregar más tareas a la misma. El equipo tiene la opción de empezar trabajo en otra columna 
o colaborar en la finalización de las tareas que están en curso. Por lo tanto, limitar el trabajo en curso establece que lo importante es finalizar tareas, no comenzar nuevas. Los ítems que se agregan al tablero incluyen descripción, estimación, prioridad, entre otros campos. Cada equipo puede decidir qué incluir. Los ítems pueden ser historias de usuario, tareas, bugs, etc.

Por otro lado, algunas columnas pueden tener, a su vez, otras columnas como "en progreso" y "listo". Esto es para diferenciar visualmente las tareas que están "en curso" dentro del estado, de aquellas que se terminaron y están listas para ser movidas al siguiente estado. Kanban ha tenido buena aceptación debido a que tiene pocas reglas, es muy flexible, se puede realizar una entrega en cualquier momento, las prioridades de las tareas no son estáticas y se puede ver fácilmente el flujo de trabajo.

Hasta ahora hemos analizado varias propuestas de procesos para desarrollar software. A continuación, se analizará un aspecto muy importante que tiene un impacto directo en la elaboración y el mantenimiento de la documentación del proyecto: la preferencia de las personas por la lectura superficial.

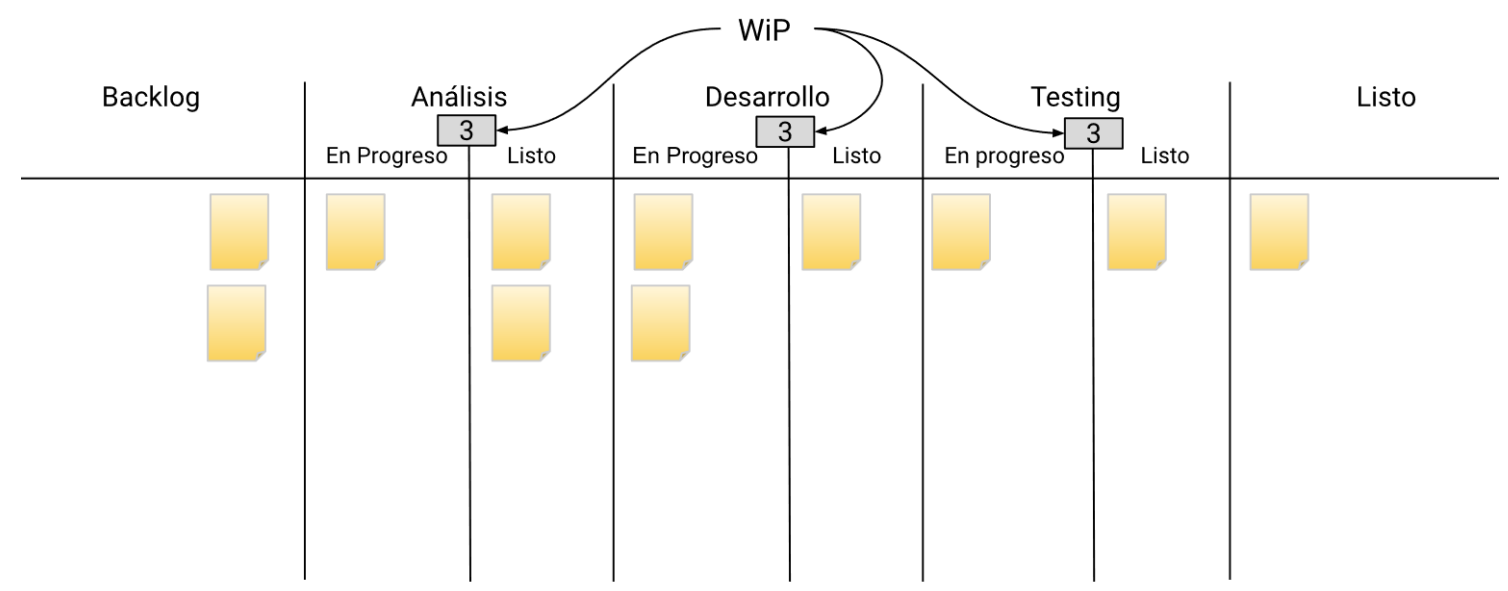

FIGURA 2.1 - Ejemplo de tablero Kanban

\section{LECTURA SUPERFICIAL}

En esta sección se analiza qué dicen los estudios sobre la tendencia de muchas personas a leer de manera superficial la información. Esto aplica tanto a texto impreso en papel como visualizado en pantalla. En el proceso propuesto la elaboración de la documentación tiene en cuenta este hallazgo y está preparada para lectores que tienden a leer de manera rápida. En esta sección se analizan los cambios en la manera de leer y escribir. Además, se incluye una teoría sobre la razón por la cual la tecnología actual ha impactado en la superficialidad del análisis de la información.

Internet, los smartphones y las redes sociales son tres elementos fundamentales en el mundo de la tecnología. Cada una de ellas presenta, en su esencia, un producto que es valioso: la información. Estas tecnologías tienen una capacidad increíble de captar la atención en cualquier instante con una alerta, notificación, pitido o incluso por el 
simple hecho de generar la idea de que, en los últimos minutos, se ha perdido algo importante. Estas interrupciones constantes hacen muy difícil concentrarse en lo que se está haciendo (Gazzaley \& Rosen, 2016). Cuando alguien está en línea, entra en un entorno que promueve la lectura sin profundidad, el pensamiento apresurado y distraído, y el aprendizaje superficial. Es posible pensar profundamente mientras se navega por internet, así como es posible pensar superficialmente mientras se lee un libro, pero el pensamiento profundo no es el tipo de pensamiento que la tecnología alienta y recompensa (Carr, 2011). A continuación, se analiza el cambio en la manera de leer que los estudios han encontrado en los últimos años.

\subsection{CAMBIOS EN LA MANERA DE LEER}

A medida que las mentes de las personas se fueron sintonizando con la gran cantidad de información disponible en Internet, las empresas de medios debieron adaptarse a las nuevas expectativas de la audiencia. Muchos productores están recortando sus productos para adaptarse a la menor capacidad de atención de los consumidores en línea. Como dijo el economista Tyler Cowen, "cuando el acceso a la información es fácil, tendemos a favorecer lo corto, lo dulce y lo mezquino” (Cowen, 2009). La influencia de internet no termina en el borde de la pantalla de una computadora. Las empresas de medios están remodelando sus productos tradicionales, incluso los físicos, para parecerse más a lo que las personas experimentan cuando están en línea. Si, en los primeros días de Internet, el diseño de publicaciones en línea se inspiró en publicaciones impresas, hoy la inspiración tiende a ir en la dirección opuesta. Muchas revistas han modificado sus diseños para imitar o, al menos, hacerse eco de la apariencia de los sitios web. Han acortado sus artículos, han presentado resúmenes al inicio y han llenado sus páginas con etiquetas y subtítulos fáciles de navegar. La revista Rolling Stone, alguna vez conocida por sus editoriales extensas, ahora las evita, para ofrecer a los lectores una gran cantidad de artículos y reseñas cortos. La mayoría de las revistas populares han llegado a estar llenas de colores, titulares de gran tamaño, gráficos, fotos y citas. La página de solo texto, que una vez fue un elemento básico de las revistas, ha sido casi desterrada. El diseño de los diarios también está cambiando. En los últimos años muchos se han movido para recortar la longitud de sus artículos e introducir más resúmenes y ayudas de navegación para facilitar el escaneo visual de sus contenidos (Carr, 2011).

En 2006 Jakob Nielsen, un consultor con mucha experiencia en diseño de páginas web, realizó un estudio de seguimiento ocular de los usuarios de Internet (Nielsen Norman Group, 2006). Para dicho estudio, se les pidió a 232 personas que usaran una pequeña cámara que rastreaba los movimientos de sus ojos mientras leían páginas de texto y buscaban otros contenidos. Los investigadores descubrieron que casi ninguno de los participantes leía textos en línea (online) de forma metódica, línea por línea, como normalmente lo harían en una página de un libro impreso. La gran mayoría hizo una lectura rápida, con sus ojos saltando por la página en un patrón que se parecía, más o menos, a la letra F, como se ve en la Figura 2.2. Comenzaron mirando las primeras dos o tres líneas de texto. Entonces sus ojos bajaron un poco, y escanearon aproximadamente a la mitad de la página algunas líneas más. Finalmente, dejaron que sus ojos se desviaran un poco más hacia el lado izquierdo de la página. Este patrón de lectura en 
línea fue confirmado por un estudio posterior (Weinreich, 2008) de seguimiento ocular llevado a cabo en el Laboratorio de Investigación de Usabilidad de Software en la Universidad Estatal de Wichita, Estados Unidos y por otro estudio realizado en noviembre de 2017, abarcando incluso la lectura en dispositivos móviles (Nielsen Norman Group, 2017). Al resumir los hallazgos para sus clientes, Nielsen escribió que "el patrón es "F" por "Fast" (palabra inglesa que significa "rápido" en español). Así es como los usuarios leen su valioso contenido. En unos segundos, sus ojos se mueven a velocidades asombrosas entre las palabras de su sitio web en un patrón que es muy diferente de lo que aprendió en la escuela".

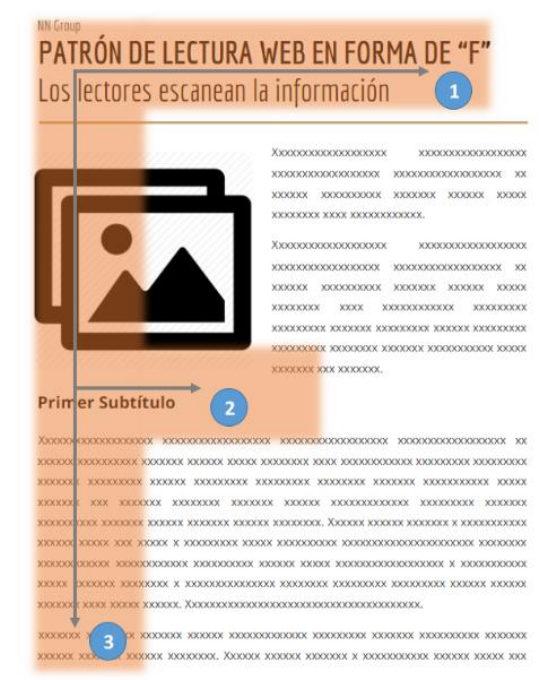

FIGURA 2.2 - Ejemplo de lectura en forma de "F"

Un equipo de investigadores de Alemania realizó un estudio del comportamiento de 25 usuarios web (Rowlands, 2008) durante un período de 100 días. Al finalizar el análisis, concluyeron que la mayoría de las páginas web son vistas durante 10 segundos o menos. En menos del 10\% de las páginas ese tiempo se extendió más allá de 2 minutos, y una parte significativa de ellas parece involucrar "ventanas del navegador dejadas abiertas en el fondo del escritorio". Los investigadores observaron que "incluso páginas nuevas con información abundante y muchos enlaces se ven regularmente solo por un breve período. Los resultados confirmaron que la navegación web es una actividad interactiva muy rápida". Los resultados también refuerzan algo que Nielsen escribió en 1997 después de su primer estudio de lectura en línea. ¿¿Cómo leen los usuarios en Internet?", preguntó entonces. Su respuesta: "No lo hacen" (Nielsen Norman Group, 2006).

Power Browsing es una palabra inglesa que se refiere a la acción de leer superficialmente o escanear información rápidamente, con frecuencia omitiendo las secciones de texto, con el fin de obtener una comprensión de los puntos principales y localizar el material más útil. Esta manera de leer parece ser la tendencia, incluso en ambientes académicos. Como parte de un estudio de cinco años Center for Information Behaviour and the Evaluation of Research (CIBER Comitee, 2008) examinó los registros que documentan el comportamiento de los visitantes de dos sitios de investigación populares, uno de la Biblioteca Británica y otro de un consorcio educativo de los Estados Unidos. Ambos sitios proporcionaron a los usuarios acceso a artículos de revistas, libros 
electrónicos y otras fuentes de información escrita. Los académicos descubrieron que las personas que usan los sitios exhiben una distintiva "forma de actividad superficial" en la que saltan rápidamente de una fuente a otra y rara vez regresan a una fuente que ya han visitado. Habían leído, como máximo, una o dos páginas de un artículo o libro antes de "saltar" a otro sitio. "Está claro que los usuarios no leen en línea en el sentido tradicional", informaron los autores del estudio. "De hecho, hay indicios de que están surgiendo nuevas formas de "lectura" a medida que los usuarios navegan horizontalmente a través de títulos, páginas de contenido y resúmenes buscando resultados rápidos. Pareciera que se conectan en línea para evitar leer de manera tradicional".

El cambio de lectura a Power Browsing está ocurriendo muy rápido. En 2003, Liu (Liu, 2003) encuestó a 113 personas bien instruidas: ingenieros, científicos, contadores, maestros, gerentes de negocios y estudiantes graduados, principalmente entre 30 y 45 años, para medir cómo habían cambiado sus hábitos de lectura en los últimos diez años. Casi el $85 \%$ de las personas informaron que pasaban más tiempo leyendo documentos electrónicos. Cuando se les pidió que describieran cómo han cambiado sus prácticas de lectura, el $81 \%$ dijo que estaban pasando más tiempo "navegando y escaneando (visualmente)" y el $82 \%$ informó que estaban haciendo más "lecturas no lineales". Solo el 27\% dijo que el tiempo que dedicaron a la "lectura profunda" iba en aumento, mientras que el 45\% dijo que estaba disminuyendo. Solo el 16\% dijo que estaban dando más "atención sostenida" a la lectura, el 50\% dijo que le daban menos "atención sostenida". Liu estableció que "el entorno digital tiende a alentar a las personas a explorar muchos temas extensamente, pero en un nivel más superficial", y que "los hipervínculos distraen a las personas de leer y pensar profundamente". Uno de los participantes en el estudio le dijo al autor del estudio: "Me parece que mi paciencia para leer documentos largos está disminuyendo. Quiero saltar al final de los artículos largos".

No hay nada de malo con la navegación y el escaneo, o incluso con el Power Browsing. La capacidad de escanear visualmente texto es tan importante como la capacidad de leerlo profundamente. Lo que es diferente y que requiere atención es que la lectura superficial se está convirtiendo en el modo dominante de lectura. En vez de ser un medio para un fin, una forma de identificar información para determinar si vale la pena un estudio más profundo, el escaneo se está convirtiendo en un fin en sí mismo, la forma preferida de reunir y dar sentido a la información de todo tipo (Carr, 2011).

\subsection{CAMBIOS EN LA MANERA DE ESCRIBIR}

Los cambios en el estilo de lectura también traen cambios en el estilo de escritura, ya que los autores y sus editores deben adaptarse a los nuevos hábitos y expectativas de los lectores. En su libro Carr (Carr, 2011) explica algunos ejemplos. En 2001, una joven japonesa empezó a componer historias en su teléfono celular como mensajes de texto y luego los subía a un sitio web, donde otras personas podían leerlos y comentarlos. Las historias se expandieron en una serie de "novelas de teléfonos celulares" y su popularidad creció. Algunas de las novelas tuvieron millones de lectores en línea. Los editores tomaron nota y comenzaron a publicar las novelas como libros impresos. Hacia el final de la década, las novelas de teléfonos celulares habían llegado a dominar las listas de best sellers del país. Las tres novelas japonesas más vendidas en 2007 fueron escritas 
originalmente en teléfonos celulares. La forma de las novelas refleja sus orígenes. Uno de los novelistas de teléfonos celulares más populares explicó por qué los lectores jóvenes están abandonando las novelas tradicionales: "No leen obras de escritores profesionales porque sus oraciones son demasiado difíciles de entender, sus expresiones son intencionadamente rebuscadas, y las historias no les resultan familiares". Las novelas de celular tradicionales tienen capítulos de menos de 200 palabras, promediando 100, se escriben de manera más vertical, conteniendo gran cantidad de espacios en blanco, puntos aparte, y un lenguaje sencillo y emocional.

Otra señal de cómo Internet está comenzando a influir en la escritura de libros llegó en 2009, cuando O'Reilly Media, un editor estadounidense de libros de tecnología, publicó un libro sobre Twitter, “The Twitter Book”, que había sido creado con PowerPoint de Microsoft. "Durante mucho tiempo hemos estado interesados en explorar cómo el medio en línea cambia la presentación, la narrativa y la estructura de los libros", dijo el director ejecutivo de la firma, Tim O'Reilly, al presentar el volumen, que está disponible tanto en ediciones impresas como electrónicas. "La mayoría de los libros todavía usan el viejo modelo de una narrativa sostenida como su principio organizativo. Aquí, hemos utilizado un modelo de páginas web independientes, cada uno de los cuales se puede leer solo (o como máximo en un grupo de dos o tres). "La arquitectura modular" refleja el cambio en la manera de leer de las personas (Carr, 2011).

\subsection{IMPACTO EN EL APRENDIZAJE}

John Sweller, un psicólogo educativo australiano, ha pasado tres décadas estudiando cómo las mentes procesan la información y, en particular, cómo aprende el ser humano. Su trabajo permite comprender cómo Internet y otros medios influyen en el estilo y la profundidad de nuestro pensamiento. Nuestros cerebros, explica el autor en su libro (Sweller, 1999), incorporan dos tipos muy diferentes de memoria: a corto y a largo plazo. Mantenemos las impresiones, sensaciones y pensamientos inmediatos como recuerdos a corto plazo, que tienden a durar solo unos segundos. Todas las cosas que hemos aprendido sobre el mundo, ya sea consciente o inconscientemente, se almacenan como recuerdos a largo plazo, que pueden permanecer en nuestros cerebros durante unos días, unos años o incluso toda la vida. Un tipo particular de memoria a corto plazo, llamada memoria de trabajo juega un papel fundamental en la transferencia de información a la memoria a largo plazo y, por lo tanto, en la creación de la reserva personal de conocimiento.

Llenar una bañera con un dedal es el desafío involucrado en la transferencia de información de la memoria a corto plazo a la memoria a largo plazo (Carr, 2011). Al regular la velocidad y la intensidad del flujo de información, los medios ejercen una gran influencia en este proceso. Cuando se lee un libro, la fuente de información proporciona un goteo constante, que se puede controlar según el ritmo de la lectura. A través de la concentración en el texto, se puede transferir la totalidad o la mayor parte de la información, dedal a dedal, a la memoria a largo plazo y crear asociaciones esenciales para la creación de esquemas mentales. Con la red, el cerebro se enfrenta a muchas canillas de información, todas funcionando a tope. El pequeño dedal se desborda cuando se pasa de una canilla a la siguiente. Se puede transferir solo una pequeña porción de la 
información a la memoria a largo plazo, y lo que se transfiere es un revoltijo de gotas de diferentes canillas, no un flujo continuo y coherente de una sola fuente. La información que fluye a la memoria de trabajo en un momento dado se llama "carga cognitiva". Cuando la carga excede la capacidad de la mente de almacenar y procesar la información, cuando el agua se desborda del dedal, no es posible retener la información o crear conexiones con la información ya almacenada en la memoria a largo plazo. No es posible convertir la nueva información en esquemas. La capacidad de aprender sufre, y la comprensión sigue siendo superficial. Debido a que la capacidad para mantener la atención también depende de la memoria de trabajo, una alta carga cognitiva amplifica la distracción que se padece. Los experimentos indican que a medida que se alcanzan los límites de la memoria de trabajo, se hace más difícil distinguir la información relevante de la información irrelevante (señal del ruido).

Las dificultades para comprender un tema o concepto parecen estar fuertemente determinadas por la carga de la memoria de trabajo y cuanto más complejo es el material que se intenta aprender, mayor es la penalización que causa una mente sobrecargada. Hay muchas fuentes posibles de sobrecarga cognitiva, pero dos de las más importantes son la "resolución de problemas externos" y la "atención dividida" (Sweller, 1999). Usar Internet puede ejercitar el cerebro de la misma forma que lo hace la resolución de crucigramas. Pero tal ejercicio intensivo, cuando se convierte en el modo primario de pensamiento, puede impedir el aprendizaje y el pensamiento profundo. Es como leer un libro mientras se completa un crucigrama. Ese es el entorno intelectual generado por Internet (Carr, 2011).

Más allá de la afluencia de mensajes personales, no solo el correo electrónico, sino también mensajes instantáneos y mensajes de texto, internet proporciona todo tipo de notificaciones automáticas. Los lectores de feeds y las suscripciones de noticias permiten saber cada vez que aparece una nueva historia en una publicación o blog favorito. Las redes sociales alertan sobre lo que hacen los amigos, a menudo momento a momento. Twitter y otros servicios de microblogging informan cada vez que una de las personas "seguidas" transmite un nuevo mensaje. También se pueden configurar alertas para monitorear cambios en el valor de las inversiones, informes de noticias sobre personas o eventos en particular, actualizaciones de software, nuevos videos subidos a YouTube, y así sucesivamente. Según la cantidad de alertas de información a los que alguien está suscrito y la frecuencia con la que envían las actualizaciones, se pueden generar una docena de alertas por hora, y para los más conectados, el número puede ser mucho mayor. Cada uno de ellos es una distracción, otra intrusión en los pensamientos, otra información que ocupa un espacio precioso en la memoria de trabajo de un individuo (Carr, 2011).

Navegar por Internet requiere una forma particularmente intensa de multitarea mental. Además de inundar la memoria de trabajo con información, este malabarismo impone lo que los neurocientíficos denominan "costos de cambio" en la cognición (Carr, 2011). Cada vez que cambiamos la atención, nuestro cerebro tiene que reorientarse a sí mismo, reduciendo aún más nuestros recursos mentales. Muchos estudios han demostrado que el cambio entre solo dos tareas puede aumentar sustancialmente la carga cognitiva, impidiendo nuestro pensamiento y aumentando la probabilidad de que pasemos 
por alto o malinterpretemos información importante. Los resultados sugieren que el aprendizaje de hechos y conceptos es muy bajo si se aprenden mientras se está distraído (Foerde \& Knowlton, 2006).

Es importante enfatizar que la capacidad de Internet para monitorear eventos y enviar mensajes y notificaciones automáticamente es uno de sus puntos fuertes como tecnología de comunicación. Muchas personas desean ser interrumpidas, porque cada interrupción les brinda una valiosa información. Desactivar estas alertas es arriesgarse a sentirse fuera de contacto, o incluso socialmente aislado. Entonces, se le pide a Internet que los siga interrumpiendo de formas cada vez más variadas. Muchos aceptan voluntariamente la pérdida de concentración, la división de la atención y la fragmentación de los pensamientos, a cambio de la riqueza de la información que se recibe (Carr, 2011).

La clave para la consolidación de la memoria es la atención. Almacenar recuerdos explícitos e, igualmente importante, formar conexiones entre ellos requiere una fuerte concentración mental, amplificada por la repetición o por un intenso compromiso intelectual o emocional. Cuanto más aguda es la atención, más nítida es la memoria. Para que un recuerdo persista la información entrante debe procesarse completa y profundamente. Esto se logra atendiendo a la información y asociándola significativa y sistemáticamente con el conocimiento que ya está bien establecido en la memoria (Kandel, 2007).

\subsection{EL CEREBRO ES PLÁSTICO}

Los expertos en neurociencias están de acuerdo en que el cerebro es "masivamente plástico" (Lawton, 2008), lo que implica que regularmente se crean nuevas células nerviosas y se descomponen las conexiones neuronales viejas y se forman nuevas. El cerebro tiene la habilidad de reprogramarse a sí mismo sobre la marcha, alterando la manera en que funciona. Cada vez que se realiza una tarea o se experimenta una sensación, ya sea física o mental, un conjunto de neuronas en el cerebro se activa. Si están próximas unas de otras, las neuronas se juntan mediante el intercambio de neurotransmisores sinápticos. A medida que la misma experiencia se repite, los enlaces sinópticos se hacen más fuertes y abundantes a través de cambios fisiológicos y anatómicos (Carr, 2011).

La neuroplasticidad proporciona una flexibilidad mental y una agilidad intelectual que permite adaptarse a situaciones nuevas, aprender nuevas habilidades y, en general, expandir los horizontes. Sin embargo, no todas son buenas noticias. Si bien la neuroplasticidad provee muchos beneficios, también impone su propia forma de comportamiento. A medida que determinados circuitos en nuestro cerebro se fortalecen por medio de la repetición de una actividad física o mental, comienzan a transformar esa actividad en un hábito. La paradoja de la neuroplasticidad es que, a pesar de toda la flexibilidad mental que concede, puede resultar en "comportamientos rígidos" (Doidge, 2008). Las sinapsis activadas que unen las neuronas estimulan el deseo de ejercitar los circuitos que han formado. Una vez que se han conectado nuevos circuitos en el cerebro, se genera la necesidad de mantenerlos activados. Esa es la forma en que el cerebro ajusta su operación. Las actividades de rutina se llevan a cabo de forma cada vez más rápida y eficiente, mientras que los circuitos no utilizados se eliminan. 
Plástico no significa elástico. Los bucles neurales no vuelven a su estado anterior como lo hace una banda elástica, sino que se aferran a su estado cambiado. Y no necesariamente ese cambio es algo deseable. Los malos hábitos pueden arraigarse en las neuronas tan fácilmente como los buenos. Así como la neuroplasticidad es un mecanismo para el desarrollo y el aprendizaje, también puede ser la causa de una patología (PascualLeone, 2005). Por eso no sorprende que la neuroplasticidad se haya relacionado con afecciones mentales que van desde la depresión hasta el trastorno obsesivo-compulsivo. Cuanto más se concentra un paciente en sus síntomas, más profundos son grabados en sus circuitos neuronales. En el peor de los casos, la mente esencialmente se entrena para estar enferma (Carr, 2011).

Dada la plasticidad del cerebro, se sabe que los hábitos en línea continúan repercutiendo en el funcionamiento de las sinapsis cuando no se está en línea. Se puede suponer que los circuitos neuronales dedicados al escaneo, la lectura superficial y la multitarea se están expandiendo y fortaleciendo, mientras que los utilizados para leer y pensar profundamente, con una concentración sostenida, se están debilitando o erosionando (Carr, 2011). En 2009, investigadores de la Universidad de Stanford, Estado Unidos (Ophir \& Nass, 2009) encontraron indicios de que este cambio ya podría estar en marcha. Le dieron una serie de pruebas cognitivas a un grupo que intensamente pasaba de una tarea a otra mientras usaba multimedia, así como a un grupo que cambiaba de tareas, pero con menos frecuencia. Descubrieron que los del primer grupo se distraían fácilmente con estímulos irrelevantes, tenían un control significativamente menor sobre el contenido de su memoria de trabajo y, en general, eran incapaces de mantener su concentración en una tarea en particular.

La inmensa cantidad de mensajes que se reciben cuando se está en línea no solo sobrecargan la memoria de trabajo, sino que hacen que sea mucho más difícil para el lóbulo frontal concentrar la atención en alguna cosa. El proceso de consolidación de la memoria ni siquiera puede comenzar. Y, una vez más, gracias a la plasticidad de las vías neuronales, cuanto más se utiliza Internet, más se entrena al cerebro para que se distraiga: para procesar información de manera muy rápida y eficiente, pero sin atención sostenida. Eso ayuda a explicar por qué a muchos les resulta difícil concentrarse incluso cuando están lejos de los dispositivos tecnológicos. El cerebro se vuelve experto en el olvido, inepto para recordar (Carr, 2011).

\subsection{TEOREMA DEL VALOR MARGINAL}

El Teorema del valor marginal (MVT, del inglés "Marginal Value Theorem") (Charnov, 1976) se ha utilizado durante décadas para explicar por qué, cómo y cuándo los animales toman la decisión de invertir tiempo y energía para viajar a un nuevo lugar con alimentos adicionales, en vez de reunir los recursos restantes de su lugar actual. En su forma más simple, el $M V T$ explica la relación costo-beneficio de permanecer en un lugar con recursos versus mudarse a un nuevo lugar, teniendo en cuenta el instinto natural de supervivencia de los animales. La habilidad de un animal para encontrar alimento pasando un "tiempo óptimo" en una fuente antes de viajar a otra es un factor crítico en su supervivencia. 
Para revisar el modelo de $M V T$, en la Figura 2.3, el lado derecho del modelo indica los beneficios de seguir en la misma fuente de recursos. Para los animales que buscan comida, la curva de consumo de recursos, que define la ingestión acumulada de recursos a lo largo del tiempo, está impulsada en gran medida por factores externos que definen las ganancias decrecientes de permanecer en el mismo lugar, como la cantidad de frutos que quedan en el árbol. A medida que los recursos disminuyen con el consumo continuo, los beneficios de permanecer en el mismo lugar disminuyen y la curva se aplana gradualmente con el tiempo. Esta meseta de la curva de entrada de recursos en el lado derecho del modelo interactúa con factores en el lado izquierdo del modelo, que reflejan el costo, o el tiempo para llegar a una nueva fuente de recursos. Es la intersección de estos dos factores (expresada por la línea tangente de la curva de consumo) que está asociada con un disparador subconsciente en el cerebro de un animal que señala el momento óptimo para permanecer en una fuente. Para los animales que buscan comida, las fuerzas instintivas impulsan este comportamiento.

Según Gazzaley y Rosen, autores del libro "The Distracted Mind" (Gazzaley \& Rosen, 2016), el modelo $M V T$ puede utilizarse para demostrar el comportamiento humano con la tecnología. Este modelo puede ayudar a explicar la necesidad aparentemente constante de cambiar el foco de atención en respuesta a una alerta externa o un impulso interno. A diferencia de lo que hacen los animales, estudio tras estudio, tanto en el laboratorio como en el campo, han demostrado que los adultos, los adolescentes y hasta los niños cambian el foco de su atención a una nueva fuente de información incluso antes de que hayan completado su tarea en la fuente original. El modelo MVT se ha extendido recientemente para explicar no sólo por qué los animales se trasladan de una fuente de alimento a otra, sino para explicar por qué los humanos se mueven de una fuente de información a otra. Puede explicar, por ejemplo, por qué alguien puede elegir: (1) dejar de trabajar en un documento que está leyendo en línea para responder a una alerta proveniente del celular, (2) abrir una nueva pestaña para buscar información adicional sobre un tema no relacionado y (3) decidir que es necesario enviar un mensaje de texto a un amigo para organizar una salida, todo antes de regresar al documento en el que está trabajando. En el caso de los animales, la curva de consumo de recursos es influenciada por factores externos, como la cantidad de alimento disponible en el lugar. Pero curiosamente, en los seres humanos parece que la situación es mucho más complicada que la influencia de los factores externos en la curva. 


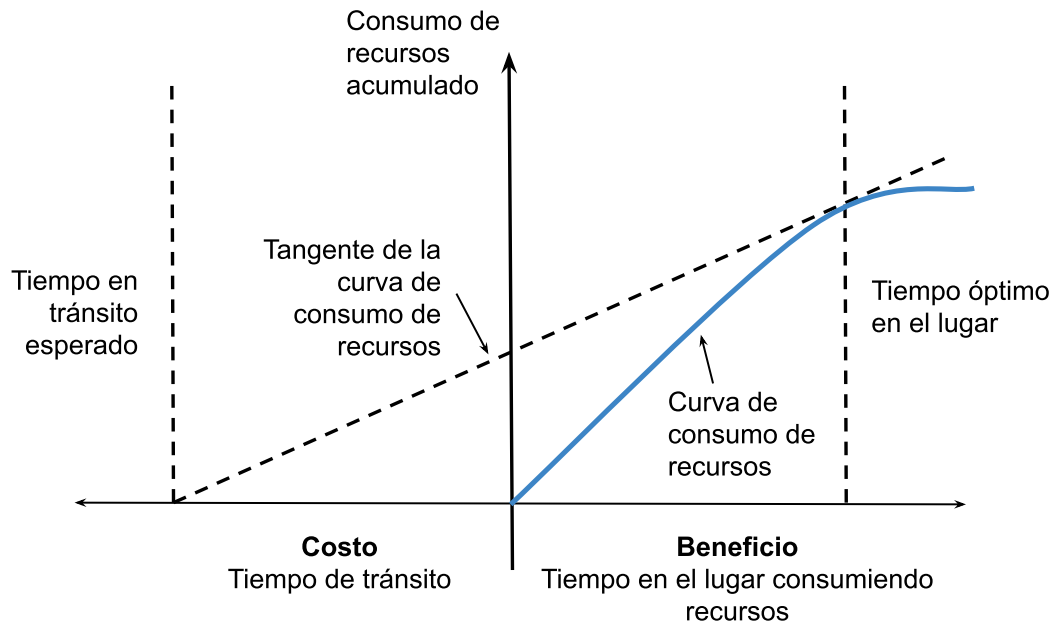

FIGURA 2.3 - Teorema de Valor Marginal

Gazzaley y Rosen proponen que el lado derecho del modelo también está fuertemente influenciado por factores internos que modulan la pendiente de la curva, independientemente de los recursos de información actuales que van disminuyendo (los factores externos). Parece que al menos dos factores internos ejercen una influencia importante en el aplanamiento de la curva: el aburrimiento y la ansiedad, como se puede ver en la Figura 2.4. Los autores afirman que la acumulación de estas dos señales internas con el paso del tiempo disminuye el tope de la curva. Esto, a su vez, impulsa el "tiempo óptimo en el lugar" hacia la izquierda (es decir, reduce el tiempo en el lugar), lo que conduce a una conmutación más rápida entre fuentes de información. Lo que sucede es que quien se aburre con lo que está haciendo, se pone ansioso y quiere avanzar lo más rápido que pueda hacia otra dirección. Esto contribuye a un patrón generalizado de curvas de consumo de recursos más superficiales y, por lo tanto, a un comportamiento multitarea más frecuente. Bajo estas condiciones, la conmutación se llevaría a cabo incluso si hubiera información restante "sustanciosa" para ser consumida en la fuente actual. En otras palabras, los factores internos de aburrimiento y ansiedad influyen en los beneficios "percibidos" de la fuente de información actual. Este cambio en el lado derecho del modelo interactúa con otro cambio que ha ocurrido en el lado izquierdo del modelo, también debido a la influencia de la tecnología moderna. El desplazamiento del lado izquierdo es una disminución en el tiempo de tránsito esperado para llegar a una nueva fuente, como resultado de un aumento dramático en el acceso a nuevas fuentes de información, particularmente debido a los smartphones, que ofrecen un suministro infinito de fuentes de información con unos toques de pantalla. Esto da como resultado un cambio aún más rápido entre las fuentes de información, a pesar de las consecuencias negativas asociadas con este comportamiento. 


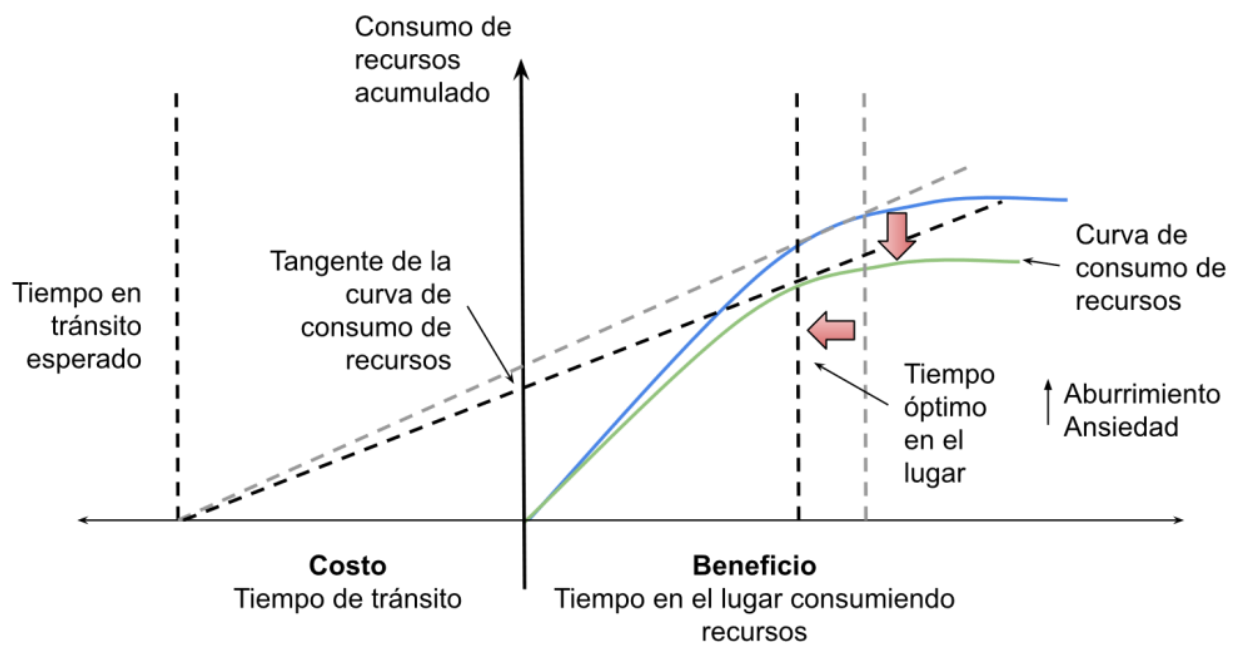

FIGURA 2.4 - MVT influenciado por el aburrimiento y la ansiedad

Aburrimiento. El aburrimiento es difícil de definir con precisión. Por ejemplo, John Eastwood y sus colegas de la Universidad de York sugieren en un trabajo (Eastwood \& Fenske, 2012) que el aburrimiento es "la experiencia aversiva de querer, pero no poder, participar en actividades satisfactorias". Eastwood aclara que una persona aburrida no es solo una que no tiene nada que hacer, sino más bien, es aquella que desea un estímulo y no puede obtenerlo. Otros especialistas (Barbalet, 1999) sugirieron que el aburrimiento es "una sensación inquieta e irritante de que la actividad o situación actual de la persona no tenga atractivo, y que hay una necesidad de continuar con algo más interesante".

Una posibilidad de por qué la tasa de acumulación de aburrimiento ha aumentado en los últimos tiempos es, según Gazzaley y Rosen (Gazzaley \& Rosen, 2016), la influencia de los ciclos de recompensa a corto plazo tan abundantes en los medios de comunicación. De décadas de investigación sobre aprendizaje y comportamiento, se sabe que cuanto más corto sea el tiempo entre recompensas, más fuerte será el impulso para completar ese comportamiento y obtener esa recompensa. La multitarea multimedia en sí misma, junto con una carga de novedades tan alta que lleva a recompensas frecuentes, también puede influir en la curva de aburrimiento. En otras palabras, esto puede ser cíclico: el aburrimiento "impulsa a" cambiar frecuentemente a nuevas tareas, lo que a su vez "induce a" recompensas rápidas, que a su vez "llevan a" un aumento de la tasa de aburrimiento en fuentes de información no estimulantes, que "conducen a" un aplanamiento rápido de la curva de consumo de recursos, lo que "lleva a" tiempos de cambio más rápidos y así sucesivamente. El impacto del aburrimiento no es solo para hacer cambiar entre fuentes de información, también parece que se ha perdido la capacidad de "no hacer nada" y soportar el aburrimiento. Esto deja poco tiempo para la reflexión, el pensamiento profundo, o simplemente sentarse y dejar que nuestros pensamientos aleatorios nos lleven a lugares en los que no podríamos haber estado manteniendo un pensamiento dirigido.

Ansiedad. Un estudio realizado por el Rosen (Rosen, 2013) descubrió que casi la mitad de los jóvenes nacidos a fines de los 90 y principios del 2000 informaron sentirse moderadamente ansiosos si no podían revisar sus mensajes de texto al menos cada 
quince minutos, y un número sustancial también informaron que se sentían ansiosos si no podían verificar con otras tecnologías, incluidas las redes sociales, las llamadas de teléfono celular y el correo electrónico, con la frecuencia deseada. Esta constante ansiedad ha recibido el nombre de FOMO (del inglés "Fear Of Missing Out"): miedo a perderse algo importante, la aprehensión generalizada de que otros podrían estar teniendo experiencias muy valiosas de las cuales se está ausente. Se caracteriza por el deseo desmedido de estar continuamente conectado con los demás y al tanto de lo que están haciendo. Pareciera que las personas tienen una necesidad creciente de permanecer conectadas, y esta "obsesión" obliga a verificar impulsivamente si hay alguna novedad en los dispositivos, en detrimento de la capacidad de mantenerse enfocadas en lo que estaban haciendo en el momento y cuando no pueden hacerlo con la frecuencia que desean, se sienten ansiosos (Gazzaley \& Rosen, 2016).

¿Por qué hay estos niveles de ansiedad? Gazzaley y Rosen (Gazzaley \& Rosen, 2016), citados previamente, creen que el aspecto principal de la tecnología moderna que ha contribuido a este cambio es que internet, los smartphones y las redes sociales aumentaron no solo el acceso a la información, sino especialmente a un tipo particular de información: la comunicación. La capacidad de conectarse con otras personas, en cualquier lugar, todo el tiempo, ha cambiado drásticamente con la llegada del correo electrónico, los teléfonos móviles, los mensajes de texto, las redes sociales y una sin fin de formas en que una persona puede conectarse a otra electrónicamente. Esto ha ejercido presión sobre las expectativas de interconectividad y ha resultado en la aparición de niveles elevados de ansiedad acompañados de $F O M O$, nomofobia y el síndrome de vibración fantasma.

Accesibilidad. Hasta ahora vimos que las dos fuerzas principales que aplanan la curva de consumo de recursos en el lado derecho del modelo MVT logran que se alcance el momento óptimo de abandonar la fuente de información de manera prematura, lo que resulta en que se cambie la atención con más frecuencia. Pero es importante apreciar que hay un factor importante en el lado izquierdo del modelo que disminuye el tiempo de tránsito esperado a una nueva fuente, lo que resulta en un cambio aún más prematuro del tiempo en la fuente de información. Ese factor es la accesibilidad (Gazzaley \& Rosen, 2016), como se muestra en la Figura 2.5. Cuanto más disponible esté (o parezca) una nueva fuente de información más temprano será el momento en que alguien decidirá cambiarse de su fuente de información actual. Es esencialmente lo mismo que sucedería con los animales que buscan comida (considerando el estudio original de $M V T$ ). Si otro árbol lleno de nueces está allí mismo, una ardilla dará el salto antes a este nuevo lugar, que si tuviera que viajar lejos para llegar a otro árbol.

En la vida cotidiana se puede percibir la poderosa influencia de los medios y la tecnología. La información es más accesible que nunca en la historia. Los dispositivos tecnológicos brindan notificaciones emergentes, alertas por correo electrónico, tweets y mensajes de texto no leídos, mensajes de chat pendientes en varias plataformas, notificaciones de redes sociales esperando, alertas de calendario, actualizaciones de software pendientes y, en algunas computadoras, incluso iconos de alertas que constantemente parpadean. Debido a los muchos dispositivos que constantemente llaman la atención, se podría dejar la fuente de información actual no porque se haya terminado el consumo 
de esa información, sino simplemente porque se ha recibido una alerta de que podría haber algo más interesante o intrigante disponible.

Cabe destacar que la accesibilidad no es solo la facilidad para llegar a la tecnología y buscar información. También abarca la poderosa forma en la que la tecnología ahora puede llegar a las personas. Sin duda que eso cambia todo. Sería como si un árbol vecino pudiera arrojar una nuez a una ardilla cada vez que esta intentará alimentarse del árbol en el que se encuentra. Estas interrupciones alteran drásticamente el tiempo de tránsito esperado a una nueva fuente de información porque constantemente alertan sobre cuán accesible está. El mayor impedimento para la concentración es el ecosistema de interrupciones que rodea a las personas: mensajería instantánea, alertas de correo electrónico, alertas RSS, Skype, etc. Cualquier cosa que requiera una respuesta, incluso inconscientemente, ocupa la atención.

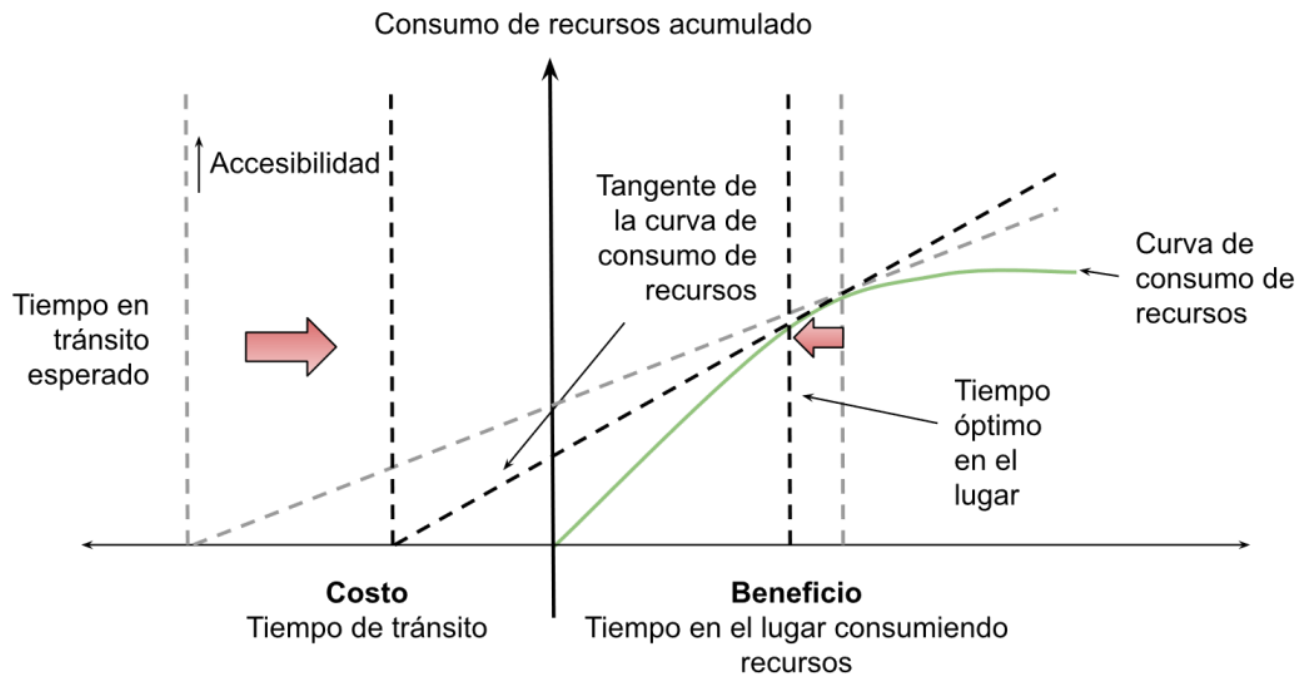

FIGURA 2.5 - MVT incluyendo la accesibilidad de información

En resumen, las influencias impulsadas por la tecnología en el lado derecho del modelo, el aburrimiento y la ansiedad, interactúan con una fuerza impulsada por la tecnología en el lado izquierdo del modelo presentado en la Figura 2.5, la accesibilidad, para cambiar el "momento óptimo" a un tiempo muy prematuro. Por supuesto esto no tiene nada de óptimo, porque mucha información importante no se toma en cuenta.

\section{Recapitulación}

En este capítulo se analizaron algunas propuestas para desarrollar software clásicas, como Waterfall y RUP, y metodologías ágiles como Scrum, XP y Kanban. Dichas propuestas se han utilizado por años en el desarrollo y han tenido éxito. Sin embargo, ninguna de ellas cumple simultáneamente con los 4 objetivos a los que apunta la propuesta de esta tesis. Por otro lado, la tendencia a leer de manera superficial de nuestra época es un factor para tener presente a la hora de elaborar la documentación en los proyectos de software. A raíz de esto se realiza la documentación mínima que facilite a los usuarios, a los clientes y al equipo la lectura de los documentos. 


\section{Capítulo 3 Trabajos Relacionados}

$\mathrm{E}$

N ESTE CAPÍTULO se analizan trabajos de otros autores publicados en congresos y revistas prestigiosas (como por ejemplo como IEEE, ACM, Springer, Science-

Direct) los cuales han sido sometidos a revisión de pares. En todos los casos se menciona un resumen de dichos trabajos y se destacan las diferencias con respecto al proceso propuesto en esta tesis. Al final se incluye una tabla resumen que compara los diferentes trabajos relacionados.

\section{RESUMEN DE LOS TRABAJOS RELACIONADOS}

En esta sección se hace una descripción de los trabajos relacionados y se los compara con la propuesta de este trabajo. En la lista no se incluyen Extreme Programming, Scrum, Kanban ni Waterfall ya que han sido explicados previamente.

Losada et al. (Losada \& Urretavizcaya, 2013) en su trabajo plantean que los métodos ágiles $(A M)$, los desarrollos dirigidos por modelos $(M D D)$ y el diseño centrado en el usuario $(U C D)$ son tres enfoques ampliamente aceptados por la comunidad que comparten un objetivo común de eficiencia en el software resultante. Sin embargo, ninguno de ellos logra el éxito sin encontrar problemas durante el desarrollo de la aplicación. Por lo tanto, los autores integraron estas técnicas para que las ventajas de uno mitiguen los problemas de los demás en InterMod, una metodología cuyo objetivo es ayudar al desarrollo preciso de software interactivo, incluido el diseño web. Esta propuesta organiza el proyecto como una serie de iteraciones, tal como lo hacen las metodologías ágiles, y distribuye el trabajo en iteraciones de acuerdo con las diferentes actividades de desarrollo e integración de los Objetivos del usuario. Estos procesos pueden ser realizados en paralelo por diferentes equipos. Cada actividad está dirigida por modelos y debe ser validada por un equipo multidisciplinario compuesto por desarrolladores y usuarios finales. A continuación, una descripción de lo que implica la metodología InterMod. Paso 0: Analizar el proyecto globalmente: Al principio, el proyecto en su totalidad debe analizarse para determinar: (a) los objetivos de los usuarios iniciales y (b) las decisiones de diseño. Es importante elaborar los modelos que ayuden a recopilar las características definitivas del tipo de sistema (por ejemplo, tipo de dispositivo, seguridad, tamaño de la ventana, color, logotipo, etc.) y las del usuario (por ejemplo, preferencias de color, fuente, tamaño, algunas limitaciones físicas de los usuarios). Estas características se recogen en el Modelo de sistema y el Modelo de usuario, respectivamente. Todas estas decisiones iniciales darán coherencia al proceso incremental y todos los desarrollos en el proyecto heredarán, complementarán o extenderán estos aspectos. Paso 1: Construir la lista de objetivos de usuario: Los requisitos de la aplicación se recopilan de forma gradual durante la construcción progresiva de la lista de objetivos del usuario. Cada iteración actualiza esta lista con nuevos objetivos obtenidos de nuevas necesidades del proyecto o de anteriores. Paso 2: Planificar la iteración paralela: InterMod incluye dos tipos de Actividades en cada iteración: Actividades de Desarrollo y Actividades de 
Integración. Todas las actividades se completan con un proceso de evaluación. Las Actividades de desarrollo pueden planearse para ejecutarse en paralelo y al final, realizar una Actividad de Integración. Paso 3: Realizar las actividades de la iteración: Cada equipo realiza las actividades establecidas en el plan. Todas las actividades de desarrollo e integración están manejadas por modelos generados y evaluados durante el proyecto siguiendo la propuesta de arquitectura dirigida por modelos.

De acuerdo con lo analizado en el trabajo de Losada, su enfoque apunta a la trazabilidad de los requerimientos, al trabajo con equipos distribuidos. Además, presenta un caso de estudio que demuestra su aplicación en 8 iteraciones, con 3 equipos de al menos 7 integrantes. Sin embargo, no apunta a una documentación mínima ni a equipos con menos de 5 integrantes.

Sampaio et al. (Sampaio \& Vasconcelos, 2004) proponen "XWebProcess" como una mejora a lo que Extreme Programming $(X P)$ ofrece para el desarrollo de aplicaciones web. Los autores eligieron $X P$ debido a los resultados positivos que se han tenido en proyectos de desarrollo de software en los cuales se ha cumplido con los tiempos y el presupuesto. En el trabajo los autores mencionan que, para el tiempo de publicación (2004), el 28\% de los proyectos realizados eran web. XWebProcess incluye características de la ingeniería web (disciplinas, actividades, artefactos y roles) y disciplinas tomadas de $X P$ adaptadas al desarrollo web. El proceso propuesto por los autores cuenta con las siguientes disciplinas: 1. Exploración, 2. Definición y revisión de los requerimientos, 3. Análisis y Diseño, 4. Navegación y Presentación Web, 5. Testing Web y 6. Soporte Web. A continuación, se presenta una breve descripción de las disciplinas antes mencionadas: Exploración: Durante las exploraciones iniciales es necesario investigar si el sistema es viable o no. En las aplicaciones web, es importante realizar sesiones de prototipos con clientes y gerentes de negocios para ayudar a definir los requisitos iniciales, el alcance y los objetivos comerciales del sistema. Definición y revisión de los requerimientos: En el desarrollo web, la construcción de una arquitectura sólida y flexible es vital para el éxito del sistema, ya que las aplicaciones web se están integrando constantemente con otros sistemas e incorporando nuevas tecnologías. Análisis y Diseño: Esta disciplina incluye el diseño de la capa de datos. El administrador de base de datos es responsable de realizar esta actividad que dará lugar al diseño de la base de datos y de la arquitectura de la información. En el caso de las aplicaciones web con uso intensivo de datos, esta actividad también puede incluir tareas como la evaluación de la calidad de los datos, la definición de la mediación de datos y la estrategia de actualización, la seguridad de los datos y las políticas de recuperación. Navegación y Presentación Web: Introducido debido a la importancia de la navegación y presentación en aplicaciones web. Las interfaces de usuario web pueden ser complejas, incluyendo gráficos, sonido, animaciones, etc. También es común tener diferentes rutas de navegación que pueden ser seguidas por los usuarios. Testing Web: Introducido para contemplar extensas pruebas. En ingeniería web, los requisitos de prueba, especialmente no funcionales, son fundamentales. Es esencial verificar problemas como el rendimiento, la carga de la red, el número de usuarios, etc. y Soporte Web: El enfoque de esta disciplina es manejar los componentes de hardware y software que forman la solución web. En las aplicaciones web hay muchos componentes distintos (hipertexto, figuras, código, base de datos, etc.) que se pueden 
distribuir a lo largo de la red. Por lo tanto, es importante tener una buena organización de los componentes para simplificar las correcciones y actualizaciones. Con respecto a la cantidad de participantes, los autores recomiendan equipos de 5 integrantes, que cumplan con los siguientes roles: tres programadores (dos de los cuales cumplirán, a su vez, el rol de diseñador web y otro de project manager), un arquitecto y un administrador Web. Los participantes deben compartir el espacio físico. Finalmente, con respecto a la documentación, los autores recomiendan utilizar prototipos, diseño de arquitectura y modelo de datos y priorizar la interacción personal sobre documentación extensa.

De acuerdo con lo analizado (Sampaio \& Vasconcelos, 2004), en su propuesta existe la trazabilidad en los requerimientos y se estimula a un desarrollo con documentación mínima. Sin embargo, no se especifica si puede utilizarse con menos de 5 personas en un equipo distribuido geográficamente. Con respecto a la evidencia empírica, sólo se probó en un ambiente controlado con estudiantes y con un proceso real.

Monteiro et al. (Monteiro \& Borges, 2012) en su trabajo plantean una modificación del Proceso Unificado Rational (RUP) para adaptarlo a equipos pequeños. Los autores plantean que RUP carece de una configuración que permita aplicarlo a empresas pequeñas (con menos de 50 empleados) o micro (con menos de 10 personas), por lo que en su trabajo buscan cerrar esa brecha, creando una nueva configuración de RUP que satisfaga esas características. La clave, según Monteiro, es reducir la cantidad de roles esenciales que plantea RUP al mínimo posible sin resignar calidad. Uno de los métodos utilizados es que ciertos roles sean absorbidos por otros roles. Por ejemplo, el Analista de Sistemas, el Diseñador Comercial y el Especificador de Casos de Uso se asigna al Administrador de Proyectos. El Arquitecto de software, el Diseñador de bases de datos, el Desarrollador de cursos y el Diseñador-Revisor de Mapas, se asignan al Integrador. El Diseñador de interfaz de usuario, el diseñador, el artista gráfico y el escritor técnico se asignan al Implementador. El Ingeniero de Casos de Uso se une al Administrador de Pruebas. Para validar su aplicación, los autores condujeron un caso de estudio con 7 equipos que tenía entre 13 y 17 integrantes, todos alumnos de la facultad. Los resultados demostraron que era posible su aplicación en un proyecto real.

De acuerdo con lo expuesto por Monteiro, la adaptación de RUP para equipos más pequeños tiene en cuenta la trazabilidad de los requerimientos y puede usarse en un proyecto real. Sin embargo, no está pensado para un equipo distribuido, ni con menos de 5 integrantes. Por otro lado, tampoco apunta a documentación mínima.

Al-Maharmeh (Al-Maharmeh M. , 2010), (Al-Maharmeh \& Unhelkar, 2009) propone el framework Composite Application Software Development Process Framework $(C A S D P F)$. El proceso está compuesto por tres capas interrelacionadas de ciclos de desarrollo de software: Modelo en cascada, Iterativo e Incremental y Ágil. El framework tiene las siguientes fases: Fase de Iniciación y Planificación del Proyecto, Fase de análisis de requerimientos, Fase de diseño, Fase de Desarrollo, Fase de Testing, Fase de Implementación y Fase de Cierre. A continuación, una descripción de cada una de ellas. Fase de Iniciación y Planificación del Proyecto: Se trata de una fase de alto nivel, en la que se inicia y aprueba la iniciativa para convertirse en un proyecto, se establece el comité directivo del proyecto y se designa un gerente de proyecto. Esta fase también incluye la estimación del tiempo y el costo para producir un presupuesto y el plan de proyecto. 
Fase de análisis de requerimientos: Esta fase implica el análisis y la ingeniería de los requisitos recopilados que se utilizan para producir un documento detallado de requisitos y construir un modelo del negocio. El proceso de análisis consiste en recopilar, analizar y validar los requisitos del sistema. CASDPF admite la recopilación, el análisis y la revisión de los requisitos del usuario en cada iteración. Los cambios o requisitos adicionales podrían incorporarse en el diseño del sistema durante las iteraciones de desarrollo. Fase de diseño: La fase de diseño implica diseñar y construir cada uno de los incrementos del sistema. La arquitectura de la solución del sistema se define y crea para ser compatible con toda la solución del sistema. Se busca identificar las entidades del negocio y cómo se relacionan entre sí. El diseñador del sistema trabaja con un analista de negocios en la preparación de un diagrama de clases o un diagrama de diseño conceptual que muestra los componentes del sistema y cómo interactúan entre sí. Fase de Desarrollo: La fase de desarrollo implica el desarrollo de incrementos del sistema. El equipo de desarrollo está involucrado en el desarrollo de los incrementos del sistema y otros productos relacionados, trabaja en paralelo en la codificación. Se requiere que un equipo de desarrollo tenga un excelente conocimiento de los lenguajes de programación y la base de datos que se utilizaría para desarrollar incrementos de proyectos. Fase de Testing: Esta fase incluye la creación y ejecución de planes de prueba, diseños de prueba y casos de prueba que describen cómo probar los incrementos desarrollados. Esta fase también implica la asignación de recursos necesarios para llevar a cabo las tareas de prueba. En esta fase se realizan una serie de tareas para determinar y garantizar la calidad de los componentes desarrollados. Los defectos se registran en una hoja de registro de defectos que los desarrolladores podrían utilizar para rastrear y gestionar los defectos. Fase de Implementación: Esta fase incluye la creación de un plan de implementación y la implementación de los incrementos del sistema en producción. Los planes de implementación se desarrollan para dirigir la implementación de los incrementos del proyecto por separado o todo el sistema como una solución integrada. Fase de Cierre: Esta fase incluye todas las actividades relacionadas con la evaluación y resolución de cualquier problema posterior a la implementación. Incluye tareas relacionadas con la preparación de materiales de capacitación, el cierre del presupuesto, la preparación de documentos de entrega y, finalmente, la finalización de todos los entregables del proyecto. Además, esta fase incluye tareas relacionadas con la revisión del costo del proyecto con respecto al presupuesto. Las revisiones del cronograma y el plan del proyecto también son importantes durante esta fase para abordar cualquier problema que causó un desplazamiento en el cronograma del proyecto. Estos problemas podrían evaluarse con el fin de dar un mejor control en proyectos futuros.

De acuerdo con lo analizado en la propuesta de Al-Maharmeh, se puede concluir que incluye la trazabilidad de los requerimientos. Además, incluye un piloto de proyecto que busca ser similar a la realidad. Sin embargo, no apunta a su utilización en un equipo distribuido y con menos de 5 integrantes. Por otro lado, tampoco busca reducir la documentación.

Vallon et al. (Vallon \& Strobl, 2016) plantean en su trabajo que el desarrollo ágil y el desarrollo de software distribuido $(D S D)$ parecen una combinación imposible. Los procesos ágiles están diseñados para que los equipos combinados colaboren 
estrechamente, lo que parece ser incompatible con DSD y sus desafíos inherentes de coordinación, control y comunicación. Además, nadie ha creado un marco integral que describa cómo aplicar prácticas ágiles a la $D S D$ con las que tanto investigadores como profesionales de la industria pueden relacionarse. Ante esa situación, los autores proponen ADAPT (del inglés "Agile Distributed Adaptable Process Toolkit", Kit de herramientas de proceso ágil distribuido y adaptable). ADAPT permite a los desarrolladores adaptar la implementación del proceso paso a paso a las restricciones de un proyecto. Esta capacidad también permite a los equipos hacer frente a las restricciones cambiantes a lo largo de la vida de un proyecto, como la adición o eliminación de un sitio de desarrollo. El framework completo de $A D A P T$ tiene tres categorías de desafíos (Coordinación, Control y Comunicación) que abarcan 10 directrices (D1. Asegurar la participación igualitaria de todos los sitios, D2. Permitir que los equipos con amplia experiencia trabajando juntos se autogestionen, D3. Establecer un flujo de conocimiento e información entre los sitios, D4. Usar la retrospectiva como un medio para la mejora continua, D5. Visualizar el trabajo de todos los sitios, D6. Involucrar al cliente en cada entrega, D7. Dar más importancia a la calidad que a las entregas apresuradas, D8. Utilizar herramientas que apoyen las prácticas ágiles, D9. Establecer retroalimentación multinivel, D10. Paso a paso, crear un ambiente en donde la metodología ágil realmente funcione) y 29 prácticas. Los desarrolladores pueden usarlo cuando ponen en marcha un nuevo proyecto en un entorno DSD o agregarlo a uno existente. Primero, los desarrolladores se refieren a las pautas $A D A P T$ para encontrar prácticas vinculadas que sean adecuadas para agregarlas a la próxima iteración del Sprint para abordar todas las pautas. La implementación de un nuevo proceso debe tener al menos una práctica por directriz. Es mejor usar menos prácticas por guía al comienzo del proceso. En segundo lugar, los desarrolladores llevan a cabo la iteración del Sprint y luego recopilan datos para evaluar la efectividad de las prácticas mediante, por ejemplo, gráficos de trabajo pendiente, recuento de errores o tiempo de espera. En tercer lugar, los desarrolladores evalúan los datos y reflexionan sobre la implementación del proceso durante la retrospectiva. Luego, comienzan de nuevo con el primer paso, pero ahora consideran agregar, modificar o eliminar prácticas mientras intentan equilibrar los desafíos de coordinación, control y comunicación.

De acuerdo con lo analizado del trabajo presentado por Vallon, el proceso propuesto está orientado a equipos distribuidos y documentación mínima. Sin embargo, no tiene en cuenta la trazabilidad de requerimientos ni que el tamaño del equipo pueda ser menor a 5 integrantes. Los autores presentan evidencia empírica de su aplicación en 7 equipos distribuidos durante un periodo de entre 6 y 15 meses.

Bernabé et al. (Bernabé, Navia, \& García-Peñalvo, 2015) proponen el framework Faat (Freelancer as a Team) para aquellos desarrolladores que suelen trabajar solos en varios proyectos a la vez. Las metodologías ágiles son prácticas confiables de ingeniería y administración, capaces de ayudar en el desarrollo de software de calidad y exitoso en entornos de negocios. Sin embargo, la mayoría de estas metodologías se centran en un equipo de desarrollo y su comunicación interna. Existe otro escenario: el de un programador que trabaja solo y, a menudo, en proyectos mucho más pequeños y en varios al mismo tiempo. También en este escenario, la proximidad del cliente no es como lo describe el ideal del entorno ágil. En ese caso, las prioridades y las necesidades cambian, la 
comunicación adquiere otro significado y los mecanismos de trabajo no siempre son comparables a los de un equipo. Los autores presentan Faat, una metodología diseñada específicamente para esos profesionales. Integrando las prácticas existentes a las necesidades y posibilidades de un programador individual. Sin embargo, se ha considerado con frecuencia la posible aplicación de esta metodología a equipos pequeños y/u otros escenarios más generales. Esta metodología ha sido probada en las aplicaciones de aprendizaje basadas en la web. Los autores presentan un conjunto de prácticas, la mayoría de ellas extraídas de las metodologías ágiles, en particular, aquellas consideradas más apropiadas y fáciles de implementar para un solo desarrollador. Se dividen en tres grupos: Prácticas estratégicas (pautas para elegir una decisión óptima en cada punto del desarrollo de software), prácticas de flujo de trabajo (describe los procesos operativos que se realizarán durante el desarrollo del producto y los elementos involucrados en ellas) y prácticas auxiliares (otras prácticas que cada desarrollador debe aplicar de acuerdo con sus capacidades, experiencia y criterio personal). A continuación, una breve descripción de cada una de ellas. Prácticas estratégicas: Simplicidad, donde los desarrolladores deben controlar el impulso de agregar funciones nuevas e innecesarias sin saber si serán necesarias en el futuro. Aceptar el cambio implica mantener la flexibilidad y eliminar los obstáculos que harían los cambios más difíciles de implementar. Tomas decisiones: Los desarrolladores deben tomar decisiones en el momento adecuado, cuando tengan la información necesaria, no antes. Mientras tanto, deberían centrarse en las cosas que requieren atención inmediata. Y una de las decisiones más difíciles es el rechazo de escenarios improbables y la implementación de características no requeridas "en anticipación de" situación que quizás no se presenten. Prácticas de flujo de trabajo: Historias de usuario, que describen funcionalidad que le aporta valor al usuario. Estimación: Es necesario conocer cuánto llevará completar una tarea. Planeamiento: El desarrollo no va a terminar nunca si no existe una planificación. La planificación permite priorizar y organizar las tareas a completar. Backlog del Producto: Panel donde se clasifican y priorizan todas las tareas a realizar en el proyecto. Test automatizados: La prueba debe ser realizada lo antes posible, pero con herramientas que permitan su automatización. Puede utilizarse TDD (Test Driven Development). Control de Código Fuente: El control de versiones es una práctica fundamental en cualquier proceso serio de desarrollo de software, no solo en metodología ágil. Re-evaluación: El trabajo realizado debe ser evaluado continuamente en todos los niveles. Prácticas auxiliares: Refactorización: La mejora continua del diseño y el código existente. Documentación limitada: Documentar, pero solo lo necesario. La utilización de la documentación debe justificar el esfuerzo asociado para desarrollarla. La proporción de lectura/escritura debe ser de 1 a 100. Hay herramientas que a menudo incluyen la generación automática de documentación que agiliza la creación y el mantenimiento, por lo que vale la pena tomarse el tiempo para aprender a usarlos. Prototipado Parcial: Es conveniente crear prototipos parciales para aclarar problemas técnicos o de diseño o para aumentar la confiabilidad de las estimaciones de las historias de usuario. Deben enfocarse solo en el problema bajo estudio e ignorar cualquier otra cosa. Rubber Duck (Pato de goma): Técnica de depuración altamente efectiva y de muy bajo costo. Se trata de seguir cuatro pasos: 1. Obtener por cualquier medio un pato de goma. 2. Colocarlos en el escritorio e 
informarle que va a revisar código. 3. Explicarle al pato lo que se supone que debe hacer el código, y luego explicarle línea por línea el código, en detalle 4. En algún momento se le dirá al pato lo que está haciendo a continuación y luego se dará cuenta de que eso no es en realidad lo que realmente está haciendo. Automatización: Cualquier cosa que pueda ser automatizada, debe hacerse lo antes posible.

De acuerdo con lo analizado del trabajo presentado en (Bernabé, Navia, \& García-Peñalvo, 2015) puede observarse que el proceso está preparado para utilizarse por un solo programador o quizás un equipo pequeño, contemplando documentación mínima. Sin embargo, no cuenta con trazabilidad de requerimientos y no especifica si puede utilizarse en un equipo distribuido geográficamente. Con respecto a la evidencia empírica, los autores establecen que lo han probado en un proyecto web.

Dos Santos et al. (Dos Santos \& L'Erario, 2018) plantean en su trabajo una modificación para utilizar Scrum en un equipo distribuido y multidisciplinario. El proceso basado en Scrum de este caso difiere del Scrum normal en la adición de una nueva función: el propietario de la integración. Este rol se creó para satisfacer las necesidades de comunicación entre los equipos involucrados en un escenario distribuido. Este profesional es responsable de mediar las interacciones entre los equipos internos de la empresa y los equipos externos, integrando las partes interesadas. En este caso, este rol no solo genera documentación, sino también acuerdos entre aquellos involucrados en un proyecto particular o la elaboración de la especificación de requisitos. El propietario de la integración participa activamente en la concepción de las reglas de negocio porque este rol integra información sobre el desarrollo de software y las reglas de negocio que no estaban bien establecidas por el cliente. Durante el caso de estudio, los investigadores notaron que Scrum no satisfizo las necesidades de desarrollo de software de la empresa estudiada. Sin embargo, la personalización de Scrum con la incorporación del Propietario de integración mejoró la productividad.

De acuerdo con lo analizado en el trabajo de Dos Santos, la modificación de Scrum permite utilizarlo en un equipo distribuido y manteniendo la documentación mínima. Sin embargo, no apunta a equipos pequeños ni a la trazabilidad de los requerimientos.

En su trabajo Rizwan et al. (Rizwan \& Hussain, 2008) proponen una mejora al proceso de Extreme Programming denominado Modelo de proceso de desarrollo de software adaptativo. Este proceso cuenta con 4 fases principales: 1. Comunicación y Planificación, 2. Análisis, Diseño y desarrollo y 3. Testing e implementación. La especificación del proyecto se prepara durante la fase de planificación comunicándolo al cliente. La especificación del proyecto se compone de evaluaciones de viabilidad y riesgo que se realizan para preparar una hoja de análisis de costos y beneficios $(C B A)$. La hoja de $C B A$ ayuda a estimar si el proyecto software es factible para los clientes o no. La fase de análisis solo se inicia si un cliente aprueba la propuesta. La fase de análisis mejora la calidad del software a través de la documentación adecuada. Esta es la fase en la que un analista reúne requisitos detallados. El documento de especificación de requisitos de software $(S R S)$ se produce al final de la fase de análisis. Los principales contenidos de $S R S$ son: resumen de requisitos, modelado de requisitos y modelado de datos. Las fases de diseño y desarrollo de $X P$ se fusionan. El proceso adaptativo utiliza el enfoque de 
prototipado para verificar el diseño y los requisitos. El software se desarrolla de forma incremental a medida que el cliente aprueba prototipos. Los casos de prueba se preparan para cada incremento al comienzo de la fase de prueba e implementación. Cada módulo se prueba por unidad. Luego se realiza una prueba de integración para verificar la integración entre los módulos. La prueba del sistema es la siguiente fase para validar todo el incremento como una unidad. La prueba de aceptación es la última prueba para verificar el incremento ante el cliente. El incremento probado se mantiene e implementa. El modelo de proceso adaptativo es cíclico y evolutivo hasta que se desarrolla todo el software. De acuerdo con los autores, el modelo de proceso adaptativo es mejor que los modelos ágiles porque elimina las limitaciones del desarrollo de componentes reutilizables, grandes equipos de desarrollo, documentación, calidad, desarrollo de software complejo.

De acuerdo con lo analizado en el trabajo de Rizwan, el proceso busca la trazabilidad de los requerimientos, contempla su utilización en equipos pequeños y distribuidos. Sin embargo, no tiene como objetivo la documentación mínima ni ofrece un caso de estudio que respalde su aplicación en un entorno de desarrollo real.

Rettig y Simons (Rettig \& Simons, 1993) plantean en su trabajo el proceso $P A-$ $D R E$, de las palabras en inglés Plan, Approve, Do, Review and Revise y Evaluate. El proceso se divide en tres niveles principales: Proceso a nivel Proyecto, Etapa y Módulo. A continuación, una descripción de cada uno de ellos. Proceso a nivel Proyecto: Se establece el proyecto, en donde la organización decide realizar el proyecto y se crea una descripción general del mismo. Se planifica el proyecto, en donde el equipo separa el proyecto principal en etapas. Se realiza el proyecto, donde el equipo completa cada una de las etapas creadas anteriormente. Finalmente se evalúa el proyecto, donde el equipo analiza maneras de mejorar el producto, el plan y el proceso del proyecto. Proceso a nivel Etapa: Se planifica la etapa, donde el equipo separa cada una en módulos. Cada uno de los módulos se asigna a un miembro del equipo. Se realiza la etapa, donde el equipo completa los módulos creados previamente. Se evalúa la etapa, en donde el equipo analiza maneras de mejorar el producto, el plan de la etapa y el proceso del proyecto. Proceso a nivel Módulo: Se planifica el módulo, en donde el programador crea el diseño a ser implementado y crea los casos de testing. Se realiza el módulo, donde el programador codifica de acuerdo con lo creado en el diseño. Y finalmente, se evalúa el módulo donde el líder del equipo y el programador buscan maneras de mejorar el producto del módulo, la etapa del plan y el proceso del proyecto. Para minimizar el impacto de la complejidad en el desarrollo, los autores proponen una estrategia iterativa que consiste en 5 "armas": Divide y conquistarás, Ciclo de Vida en espiral, Tecnología orientada a objetos, Herramientas de prototipado rápido y Testing Incremental. A continuación, una descripción de cada uno. Divide y conquistarás: Separar el proyecto en ciclos de 2 semanas de desarrollo. Ciclo de Vida en espiral: Cada versión del producto es iterativa e incremental y va pasando por las etapas de Plan, Approve, Do, Review and Revise y Evaluate. Tecnología orientada a objetos: Utilizar durante el proceso análisis, diseño y codificación orientada a objetos. Herramientas de prototipado rápido: Los prototipos permiten compartir con el usuario las ideas de los diseñadores y permite a los usuarios dar su punto de vista y, finalmente Testing Incremental: Cada módulo es testeado 
completamente antes de ser incluido en la nueva versión del producto. Con respecto al equipo de desarrollo, los autores definen que debe existir un equipo de proyecto que conste de un líder de proyecto, por lo menos 3 integrantes con los roles de "implementador", "especialista en dominio" y "Revisor Técnico". Estos últimos deben compartir espacio físico para reunirse, por lo menos, una vez a la semana. Además, consideran conveniente utilizar un facilitador que dirija las reuniones. Por otro lado, animan a contar con un soporte administrativo que se encargue de atender las llamadas, mantener los documentos actualizados y la agenda.

De acuerdo con lo analizado en (Rettig \& Simons, 1993) existe la trazabilidad en los requerimientos y podría utilizarse en un grupo pequeño, de menos de 5 integrantes. Sin embargo, no se especifica si puede utilizarse en un equipo distribuido geográficamente. Por otro lado, no está orientado a documentación mínima. Finalmente, no hay evidencia empírica que respalde su utilización en un ambiente real.

Mandal (Mandal, 2009) propone un proceso de desarrollo que ayude a superar los desafíos del desarrollo de software actual, donde las computadoras que ejecutan con software de aplicaciones para fines especiales se están utilizando como una ayuda extensa para resolver problemas complejos en casi todos los lugares, desde los juegos hasta la ingeniería, las aplicaciones industriales, científicas, y otros campos afines. Desarrollar un software tan complejo no es fácil debido a las diferentes restricciones. Según el autor, los modelos de software existentes no proporcionan la flexibilidad adecuada para ser aplicados en proyectos tan grandes y complejos. Como ayuda para resolver la crisis actual, Mandal propone BRIDGE, un proceso de desarrollo para software moderno. El proceso consiste en varias fases que serán explicadas a continuación. Fase 1: Análisis de Requerimientos, Verificación y Especificación: El objetivo de esta fase es identificar los requisitos exactos del cliente utilizando diferentes técnicas y especificarlos en un documento para uso futuro después de la verificación. Durante la recopilación de requisitos, el analista extrae los requisitos del sistema del cliente. Finalmente, los requisitos verificados deben especificarse en un documento Especificación de requisitos de software $(S R S)$ y almacenarse para su uso futuro. Fase 2: Análisis de viabilidad, análisis de riesgos, verificación y especificación: El objetivo de esta fase es analizar la viabilidad del proyecto, teniendo en cuenta aspectos económicos, técnicos y operacionales. El resultado del análisis se especifica en un documento llamado "reporte de viabilidad". Además, en esta etapa los riesgos del proyecto deben identificarse, analizarse y especificarse en un documento llamado "Documento de Especificación de Riesgos". Fase 3: Diseño, verificación y especificación de la arquitectura de software: El objetivo de esta etapa es identificar los subsistemas, bloques de construcción o los componentes del sistema junto con sus interfaces de comunicación externa. Una vez realizado el diseño, debe ser verificado para determinar si cumple con los requerimientos especificados en la fase 1. Finalmente, el diseño se plasma en el "Documento de diseño de arquitectura de software". Fase 4: Diseño, verificación y especificación detallada de software: El objetivo de esta etapa es crear un diseño de bajo nivel llegando a la implementación, de tal forma que pueda llegar a ser codificado. Las estructuras de datos y los algoritmos son desarrollados en esta etapa. El diseño verificado se especifica en un documento llamado "Documento de diseño de software”. Fase 5: Identificación de patrones, búsqueda de componentes, 
verificación y especificación: El objetivo es identificar módulos o componentes, desarrollados en proyectos previos, que sirvan para resolver el mismo problema y reutilizarlos. Una vez realizada la búsqueda y la identificación, los resultados se plasman en un documento llamado "Documento de especificación de componentes". Fase 6: Estándar de código, testing de unidad, verificación y especificación: El objetivo de esta etapa es escribir código para los componentes que no se encontraron en la fase 5. Estos deben ser codificados siguiendo los estándares de codificación y buenas prácticas de la organización. Estos nuevos módulos deben ser testeados a través de testing de unidad o componente, para verificar que funcionan de acuerdo con los requisitos y se complementan con el software existente. Fase 7: Desarrollo del sistema: Integración de componentes, testing del sistema, verificación y validación: Una vez que todos los componentes son finalizados y reunidos, es tiempo de integrarlos al sistema completo. Aquí es donde el testing se realiza a nivel global. Los resultados se reúnen en un documento llamado "Reporte de Testing”. Fase 8: Validación del sistema, verificación y especificación: El objetivo es verificar que el sistema cumple con los requerimientos del usuario. Para esto se utiliza el documento $S R S$ generado en la fase 1. El resultado se reúne en el documento "Reporte de Validación”. Fase 9: Desarrollo del Sistema, implementación y especificación: Una vez que el sistema fue validado, es tiempo de realizar la entrega al cliente e implementarlo en producción. Además de la implementación, en esta etapa se incluye la capacitación del cliente en el uso del sistema. Fase 10: Verificación y testeo del sistema en producción: El objetivo es verificar el correcto funcionamiento del sistema en producción. Al finalizar el testing, se incluyen los resultados en el documento "Testing en producción del sistema”. Fase 11: Mantenimiento del sistema, verificación y especificación: El objetivo es proveer el mantenimiento post implementación para que el sistema funcione de acuerdo con lo deseado por el usuario. Cada vez que se realiza un cambio, debe plasmarse en el documento "Reporte de Mantenimiento". Fase 12: Manejo de configuración: El propósito de esta fase es desarrollar procedimientos y estándares para manejar con efectividad los cambios del sistema y mantener registro de estos. Fase 13: Manejo del proyecto: El objetivo es realizar las actividades que permitan llevar adelante el proyecto como planificación, monitoreo, control, dirección, motivación y coordinación.

De acuerdo con lo analizado del trabajo presentado por Mandal, el proceso permitiría hacer trazabilidad de requerimientos. Sin embargo, no especifica cómo utilizarlo con equipos de menos de 5 integrantes y distribuidos. Además, requiere gran cantidad de documentación. No presenta evidencia empírica de que el proceso pueda utilizarse en un proyecto real.

Lin et al. (Lin \& Yang, 2012) presentan en su trabajo un método basado en capas para el desarrollo rápido de aplicaciones. Sigue los lineamientos de Extreme Programming y herramientas $C A S E$. Al utilizar XP como base, apunta al desarrollo de proyectos pequeños o medianos. El método también utiliza $U M L$ y Red de Petri $(P N)$ como herramientas de modelado. El modelo consta de 4 pasos: 1. Identificación de casos de uso, 2. Especificación arquitectónica, 3. Construcción de componentes y 4. Iteraciones para la especificación y construcción de componentes en capas. A continuación, una explicación más detallada de los mismos. Identificación de casos de uso: El primer paso es 
identificar los requisitos del usuario que deben cumplirse en el sistema. Como en muchos enfoques existentes, todos los requisitos deseados del usuario pueden identificarse mediante diversas técnicas, como entrevistas, cuestionarios, observaciones, reuniones de intercambio de ideas, etc., y los requisitos identificados se representan mediante casos de uso en un diagrama de casos de uso de UML. Especificación arquitectónica: Para cada caso de uso/incremento deseado, el trabajo de diseño comienza con la identificación de una partición arquitectónica de componentes físicos que apoyan de manera colaborativa la realización de este caso de uso/incremento. Para un mejor conocimiento, clarificar los componentes del sistema y sus interacciones es el medio más adecuado para garantizar el cumplimiento de los casos de uso deseados. En función de las características del sistema y/o los requisitos funcionales/no funcionales deseados, estos componentes pueden identificarse aplicando algunos frameworks arquitectónicos como MVC (Modelo, Vista y Controlador). Este es el más comúnmente elegido para el desarrollo de proyectos pequeños o medianos debido a su concepto basado en roles bien conocidos, un uso clásico de la separación de preocupaciones en el diseño orientado a objetos, y los patrones de diseño más favorables. Construcción de componentes: Mientras que los componentes arquitectónicos para un caso de uso/incremento se identifican y sus estructuras/comportamientos se especifican en capas, su construcción se puede lograr directamente al vincular el trabajo de diseño (es decir, los diagramas de comportamiento de $P N$ ) en un código Java ejecutable para permitir un desarrollo rápido. Las pruebas para los componentes individuales, las interacciones entre los diversos componentes y el cumplimiento de los casos de uso en todos los componentes deben asegurarse con testing. Iteraciones para la especificación y construcción de componentes en capas: Se logra mediante una secuencia de creación de diagramas de diseño y su vinculación con el código Java de acuerdo con el orden prescrito en el proceso de identificación, que realiza el caso de uso deseado especificando y construyendo componentes arquitectónicos a través de los pasos 2 y 3 de manera iterativa en capas.

De acuerdo con lo analizado del trabajo presentado por Lin, el proceso propuesto está orientado a equipos pequeños y documentación mínima. Sin embargo, no tiene en cuenta la trazabilidad de requerimientos ni presenta evidencia empírica sobre la aplicación del proceso en proyecto real.

Abrahamsson et al. (Abrahamsson, 2004) en su trabajo explican que, para el tiempo de la publicación (2004), se ha abierto una oportunidad comercial importante para que cualquiera pueda desarrollar aplicaciones de software, como juegos, para teléfonos móviles. Sin embargo, desarrollar aplicaciones móviles es actualmente una tarea desafiante debido a las demandas específicas y las limitaciones técnicas. Además, en este momento se sabe muy poco acerca de la idoneidad de los diferentes procesos de desarrollo para el desarrollo de aplicaciones móviles. Debido a estos problemas, los autores proponen un enfoque de desarrollo ágil llamado Mobile- $D$. Cualquier persona con las habilidades necesarias puede desarrollar aplicaciones para teléfonos móviles. Sin embargo, esto requiere un buen conocimiento de las características específicas y los desafíos del desarrollo de software para dispositivos móviles. Se puede ver que las soluciones de desarrollo de software ágiles son una buena opción para el desarrollo de aplicaciones móviles. Sin embargo, las características de los teléfonos móviles, terminales y el 
entorno de red ponen algunas restricciones en la aplicación de cualquiera de los métodos de desarrollo ágil de software existentes. Se necesitan nuevos enfoques específicos para dispositivos móviles. El enfoque de Mobile-D presentado por los autores sirve a este propósito. El enfoque se basa en Extreme Programming (prácticas de desarrollo), las metodologías Crystal (escalabilidad) y el Proceso Unificado Racional (ciclo de vida). El enfoque de Mobile-D está optimizado para un equipo de menos de diez desarrolladores que trabajan en un espacio de oficina ubicado juntamente con el objetivo de ofrecer una aplicación móvil totalmente funcional en un corto período de tiempo (es decir, menos de 10 semanas). Un proyecto de desarrollo, siguiendo el enfoque de Mobile- $D$, se divide en cinco iteraciones. Estas fases son: configuración, núcleo, núcleo2, estabilización y conclusión. Cada fase consta de tres tipos diferentes de días de desarrollo: Día de planificación, Día de trabajo y Día de entrega. Si varios equipos desarrollan simultáneamente diferentes partes del mismo producto, también se necesita un Día de la Integración. Las prácticas de las diferentes fases comprenden nueve elementos principales. Estos elementos son los siguientes: 1. Fases y estimulación, 2. Línea de Arquitectura, 3. Desarrollo basado en pruebas móviles, 4. Integración continua, 5. Programación en pareja, 6. Métricas, 7. Mejora del proceso de software ágil, 8. Cliente fuera del sitio, 9. Enfoque centrado en el usuario. La mayoría de estos elementos son prácticas ágiles bien conocidas y se han especializado para el desarrollo de software móvil. La práctica de "Línea de Arquitectura" es un ejemplo de un elemento específico de Mobile-D. La línea de arquitectura de una organización captura sistemáticamente el conocimiento arquitectónico actual sobre los patrones y soluciones que han demostrado ser útiles y funcionan en los proyectos de la organización o en aplicaciones similares fuera de la organización. Estas arquitecturas de software típicas, cuya justificación está documentada con patrones arquitectónicos aplicados previamente y ejemplos de funcionamiento, pueden utilizarse ágilmente en proyectos Mobile-D. Para garantizar el funcionamiento correcto del producto en múltiples plataformas móviles lo antes posible, para mejorar el diseño del software y para mejorar la capacidad de cambio del software, se requiere que el desarrollo esté orientado a pruebas (TDD, de sus siglas en inglés). La práctica de desarrollo impulsado por pruebas empleada en Mobile-D implica escribir pruebas antes de la implementación real, automatizar los procedimientos de prueba de unidades y la aceptación de todas las funciones con el cliente.

De acuerdo con lo analizado del trabajo presentado por Abrahamsson, el enfoque busca minimizar la documentación, sin embargo, el proceso no está pensado para equipos de menos de 5 integrantes, distribuidos geográficamente, ni contempla la trazabilidad de requerimientos. Además, no ofrece evidencia empírica de su utilización en un contexto real.

Cerqueira et al (Cerqueira \& Magalhães, 2018) analizan en su trabajo que el crecimiento en la demanda de aplicaciones móviles y la necesidad de una rápida disponibilidad de productos para el cliente promueven el surgimiento de proyectos que tienen un ciclo de vida de unos pocos días. Este tipo de proyectos se llaman súper ágiles. Sin embargo, el campo del desarrollo de software súper ágil aún se encuentra en sus etapas iniciales, tal vez porque es un problema reciente que enfrentan las empresas. Por lo tanto, los autores proponen un proceso de desarrollo que cumple con las características 
de los proyectos con ciclos de vida cortos de hasta 2 semanas. El proceso propuesto, basado en las demandas del mercado, integra las metodologías ágiles más actuales. El proceso de desarrollo de software para proyectos súper ágiles está compuesto por tres etapas: concepción de la idea, reutilización y búsqueda por conocimiento, y ejecución. Se basa en las metodologías ágiles Scrum y XP, en el método Kanban y en el proceso de diseño Sprint. Además, el proceso también engloba prácticas y técnicas de la Ingeniería de Software, como: integración continua, planificación en ondas sucesivas, reúso, prototipado y corriente crítica. La primera etapa del proceso se basa en el diseño del Sprint. Inicialmente, los integrantes del equipo comparten sus dudas, conocimientos y cuestiones sobre el problema. Para entender mejor el contexto del proyecto o producto, es importante definirlo, sea a través de storyboard u otra herramienta y técnica. Además, el equipo puede elegir buscar de 3 a 5 proyectos similares para obtener inspiración. Después, es necesario decidir el punto del proyecto que será trabajado. Para ello, cada uno escribirá en pequeñas tarjetas posibles soluciones. Cada miembro del equipo tiene un determinado número de votos y elige el grupo de ideas que más le gustaron, y las personas del equipo con mayor poder de decisión tienen derecho a más votos. Después de la elección de la idea o ideas, el siguiente paso es el prototipado. Dependiendo del proyecto o producto, el equipo hace la elección de crear un prototipo de "baja fidelidad", en el papel, por ejemplo, o de hacer un prototipo de alta fidelidad. Este utiliza herramientas de software para su creación que permiten la creación de pantallas para Web y aplicaciones móviles. Por último, se realizarán pruebas para evaluar el prototipo, pudiendo ser pruebas de usabilidad, navegabilidad, accesibilidad y otras. Las pruebas con usuario son importantes cuando se busca obtener una retroalimentación rápida de la idea que se busca validar, ahorrando tiempo y recursos. La segunda etapa es la fase de reutilización y búsqueda de conocimiento por el equipo. En esta etapa, se hacen estudios en pares, como en la Programación en pareja de $X P$, buscando en foros, sitios, discutiendo con personas del área mejores soluciones para determinadas funcionalidades o actividades. Dos personas trabajando juntas acostumbran a pensar en más soluciones a un problema y ayudarse cuando hay necesidad de análisis y diseño, disminuyendo las posibilidades de persistir en una mala idea. Con ello, el intercambio de ideas y experiencias, el debate y el feedback, posibilitados por el trabajo en par, es muy importante en esta etapa. Además, se buscan también en el repositorio o biblioteca de componentes reutilizables, artefactos que puedan ser usados nuevamente en el desarrollo del nuevo producto. La tercera y última etapa, basada en Scrum, define un alcance mínimo a partir del prototipo hecho en el paso I y lo divide en funcionalidades de software que alimentará el Backlog de los sprints. Se define también un cronograma con las grandes entregas para tener una planificación macro del proyecto. Los sprints tienen una duración de 2 días, con reuniones diarias para discutir lo que se hará en el día y lo que se hizo el día anterior, la revisión del Sprint, y la retrospectiva del Sprint, si es necesario. Se utiliza integración continua en los sprints, técnica heredada del XP y también se realizan pruebas de integración automatizadas entre los sprints. Al final de la etapa, se realiza una prueba final funcional, pudiendo hacerse también pruebas en ambientes reales para obtener una retroalimentación más rápida. En paralelo a estas pruebas, se hace también un análisis de las lecciones aprendidas y de las estrategias adoptadas que proporcionaron resultados 
positivos en el desarrollo del proyecto, con el objetivo de alimentar la base de conocimiento utilizada en la etapa II. La planificación y el seguimiento del proceso de desarrollo se realiza a través de Kanban. El tablero Kanban se utiliza como un medio para ver el flujo de desarrollo del software. Las cartas pegadas en él muestran las tareas que se deben hacer, la firma del responsable y un código para que se tenga acceso a más información sobre esa carta en algún sistema. Las columnas representan etapas del flujo de desarrollo. Cada paso tiene un número para limitar el trabajo en curso (WIP) de cada columna. Así, se tiene un proceso de desarrollo de software para proyectos súper ágiles, que duran hasta 2 semanas, respetando la necesidad de rápida colocación en el mercado y calidad del producto, para obtener feedback de los usuarios.

De acuerdo con lo analizado del trabajo presentado en Cerqueira, el proceso apunta a tener documentación mínima, sin embargo, no apunta a la trazabilidad de los requerimientos ni a equipos distribuidos de menos de 5 integrantes. Además, no se ofrece evidencia empírica que valide su aplicación.

\section{TABLA COMPARATIVA}

La Tabla 3.1 muestra los trabajos relacionados que se tuvieron en cuenta a la fecha de la elaboración de este trabajo. Las columnas de la tabla representan las 4 características principales de la propuesta de este trabajo y una columna adicional "Evidencia Empírica" que permite conocer si determinado trabajo tiene por lo menos un caso de estudio que respalde su aplicación. Cuando no se especifica "Si" o "No", es porque no hay suficiente información en la propuesta para determinarlo. Para ordenarlos de acuerdo con la relevancia se estableció un sistema de puntaje: Evidencia Empírica y Trazabilidad de Requerimientos suman 1 punto por cada una. El resto suma 0.5 puntos.

\section{RECAPITULACIÓN}

En este capítulo se analizaron varios trabajos muy interesantes que buscan facilitar el desarrollo de software resolviendo situaciones específicas a las que puede enfrentarse el equipo de desarrollo. Sin embargo, ninguna de ellas resuelve simultáneamente los 4 pilares en los que se enfoca el trabajo de esta tesis. Por ejemplo, solo 8 tienen trazabilidad de requerimientos, 7 pueden aplicarse a equipos pequeños, 4 a equipos distribuidos y 10 se focalizan en documentación mínima. Finalmente, 6 trabajos no tienen evidencia empírica de su aplicación, algo que sí tiene el trabajo de esta tesis.

TABLA 3.1 - Comparación entre los trabajos relacionados

\begin{tabular}{|c|l|c|c|c|c|l|c|}
\hline \multicolumn{1}{|c|}{ Propuesta } & TR & EP & ID & DM & \multicolumn{1}{|c|}{ Evidencia Empírica } & P \\
\hline 1 & $\begin{array}{l}\text { InterMod (Losada \& Urretavizcaya, } \\
\text { 2013) }\end{array}$ & $\mathrm{Si}$ & $\mathrm{No}$ & $\mathrm{Si}$ & No & $\begin{array}{l}\text { Si. Tres equipos de 7 inte- } \\
\text { grantes en un mismo pro- } \\
\text { yecto con 8 iteraciones. }\end{array}$ & 2.50 \\
\hline 2 & Waterfall (Royce, 1970) & $\mathrm{Si}$ & $\mathrm{Si}$ & $\mathrm{No}$ & $\mathrm{No}$ & $\mathrm{Si}$ & 2.50 \\
\hline 3 & $\begin{array}{l}\text { XWebProcess (Sampaio \& } \\
\text { Vasconcelos, 2004) }\end{array}$ & $\mathrm{Si}$ & $\mathrm{No}$ & $\mathrm{No}$ & $\mathrm{Si}$ & $\begin{array}{l}\text { Si. Estudiantes. 2 iteraciones } \\
\text { de 10 días. }\end{array}$ & 2.50 \\
\hline
\end{tabular}




\begin{tabular}{|c|c|c|c|c|c|c|c|}
\hline & Propuesta & TR & EP & ID & $\mathbf{D M}$ & Evidencia Empírica & $\mathbf{P}$ \\
\hline 4 & $\begin{array}{l}\text { RUP Reduce Model (Monteiro \& } \\
\text { Borges, 2012) }\end{array}$ & $\mathrm{Si}$ & No & No & No & Si. 7 equipos de estudiantes. & 2.00 \\
\hline 5 & $\begin{array}{l}\text { CASDPF (Al-Maharmeh M. , A } \\
\text { composite application software } \\
\text { development process framework } \\
\text { (CASDPF), 2010) }\end{array}$ & $\mathrm{Si}$ & No & - & No & Si. Un proyecto piloto & 2.00 \\
\hline 6 & ADAPT (Vallon \& Strobl, 2016) & No & No & $\mathrm{Si}$ & $\mathrm{Si}$ & \begin{tabular}{|l|} 
Si. Proyectos de 7 equipos \\
distribuidos, por un periodo \\
de entre 9 y 15 meses.
\end{tabular} & 2.00 \\
\hline 7 & $\begin{array}{l}\text { Extreme Programming (Beck \& } \\
\text { Andres, 2004) }\end{array}$ & No & $\mathrm{Si}$ & No & $\mathrm{Si}$ & $\mathrm{Si}$ & 2.00 \\
\hline 8 & $\begin{array}{l}\text { Faat (Bernabé, Navia, \& García- } \\
\text { Peñalvo, 2015) }\end{array}$ & No & $\mathrm{Si}$ & - & $\mathrm{Si}$ & Si. Un proyecto web. & 2.00 \\
\hline 9 & $\begin{array}{l}\text { Kanban (Anderson \& Carmichael, } \\
\text { 2016) }\end{array}$ & No & $\mathrm{Si}$ & No & $\mathrm{Si}$ & $\mathrm{Si}$ & 2.00 \\
\hline 10 & $\begin{array}{l}\text { Distributed Scrum-based process (Dos } \\
\text { Santos \& L'Erario, 2018) }\end{array}$ & No & No & $\mathrm{Si}$ & $\mathrm{Si}$ & $\begin{array}{l}\text { Si. Un Proyecto real, por } 2 \\
\text { meses. }\end{array}$ & 2.00 \\
\hline 11 & \begin{tabular}{|l|} 
Adaptative Process Model (Rizwan \& \\
Hussain, 2008)
\end{tabular} & $\mathrm{Si}$ & $\mathrm{Si}$ & $\mathrm{Si}$ & No & No & 2.00 \\
\hline 12 & PADRE (Rettig \& Simons, 1993) & $\mathrm{Si}$ & $\mathrm{Si}$ & No & No & No & 1.50 \\
\hline 13 & $\begin{array}{l}\text { Scrum (Sutherland \& Schwaber, } \\
\text { 2017) }\end{array}$ & No & No & No & $\mathrm{Si}$ & $\mathrm{Si}$ & 1.50 \\
\hline 14 & BRIDGE (Mandal, 2009) & $\mathrm{Si}$ & No & - & No & No & 1.00 \\
\hline 15 & $\begin{array}{l}\text { Layer-based Development Method } \\
\text { (Lin \& Yang, 2012) }\end{array}$ & No & $\mathrm{Si}$ & - & $\mathrm{Si}$ & No & 1.00 \\
\hline 16 & Mobile-D (Abrahamsson, 2004) & No & No & No & $\mathrm{Si}$ & No & 0.50 \\
\hline 17 & $\begin{array}{l}\text { Proceso Súper Ágil (Cerqueira \& } \\
\text { Magalhães, 2018) }\end{array}$ & No & No & - & $\mathrm{Si}$ & No & 0.50 \\
\hline & Cantidad (Si) & 8 & 7 & 4 & 10 & 11 & \\
\hline
\end{tabular}




\section{Capítulo 4}

\section{Klein: Proceso de desarrollo propuesto}

$\mathrm{L}$ OS MARCOS de trabajo de desarrollo que se han analizado previamente tienen muchas fortalezas. El proceso de desarrollo propuesto en esta tesis, llamado

Klein, tiene varias de esas fortalezas incluidas. Klein se basa en los conceptos establecidos en el Manifiesto de Desarrollo Ágil (Agile Alliance, 2001) y sus principios, aunque hay aspectos del desarrollo tradicional que también forman parte de él. Por otro lado, para que tanto el equipo como los clientes puedan entender con facilidad la documentación el foco está en que sea lo más simple, puntual y breve posible. Este capítulo comienza analizando los principios de la propuesta, luego presenta el proceso de desarrollo y finaliza tratando algunas consideraciones que deben tenerse en cuenta cuando surgen situaciones especiales durante el desarrollo.

\section{PRINCIPIOS DEL PROCESO}

A continuación, se explicarán los principios que sirven de base para el proceso cuyo origen se relaciona con el desarrollo ágil. Los principios son: 1) Documentar solo lo necesario, 2) software funcionando es la medida principal de progreso, 3) conversación fluida, 4) flexibilidad ante el cambio, 5) validar la calidad durante todo el proceso y 6) diseño incremental.

Documentar solo lo necesario. Como se explicó en el capítulo "Background" la era de Internet, las redes sociales y los smartphones han producido un cambio en la manera de leer de muchas personas, quienes prefieren la lectura superficial y prefieren textos cortos y puntuales, sobre los extensos y detallados. Teniendo en cuenta esos aspectos, documentar solo lo necesario es un principio muy importante del proceso. Solo debe documentarse lo que sea estrictamente necesario. La documentación debe cumplir el propósito de aportar algo útil al equipo y los clientes. El paso del tiempo puede ayudar a determinar qué debe documentarse y qué no (Beck, 2004).

Documentación para el cliente: si el cliente necesita un documento deberá solicitarlo formalmente, como lo hace con cualquier requisito (Beck, 2004). La elaboración de este documento se tratará como cualquier otra tarea dentro del proyecto. En caso de que el cliente, por políticas internas, necesite que los avances del proyecto se comuniquen por medio de un documento, el equipo lo incluirá y lo tendrá presente en su planificación y estimación de tiempos.

Documentación del equipo: si el equipo necesita tablas, gráficos, diagramas o documentos escritos, debería crearlos. Pero si con el tiempo nunca se los utiliza, es evidente que no eran tan necesarios como se pensaba. En próximas etapas del desarrollo, no deberían incluirse. Por otro lado, si constantemente se genera algún vacío de información, puede ser evidencia de que es necesario incluir un documento que la contenga (Beck, 2004).

El software funcionando es la medida principal de progreso. Este principio es uno de los que corresponden al desarrollo ágil, como se explicó en el capítulo 
"Background". Cuando se piensa en un equipo de desarrollo de software y su propósito lo cierto es que no hay otra medida más adecuada para establecer su progreso que el software funcional (Flewelling, 2018). No se puede estar completamente seguros de que lo que se está construyendo es correcto hasta que el cliente no confirma que el software entregado hace lo que se supone que tienen que hacer. Todo lo demás que el equipo de desarrollo produce es solo un soporte para entregar el software, desde documentos de análisis y diseño hasta guías de usuario.

Conversación fluida. Otro de los principios del desarrollo ágil, que se explicaron en el capítulo "Background". La comunicación entre los miembros del equipo y los usuarios o clientes es de vital importancia en todo el proceso de desarrollo. La conversación cara a cara tiene un ancho de banda muy alto, porque incluye además de las palabras, las expresiones faciales. Es la manera más rápida de obtener información (Beck, 2004). Es una actividad que puede ser usada para resolver cualquier ambigüedad. Si bien algunos miembros del equipo pueden estar físicamente distribuidos, todavía pueden usarse herramientas como las videoconferencias o llamadas telefónicas. Esos medios se prefieren por encima del chat o los correos electrónicos.

Flexibilidad ante el cambio. Este es otro de los principios del desarrollo ágil, que se explicaron en el capítulo "Background". Se acepta que los requisitos y las condiciones cambien, incluso en etapas avanzadas del desarrollo. En vez de ser rígidos, se busca ser adaptables a esos cambios. Durante el proyecto pueden surgir nuevas ideas, cambios en el diseño, cancelación de tareas o reemplazo de necesidades (Flewelling, 2018). El proceso debe ser flexible ante esa situación y permitir incorporarlos como parte natural, lo que incluiría modificar plazos, tareas previstas, etc. Hay que promover la resolución de estos imprevistos con el cliente y llegar a un acuerdo en común.

Validar la calidad durante todo el proceso. Si bien la idea de validar la calidad se trata en los procesos analizados en "Background", para el proceso propuesto este punto es específico y se ha adaptado puntualmente para cumplir con el punto de "trazabilidad de requerimientos”. Para que el producto cumpla con lo esperado por el cliente, es necesario tener su opinión constantemente. En las etapas iniciales, el proceso permite al cliente establecer lo que necesita para la versión del producto, y al final, verificar que se cumplió con lo que esperaba de manera explícita. La entrega rápida de la versión del producto permite la retroalimentación del cliente de manera temprana, lo que facilita corregir cualquier desvío con respecto a lo esperado. El proceso incluye etapas donde el cliente puede validar que el producto a construir sea lo que desea y al finalizar la entrega, validar su calidad. Por otro lado, el proceso alienta la entrega rápida de la versión del producto, desde 1 a 10 días máximo.

Diseño incremental. Este es uno de los principios de Extreme Programming analizados en el capítulo "Background". Sólo se debe profundizar en los detalles del diseño cuando sea estrictamente necesario, a medida que se va avanzando en el proyecto y de acuerdo con la información más reciente. Mientras tanto, el diseño debe mantenerse lo más simple posible (Beck, 2004). 


\section{PROCESO DE DESARROLLO PROPUESTO}

Klein cuenta con 6 etapas: Iniciación, Definición Preliminar, Requerimientos a Tareas, Ejecución de Tareas, Entrega de Versión y Revisión. Cada iteración del producto pasa por todas las etapas. El proceso puede verse en la Figura 4.1.

\section{PROCESO DE DESARROLLO KLEIN}

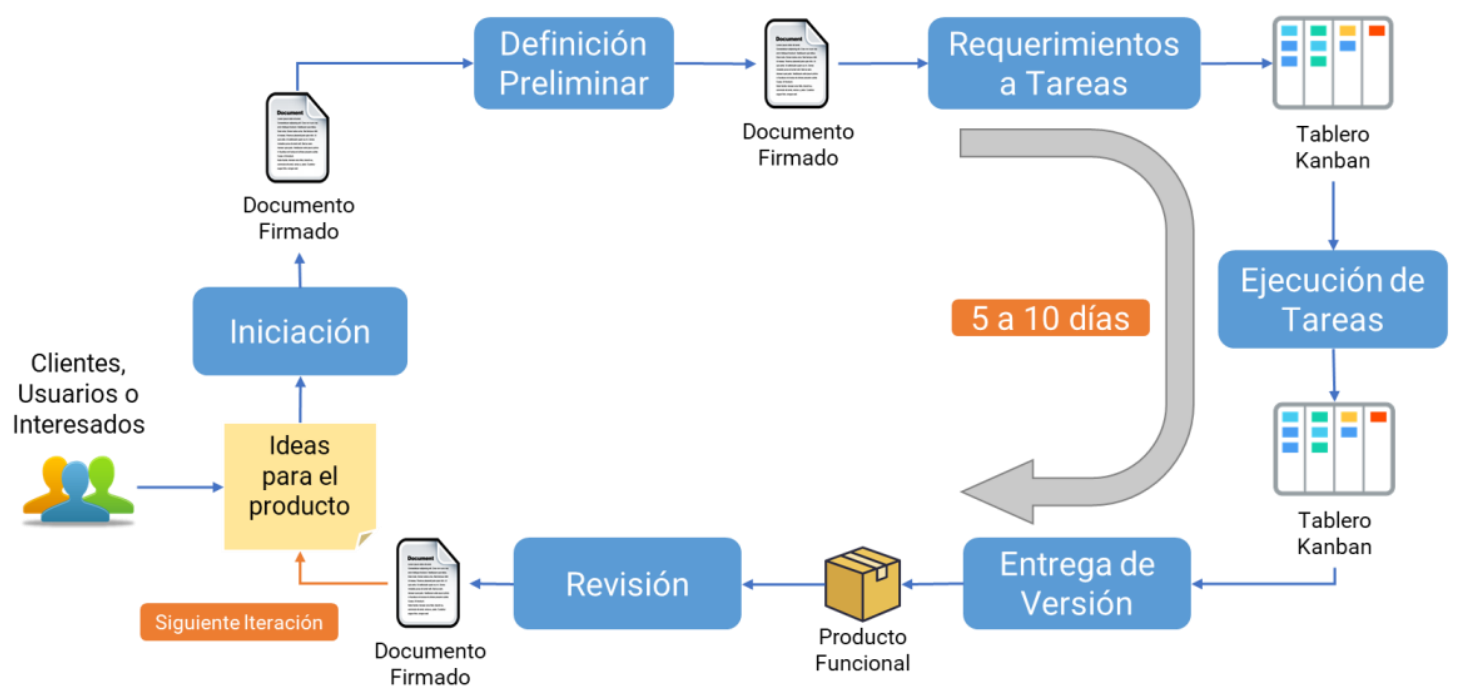

FIGURA 4.1 - Proceso de Desarrollo Klein

\subsection{INICIACIÓN}

Descripción. Esta es la primera etapa de cada iteración del proyecto, donde deben definirse los elementos que son clave para el resto de las etapas. Durante la iniciación, se describe a grandes rasgos las razones de la iteración, cuáles son los resultados esperados, los límites que tendrá la entrega del producto, análisis inicial de riesgos y si habrá terceros involucrados. Al inicio de un proyecto es el punto de partida general, pero a medida que las iteraciones van sucediendo y el producto va incrementado su funcionalidad, esta etapa recibirá información más específica de las iteraciones completadas. A continuación, se describen los objetivos, las técnicas, las herramientas, los recursos y los resultados de esta etapa.

\section{Objetivos.}

- Establecer la viabilidad de la iteración.

- Desarrollar el concepto global de la iteración.

- Determinar los resultados esperados al final de la iteración.

- Establecer los límites establecidos.

- Determinar los terceros involucrados reconocidos.

Técnicas.

- Identificar los riesgos.

- Tormenta de ideas: técnica de reuniones en grupo cuyo objetivo es la generación de ideas en un ambiente libre de críticas. 
- Entrevistas: reuniones entre pocas personas, normalmente dos, en donde se plantean preguntas para obtener la información necesaria para tener una idea general de lo que tiene que hacerse.

- Observación in situ: consiste en observar de manera directa a los usuarios realizando las tareas que va a realizar el software luego del desarrollo.

\section{Herramientas.}

- Diagramas: herramientas que permiten, de manera visual, mostrar el entendimiento actual de lo que hay que realizar. Por ejemplo, puede utilizarse diagramas UML (Unified Modeling Languaje).

- Herramientas CASE (Computer Aid Software Engineering): aplicaciones informáticas destinadas a aumentar la productividad en el desarrollo de software. Por ejemplo: editores $U M L$ y editores de texto colaborativo como Google Docs.

- Aplicaciones de mensajería instantánea y videoconferencias, como Google Meet, Google Chat y Microsoft Teams.

\section{Recursos.}

- Si al iniciar el proyecto hay otros proyectos relacionados conocidos, esa información deberá incluirse.

- Si el proyecto es el primero de su tipo y no tiene relación con ningún otro, quizás no haya recursos que deban incluirse.

- A medida que las iteraciones van sucediendo y el producto va incrementando su funcionalidad, la información obtenida será un recurso importante para esta etapa.

\section{Resultados.}

- Documento "Iniciación" completo donde el cliente firmó que está de acuerdo con lo propuesto. En la Tabla 4.1 se puede observar la estructura del documento.

TABLA 4.1 - Documento Iniciación

\begin{tabular}{|l|l|}
\hline \multicolumn{2}{|c|}{ INICIACIÓN } \\
\hline \multicolumn{2}{|c|}{ Nombre del Proyecto y Versión (de la aplicación) } \\
\hline Razones de la iteración & Explicar las razones de la iteración. \\
\hline Resultados esperados & $\begin{array}{l}\text { Listar los resultados que espera el cliente después de la ejecución de la ite- } \\
\text { ración ordenados por prioridad. Incluir el entregable, que podría ser una } \\
\text { aplicación, un documento o el resultado de una investigación. }\end{array}$ \\
\hline Aprobado por & Nombre y Apellido Cliente \\
\hline Fecha & \multicolumn{1}{|c|}{ Opcional, pero recomendado } \\
\hline Firma & \multicolumn{1}{|c|}{} \\
\hline &
\end{tabular}




\begin{tabular}{|l|l|}
\hline Viabilidad & $\begin{array}{l}\text { Explicar si es viable la iteración en cuanto a los aspectos técnicos, económi- } \\
\text { cos o de otra índole. }\end{array}$ \\
\hline Límites & $\begin{array}{l}\text { Listar los límites del que tendrá la iteración, como, por ejemplo, límites de } \\
\text { licencias de prueba, límites de testing e implementación. }\end{array}$ \\
\hline Terceros & $\begin{array}{l}\text { Terceros que pueden participar directa (contratados) o indirectamente } \\
\text { (compra de producto) }\end{array}$ \\
\hline Riesgos & $\begin{array}{l}\text { Completar en forma de tabla los principales riesgos que podrían presentarse } \\
\text { y su tratamiento. }\end{array}$ \\
\hline Anexos & $\begin{array}{l}\text { Links a los anexos que podrían incluirse, como por ejemplo documentos de } \\
\text { definiciones del dominio, reglamentaciones aplicables, etc. }\end{array}$ \\
\hline
\end{tabular}

\subsection{DEFINICIÓN PRELIMINAR}

Descripción. Esta es la segunda etapa de cada iteración del proyecto, donde deben definirse los elementos que son clave para el resto de las etapas. Durante la definición preliminar, se definen los requerimientos funcionales y no funcionales que se desarrollarán en la iteración. Además, se establecen los límites de la iteración, las precondiciones y la estimación en días en las que se entregará el producto para ser evaluado por el cliente. En caso de aplicar, también se incluye el diagrama de la arquitectura de la solución. A continuación, se describen los objetivos, las técnicas, las herramientas, los recursos y los resultados de esta etapa.

\section{Objetivos.}

- Definir los requerimientos a ser completados en la iteración.

- Establecer las precondiciones.

- Definir la estimación en días hasta la entrega del producto.

Técnicas.

- Determinar la arquitectura de la solución.

- Tormenta de ideas: técnica de reuniones en grupo cuyo objetivo es la generación de ideas en un ambiente libre de críticas.

- Entrevistas: reuniones entre pocas personas, normalmente dos, en donde se plantean preguntas para obtener la información necesaria para tener una idea general de lo que tiene que hacerse.

- Observación in situ: consiste en observar de manera directa a los usuarios realizando las tareas que va a realizar el software luego del desarrollo.

\section{Herramientas.}

- Diagramas: herramientas que permiten, de manera visual, mostrar el entendimiento actual de lo que hay que realizar. Por ejemplo, puede utilizarse diagramas UML (Unified Modeling Languaje).

- Historias de usuario: es una representación de un requerimiento escrito en dos o tres frases utilizando el lenguaje del usuario, del tipo "Como (rol) quiero (algo) para poder (beneficio). 
- Herramientas CASE (Computer Aid Software Engineering): aplicaciones informáticas destinadas a aumentar la productividad en el desarrollo de software. Por ejemplo: editores $U M L$ y editores de texto colaborativo como Google Docs.

- Aplicaciones de mensajería instantánea y videoconferencias, como Google Meet, Google Chat y Microsoft Teams.

\section{Recursos.}

- Para comenzar con la etapa, se analiza lo escrito en el documento de Iniciación que tiene una idea global de lo que se realizará en la iteración. Con esa información, se comienza a desglosar la idea general en requerimientos más específicos.

\section{Resultados.}

- Documento "Definición preliminar" completo donde el cliente firmó que está de acuerdo con lo propuesto. En la Tabla 4.2 se puede observar la estructura del documento.

TABLA 4.2 - Documento Definición Preliminar

\begin{tabular}{|c|c|}
\hline \multicolumn{2}{|r|}{ DEFINICIÓN PRELIMINAR } \\
\hline \multicolumn{2}{|r|}{ Nombre del Proyecto y Versión (de la aplicación) } \\
\hline \multicolumn{2}{|r|}{ Obligatorio } \\
\hline Requerimientos & $\begin{array}{l}\text { Requerimientos funcionales y no funcionales redactados en lenguaje natural. Pueden } \\
\text { ser en forma de historias de usuario. Mantenerlos simples. }\end{array}$ \\
\hline Estimación & En días. Utilizar, por ejemplo, horas/hombre no es fácil de comprender. \\
\hline \multicolumn{2}{|l|}{ Fecha } \\
\hline \multicolumn{2}{|l|}{ Firma } \\
\hline \multicolumn{2}{|r|}{ Opcional, pero recomendado } \\
\hline Precondiciones & $\begin{array}{l}\text { Requisitos que deben cumplirse para que el producto entregado pueda ser utilizado } \\
\text { en producción, como versiones de software, frameworks y/o permisos. }\end{array}$ \\
\hline Limitaciones & Límites de diseño, implementación, tecnología, licencias. \\
\hline \multicolumn{2}{|r|}{ Opcional } \\
\hline Arquitectura & $\begin{array}{l}\text { En caso de aplicar puede incluirse un diagrama de la solución o dónde estaría inte- } \\
\text { grado el producto dentro del sistema global. }\end{array}$ \\
\hline Anexos & $\begin{array}{l}\text { Links a los anexos que podrían incluirse, como por ejemplo documentos de defini- } \\
\text { ciones del dominio, reglamentaciones aplicables, etc. El mantener esta información } \\
\text { por fuera del documento ayuda a mantenerlo simple. }\end{array}$ \\
\hline
\end{tabular}

\subsection{REQUERIMIENTOS A TAREAS}

Descripción. En esta fase los requerimientos definidos en el documento "Definición Preliminar" se convierten en tareas cuya realización darán como resultado una versión del producto desarrollado. Los requerimientos han sido escritos en lenguaje natural y deben convertirse en tareas, que pueden ser nueva funcionalidad o corrección de 
errores. Cada una de estas tareas debe tener un tipo (historia, tarea o bug), estar asignada a alguien, contener criterios de aceptación, estar asociadas a una versión del producto y conocerse a qué requerimiento o requerimientos corresponde. Las tareas pueden tener una descripción y, en caso de corresponder, con qué tareas están relacionadas. Se podría incluir además una estimación, anexos como gráficos, diagramas y diseños de pantalla.

\section{Objetivos.}

- Convertir los requerimientos establecidos en el documento "Definición preliminar" en tareas a ser completadas.

- Asignar a las tareas un responsable.

- Determinar los criterios de aceptación.

- En caso de ser necesario, refinar la descripción de las tareas con diagramas, estimación, diseños de pantalla, etc.

Técnicas.

- Tormenta de ideas: técnica de reuniones en grupo cuyo objetivo es la generación de ideas en un ambiente libre de críticas.

\section{Herramientas.}

- Diagramas: herramientas que permiten, de manera visual, mostrar el entendimiento actual de lo que hay que realizar. Por ejemplo, puede utilizarse diagramas UML (Unified Modeling Languaje).

- Herramientas CASE (Computer Aid Software Engineering): aplicaciones informáticas destinadas a aumentar la productividad en el desarrollo de software. Por ejemplo: Fira Software, Azure DevOps, Diseñadores de Interfaz de Usuario, Editores $U M L$ y editores de texto colaborativo como Google Docs.

- Aplicaciones de mensajería instantánea y videoconferencias, como Google Meet, Google Chat y Microsoft Teams.

\section{Recursos.}

- Para comenzar con la etapa, se analiza lo escrito en el documento "Definición Preliminar" que tiene los requerimientos a ser completados en la iteración. Con esa información, se comienza a desglosar cada requerimiento en tareas

\section{Resultados.} específicas que serán completadas por el equipo de desarrollo.

- Tablero Kanban (Brechner, 2015) con todas las tareas a ser realizadas en la iteración en la columna "Backlog". Como se ve en la Figura 4.2, dicho tablero debe tener las siguientes columnas: Backlog, Análisis (En Progreso y Listo), Desarrollo (En Progreso y Listo), Testing (En Progreso y Listo) y Listo. 


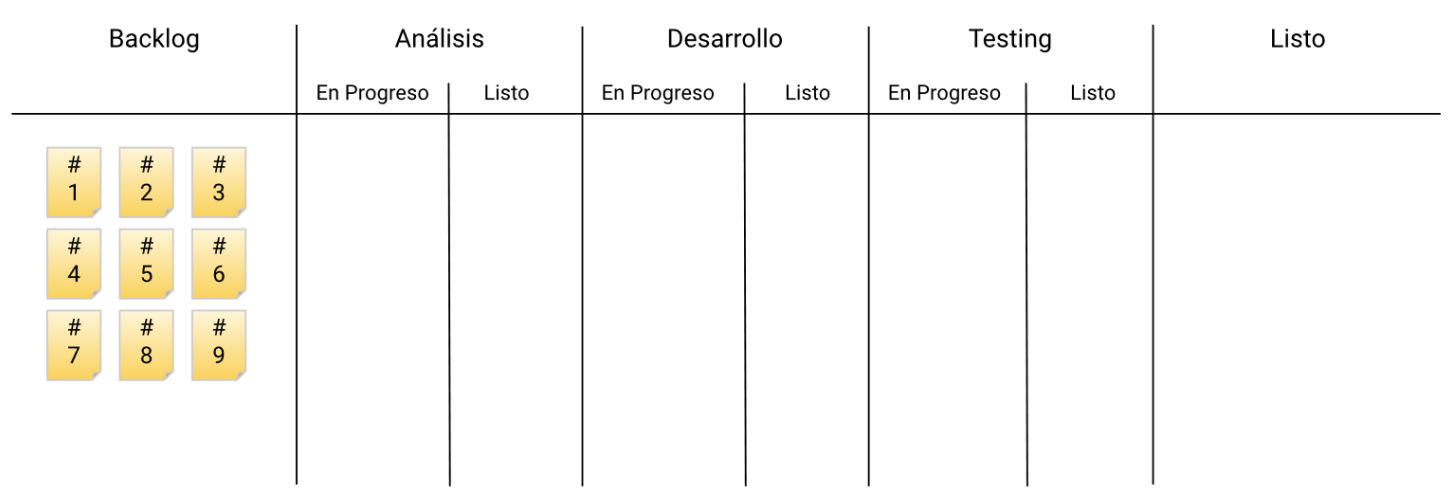

FIGURA 4.2 - Tablero Kanban con los requerimientos como tareas

\subsection{EJECUCIÓN DE TAREAS}

Descripción. Esta es la cuarta etapa del proceso y es la más relacionada con el desarrollo del producto. Las tareas se visualizan en el tablero Kanban creado en la etapa "Requerimientos a Tareas". En esta etapa es donde el equipo transforma las tareas en un producto funcional. En la Figura 3.3 se puede ver un ejemplo. A continuación, el detalle de cada una de las etapas que tiene el tablero.

- Backlog: en esta columna se colocan todas las tareas que fueron escritas en el documento "Definición Preliminar". Se coloca el nombre de la tarea, a qué requerimiento corresponde y la versión del producto a la que pertenece.

- Análisis: desde el Backlog se seleccionan las tareas y se les da el tratamiento necesario para que puedan ser completadas por el equipo de desarrollo. En esta columna las tareas pueden dividirse en otras más simples o crearse subtareas. Se asignan las tareas y se les agrega el criterio de aceptación. Además, se incorpora lo necesario para completar la tarea como anexos (gráficos, diagramas, diseños de pantalla) y la descripción. A medida que las tareas se van tratando, se pasan de la columna "En Progreso" a "Listo", indicando que la tarea está disponible para ser desarrollada.

- Desarrollo: en esta etapa se desarrolla de acuerdo con lo establecido por las tareas creadas durante el análisis. En este paso es donde se codifica la versión del producto.

- Testing: se verifica que las tareas cumplan con los criterios de aceptación establecidos durante la etapa de análisis. En caso de que una tarea no se cumpla, se agrega una nota y la tarea vuelve a la etapa de "Análisis" o "Desarrollo" dependiendo del origen del problema. Las tareas que cumplan con lo establecido se pasan a la columna "Listo".

- Listo: en esta etapa la tarea se da por finalizada. Cuando todas las tareas llegan a este punto, se realiza la entrega de la versión para ser validada por el cliente.

Además de los estados por lo que las tareas navegan, el tablero también contempla los límites de "Work In Progress" (WiP), que determinan la cantidad de tareas máximas que son aceptables en cada estado. Este es un indicador del ritmo de trabajo del equipo y pone en evidencia la existencia de obstáculos. En caso de que una columna 
llegue al límite, el equipo deberá tomar medidas para corregir cualquier problema que se esté presentando.

\section{Objetivos.}

- Completar las tareas creadas en la etapa "requerimientos a tareas" cumpliendo con los criterios de aceptación.

- Simplificar tareas que hayan sido subestimadas o agrupar tareas que hayan sido subestimadas.

- Realizar testing de las tareas para asegurar que cumplen con el criterio de aceptación.

\section{Técnicas.}

- Tormenta de ideas: técnica de reuniones en grupo cuyo objetivo es la generación de ideas en un ambiente libre de críticas.

- Programación en pareja distribuida: similar a la Programación en pareja de Extreme Programming, pero compartiendo la pantalla del código utilizando una aplicación de video conferencia.

\section{Herramientas.}

- Reuniones.

- Diagramas: herramientas que permiten, de manera visual, mostrar el entendimiento actual de lo que hay que realizar. Por ejemplo, puede utilizarse diagramas UML (Unified Modeling Languaje).

- Herramientas CASE (Computer Aid Software Engineering): aplicaciones informáticas destinadas a aumentar la productividad en el desarrollo de software. Por ejemplo: Fira Software, Azure DevOps, Diseñadores de Interfaz de Usuario, Editores UML y editores de texto colaborativo como Google Docs.

- Aplicaciones de mensajería instantánea y videoconferencias, como Google Meet, Google Chat y Microsoft Teams.

\section{Recursos.}

- Esta etapa utiliza las tareas creadas en la etapa anterior. A muchas de estas tareas se las refina para incluir más detalles de lo que hay que realizar. Otras pueden ser divididas en varias partes para facilitar su planificación.

\section{Resultados.}

- El resultado de esta etapa es una nueva versión del producto que ha sido validada por el equipo de desarrollo y está lista para ser probada en el ambiente de testing del usuario. 


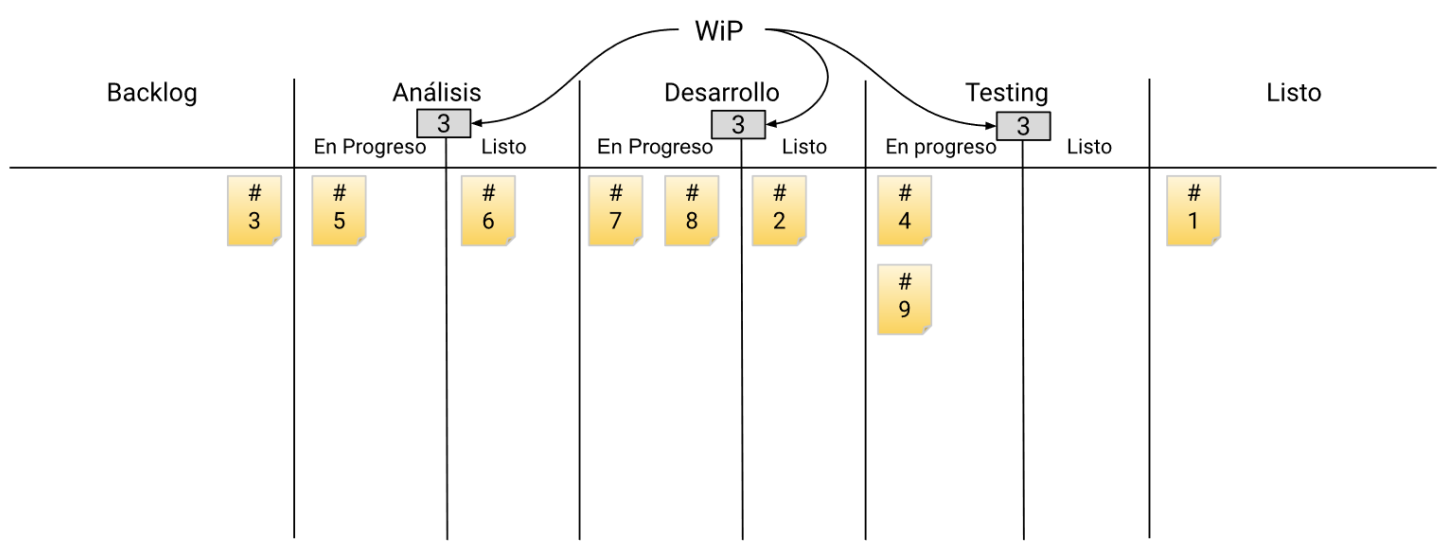

FIGURA 4.3 - Tablero Kanban con las tareas en ejecución

\subsection{ENTREGA DE VERSIÓN}

Descripción. En esta etapa se realiza la entrega de la versión del producto al cliente, lo que implica realizar la instalación en un ambiente de prueba para ser evaluada o en producción si es una etapa avanzada del producto. El lugar donde se realice dependerá del cliente y debe establecerse de antemano en el inicio del proyecto, ya que podría afectar los tiempos estimados. Por otro lado, el "Producto" puede ser una aplicación, un documento, una presentación del tipo PowerPoint o un mockup. Esto es común cuando el proyecto es una investigación.

\section{Objetivos.}

- Entregar el producto realizado en la etapa "Ejecución de tareas" para ser evaluado por el cliente.

- Entrenar al usuario sobre cómo utilizar el producto.

- Escribir documentación de usuario sobre la versión del producto.

- Escribir documento de implementación.

\section{Técnicas.}

\section{Herramientas.}

- Reuniones.

- Herramientas CASE (Computer Aid Software Engineering): aplicaciones informáticas destinadas a aumentar la productividad en el desarrollo de software. Por ejemplo: Fira Software, Azure DevOps, Diseñadores de Interfaz de Usuario, Editores $U M L$ y editores de texto colaborativo como Google Docs.

- Aplicaciones de mensajería instantánea y videoconferencias, como Google Meet, Google Chat y Microsoft Teams.

\section{Recursos.}

- En esta etapa utiliza la evaluación del producto entregado y el documento de "Definición preliminar" para comparar lo entregado versus lo que debería haberse entregado. 


\section{Resultados.}

- Como resultado se instala una nueva versión del producto en el ambiente del cliente que será evaluada por los usuarios, con su correspondiente documentación y capacitación.

\subsection{REVISIÓN}

Descripción. La etapa final es la revisión, que consiste en la evaluación por parte del cliente con respecto a la satisfacción del producto entregado. Para esta etapa el cliente realizará una comparación entre las tareas comprometidas en el documento "Definición Preliminar" y las completadas en la versión del producto entregada. Además, tendrá en cuenta si se cumplió con la estimación de tiempo. Cualquier desvió debe incluirse en el documento con una explicación. Como lo indica uno de los valores del proceso, se aceptan los cambios, aunque sean posteriores al inicio del proyecto, por lo cual, en la revisión se puede incluir y justificar cualquier cambio presentado. En la Tabla 4.3 se puede observar una plantilla de lo que incluiría el documento de Revisión, que incluye varios aspectos que le permiten al cliente validar la calidad del producto entregado. La mayoría de los puntos son obligatorios.

\section{Objetivos.}

- Evaluar que el producto entregado cumple con los requerimientos acordados con el cliente.

- Determinar cualquier desvío con respecto a lo acordado con el cliente.

- Evaluar el cumplimiento en tiempo y forma del producto.

\section{Técnicas.}

- Reuniones.

\section{Herramientas.}

- Editores de texto colaborativo como Google Docs.

- Aplicaciones de mensajería instantánea y videoconferencias, como Google Meet, Google Chat y Microsoft Teams.

\section{Recursos.}

- Esta etapa recibe el producto finalizado por la etapa "Ejecución de tareas" y se lo prepara para instalarlo en el ambiente del usuario. Este puede ser ambiente de pruebas para versiones iniciales o en producción para entregas avanzadas del producto.

\section{Resultados.}

- Documento "Revisión" completo donde el cliente verificó o no el cumplimiento de lo pactado en la versión del producto. En todos los casos, es firmado por él. En la Tabla 4.3 se puede observar la estructura del documento. 
TABLA 4.3 - Documento Revisión

\section{REVISIÓN}

Versión del Producto

Obligatorio

\begin{tabular}{|l|l|}
\hline Estimación Inicial & En días. \\
\hline Fecha de Fin & $\begin{array}{l}\text { En caso de ser posterior a la estimación, hay que incluir la justificación. } \\
\text { La razón podría estar del lado del cliente o el equipo. Normalmente po- } \\
\text { dría ser el resultado de una negociación por cambios introducidos sobre } \\
\text { la marcha del proyecto. }\end{array}$ \\
\hline $\begin{array}{l}\text { Requerimientos } \\
\text { no completados }\end{array}$ & Lista de requerimientos total o parcialmente completados y el motivo. \\
\hline Revisado por & Opcional \\
\hline Fecha & \multicolumn{1}{|c|}{} \\
\hline Firma & \\
\hline Porcentaje de completitud & \\
\hline
\end{tabular}

\subsection{TABLA RESUMEN}

A continuación, se resume en la Tabla 3.4 las etapas del proceso Klein con sus objetivos, técnicas, herramientas, recursos y resultados.

TABLA 4.4 - Resumen del proceso

\begin{tabular}{|c|c|c|c|c|c|}
\hline Etapa & Objetivos & Técnicas & Herramientas & Recursos & Resultados \\
\hline Iniciación & $\begin{array}{l}\text { Viabilidad. } \\
\text { Concepto global. } \\
\text { Resultados espe- } \\
\text { rados. } \\
\text { Límites estableci- } \\
\text { dos. } \\
\text { Terceros. } \\
\text { Riesgos. }\end{array}$ & $\begin{array}{l}\text { Tormenta de } \\
\text { ideas. } \\
\text { Entrevistas. } \\
\text { Observación } \\
\text { in situ. }\end{array}$ & $\begin{array}{l}\text { Diagramas. } \\
\text { Aplicaciones de } \\
\text { mensajería instan- } \\
\text { tánea y videoconfe- } \\
\text { rencias. }\end{array}$ & $\begin{array}{l}\text { Idea inicial o re- } \\
\text { troalimentación } \\
\text { de iteraciones } \\
\text { previas. }\end{array}$ & $\begin{array}{l}\text { Documento } \\
\text { "Iniciación" } \\
\text { completo. }\end{array}$ \\
\hline $\begin{array}{l}\text { Definición } \\
\text { Preliminar }\end{array}$ & $\begin{array}{l}\text { Requerimientos. } \\
\text { Precondiciones. } \\
\text { Estimación. } \\
\text { Arquitectura. }\end{array}$ & $\begin{array}{l}\text { Tormenta de } \\
\text { ideas. } \\
\text { Entrevistas. } \\
\text { Observación } \\
\text { in situ. }\end{array}$ & $\begin{array}{l}\text { Diagramas. } \\
\text { Historias de usua- } \\
\text { rio. } \\
\text { Herramientas } \\
C A S E \text {. } \\
\text { Aplicaciones de } \\
\text { mensajería instan- } \\
\text { tánea y videoconfe- } \\
\text { rencias. }\end{array}$ & $\begin{array}{l}\text { Documento } \\
\text { "Iniciación". }\end{array}$ & $\begin{array}{l}\text { Documento } \\
\text { "Definición } \\
\text { Preliminar" } \\
\text { completo. }\end{array}$ \\
\hline $\begin{array}{l}\text { Requerimien- } \\
\text { tos a Tareas }\end{array}$ & $\begin{array}{l}\text { Requerimientos } \\
\text { en tareas. } \\
\text { Responsable. } \\
\text { Criterios de acep- } \\
\text { tación. } \\
\text { Refinamiento de } \\
\text { tareas. }\end{array}$ & $\begin{array}{l}\text { Tormenta de } \\
\text { ideas. }\end{array}$ & $\begin{array}{l}\text { Diagramas. } \\
\text { Historias de usua- } \\
\text { rio. } \\
\text { Herramientas } \\
C A S E \text {. } \\
\text { Aplicaciones de } \\
\text { mensajería }\end{array}$ & $\begin{array}{l}\text { Documento } \\
\text { "Definición Pre- } \\
\text { liminar". }\end{array}$ & $\begin{array}{l}\text { Tablero } \\
\text { Kanban con } \\
\text { todas las ta- } \\
\text { reas a reali- } \\
\text { zar en la co- } \\
\text { lumna "Ba- } \\
\text { cklog". }\end{array}$ \\
\hline
\end{tabular}




\begin{tabular}{|c|c|c|c|c|c|}
\hline Etapa & Objetivos & Técnicas & Herramientas & Recursos & Resultados \\
\hline & & & $\begin{array}{l}\text { instantánea y vi- } \\
\text { deoconferencias. }\end{array}$ & & \\
\hline $\begin{array}{l}\text { Ejecución de } \\
\text { Tareas }\end{array}$ & $\begin{array}{l}\text { Completitud de } \\
\text { tareas. } \\
\text { Refinamiento. } \\
\text { Testing. }\end{array}$ & $\begin{array}{l}\text { Tormenta de } \\
\text { ideas. } \\
\text { Programación } \\
\text { en pareja dis- } \\
\text { tribuida. } \\
\text { Reuniones. }\end{array}$ & $\begin{array}{l}\text { Diagramas. } \\
\text { Herramientas } \\
\text { CASE. } \\
\text { Aplicaciones de } \\
\text { mensajería instan- } \\
\text { tánea y videoconfe- } \\
\text { rencias. }\end{array}$ & $\begin{array}{l}\text { Tablero Kanban } \\
\text { con las tareas } \\
\text { definidas en la } \\
\text { etapa anterior. }\end{array}$ & $\begin{array}{l}\text { Nueva ver- } \\
\text { sión del } \\
\text { producto } \\
\text { listo para } \\
\text { testear por } \\
\text { el usuario. }\end{array}$ \\
\hline $\begin{array}{l}\text { Entrega de } \\
\text { Versión }\end{array}$ & $\begin{array}{l}\text { Entrega del pro- } \\
\text { ducto. } \\
\text { Entrenamiento de } \\
\text { usuario. } \\
\text { Creación de docu- } \\
\text { mentación de } \\
\text { usuario. }\end{array}$ & Reuniones. & $\begin{array}{l}\text { Herramientas } \\
C A S E \text {. } \\
\text { Aplicaciones de } \\
\text { mensajería instan- } \\
\text { tánea y videoconfe- } \\
\text { rencias. }\end{array}$ & $\begin{array}{l}\text { Producto creado } \\
\text { en la etapa an- } \\
\text { terior y docu- } \\
\text { mento "Defini- } \\
\text { ción Prelimi- } \\
\text { nar". }\end{array}$ & $\begin{array}{l}\text { Producto } \\
\text { instalado en } \\
\text { ambiente } \\
\text { del cliente. } \\
\text { Documenta- } \\
\text { ción. }\end{array}$ \\
\hline Revisión & $\begin{array}{l}\text { Evaluación del } \\
\text { producto. } \\
\text { Desvíos. }\end{array}$ & Reuniones. & $\begin{array}{l}\text { Editores de texto } \\
\text { colaborativo. } \\
\text { Aplicaciones de } \\
\text { mensajería instan- } \\
\text { tánea y videoconfe- } \\
\text { rencias. }\end{array}$ & $\begin{array}{l}\text { Producto eva- } \\
\text { luado por el } \\
\text { cliente y docu- } \\
\text { mento "Defini- } \\
\text { ción Prelimi- } \\
\text { nar". }\end{array}$ & $\begin{array}{l}\text { Documento } \\
\text { "Revisión" } \\
\text { completo. }\end{array}$ \\
\hline
\end{tabular}

\section{OTRAS CONSIDERACIONES}

En esta sección se analizan algunas situaciones que podrían presentarse y cómo podría el equipo de desarrollo manejarlas aplicando los principios de Klein. Por ejemplo, cómo tratar con gran cantidad de requerimientos, cómo manejar los cambios de requerimientos durante el proceso iniciado, qué hacer en caso de que se solicite un manual de usuario y cómo tratar la estimación de las tareas.

Cómo tratar gran cantidad de requerimientos. Un aspecto fundamental del proceso es realizar entregas lo más pronto posible, dentro de un tiempo máximo de 10 días, por lo cual no sería recomendable para el equipo abarcar muchas funcionalidades en una misma versión. Es importante tener en cuenta que, una vez finalizada la versión del producto, el cliente con algo tangible que no tenía al inicio, podría modificar su visión, necesidades y requisitos. Esto podría hacer que muchos requisitos pendientes se modifiquen o hasta descarten. El equipo puede alentar al cliente a definir pocos requisitos iniciales e ir incorporando nuevos a medida que las versiones del producto se vayan desarrollando.

Cómo tratar cambios de requerimientos durante el proceso. Como bien especifica uno de los valores del proceso, se acepta que los requisitos y las condiciones cambien, incluso en etapas avanzadas del desarrollo. En vez de ser rígidos, se busca ser adaptables a esos cambios. Durante el proyecto pueden surgir nuevas ideas, cambios en el diseño, cancelación de tareas o reemplazo de necesidades. Cuando esto suceda, es importante realizar una negociación con el cliente y explicar el impacto de este. Si se va a necesitar más tiempo que el previsto, podría modificarse el acuerdo escrito en el documento "Definición Preliminar" y cambiar, por ejemplo, la fecha de entrega. En el mismo documento podría agregarse el nuevo requerimiento o modificar uno existente que, luego, se convertirá en una tarea a ser completada en el tablero Kanban. Por otro 
lado, podría proponerse que el cambio se realice en la próxima versión. Como los plazos de entrega son cortos, normalmente el cliente no tendría inconveniente en que eso suceda.

Manuales de Usuario. En caso de que sea necesario elaborar un manual de usuario, una estrategia sería escribirlo con frases cortas y puntuales, incluir imágenes sencillas y evitar párrafos largos. Quizás podría pensarse el manual de usuario como una presentación con diapositivas del tipo PowerPoint. Esto favorece la lectura de los usuarios.

Estimación. Una buena práctica sería dejar un margen dentro de la estimación para contingencias (Beck, 2004) ya que podría darse el caso de que, al implementar la nueva versión, se presenten situaciones inesperadas cuya responsabilidad sea del equipo de desarrollo. Por ejemplo, actualizaciones de software, permisos, dependencias u otros factores que no se presentaron durante las pruebas, pero que son un impedimento en producción. Estas diferencias entre el ambiente de pruebas y el de producción pueden dar lugar a errores difíciles de detectar que consuman mucho tiempo. Al tener un margen para contingencias, el equipo puede trabajar tranquilo en caso de que se presenten.

\section{CICLO DE ENTREGA: UN EJEMPLO DE APLICACIÓN}

Una manera sencilla de ver todas las piezas que abarcan el proceso es visualizar un ciclo de versión típico, desde la idea propuesta hasta el documento de revisión, dentro de una iteración de ejemplo. Como se ve en la Figura 4.4 los pasos no necesariamente son secuenciales. En las diferentes versiones del producto las etapas tendrían el orden descrito, sin embargo, si hay cambios en los requerimientos en la etapa de "Requerimientos a Tareas", se debería modificar el documento elaborado en la etapa de "Definición Preliminar". Lo mismo podría ocurrir durante la revisión: un cambio o una interpretación errónea podría hacer que se retorne a etapas anteriores del proceso. Se acepta que eso ocurra. Por ejemplo, la etapa de "revisión" puede dar lugar a cambios en los documentos y hasta las tareas que se habían completado. Lo que se busca es satisfacer las necesidades del cliente y el proceso es flexible al permitirlo.

\section{RECAPITULACIÓN}

En este capítulo se presentó el proceso de desarrollo Klein, que contiene seis etapas, tres de las cuales tienen un documento asociado que es firmado por el cliente para garantizar la trazabilidad de los requerimientos. El proceso está pensado para utilizarse por equipos pequeños, ya que no contiene roles predefinidos y los integrantes pueden estar distribuidos geográficamente. Además, la documentación es mínima para ayudar en la lectura a los usuarios, desarrolladores y clientes. 

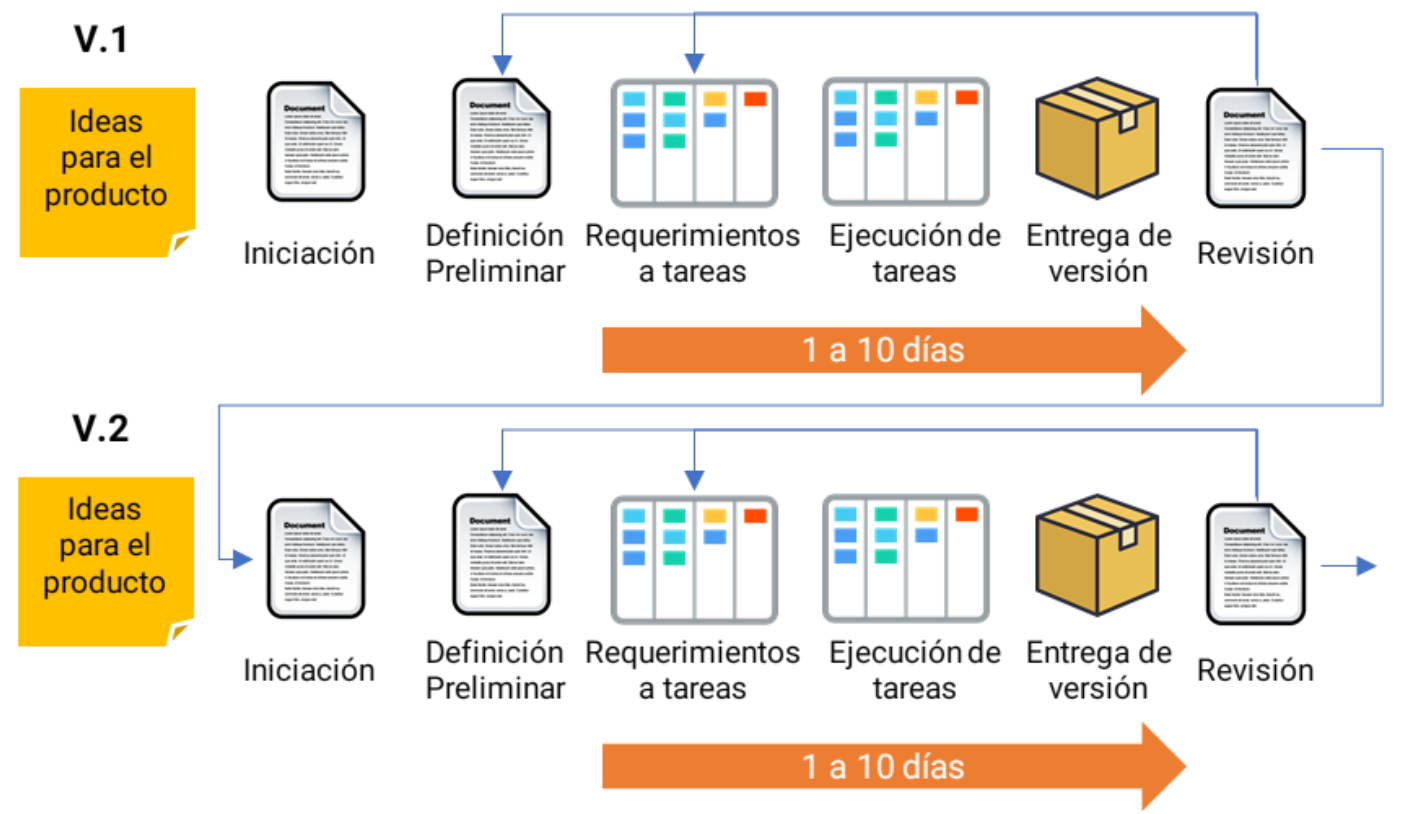

FIGURA 4.4 - Ejemplo de dos ciclos de entrega 


\section{Capítulo 5 Caso de Estudio}

$\mathrm{E}$

L OBJETIVO de este capítulo es proveer evidencia empírica que valide la efectividad de aplicar el proceso de desarrollo propuesto en proyectos de desarrollo de software reales, con un equipo real y con un cliente real. Como la meta es la trazabilidad para asegurar satisfacción del cliente, se utilizó la técnica de caso de estudio, que es una técnica que consiste en la investigación de fenómenos en su contexto natural (Yin, 2008) para buscar evidencia, adquirir comprensión o probar teorías principalmente utilizando análisis cualitativo (Runeson \& Höst, 2009).

El caso de estudio se realizó en una empresa especializada en software y hardware para la industria de hidrocarburos y telemetría. Específicamente, se realizó con dos proyectos tecnológicos para la industria petrolera: el primero consistió en el desarrollo de una interfaz entre un sistema de telesupervisión de pozos petroleros y un sistema $S C A D A^{4}$ y el segundo en la migración de una aplicación monolítica a una arquitectura de microservicios. Ambos proyectos fueron realizados con tecnologías que el equipo de desarrollo conocía muy poco.

\section{OBJETIVO Y PREGUNTAS DE LA INVESTIGACIÓN}

La evidencia de que el proceso de desarrollo propuesto en este trabajo pueda utilizarse se logra al llevarlo a la práctica con un proyecto de desarrollo de software real. No obstante, el objetivo de la investigación es evaluar la efectividad del proceso y cuán útil puede serle al equipo de desarrollo. El criterio para validar el cumplimiento del objetivo es determinar si permite asegurar la trazabilidad de los requerimientos. Al mismo tiempo, que el proceso tenga la capacidad de utilizarse por hasta cinco desarrolladores, con por lo menos uno de ellos distribuido geográficamente y con documentación mínima. Por lo tanto, las preguntas que deben responderse sobre el proceso Klein, a través del caso de estudio son las siguientes:

1) ¿Puede asegurar la trazabilidad de los requerimientos?

2) ¿Puede utilizarse el proceso de desarrollo con hasta cinco desarrolladores?

3) ¿Es viable su utilización en un equipo distribuido geográficamente?

4) ¿Reduce la cantidad de documentación?

La pregunta 1 apunta a lograr que se pueda trazar desde el inicio al final de cada entrega que los requisitos solicitados, son los que se realizaron. Debería existir una manera explícita de hacerlo. El objetivo de la pregunta 2 es asegurarse de que el proceso

\footnotetext{
${ }^{4}$ SCADA, acrónimo de Supervisory Control And Data Acquisition (Supervisión, Control y Adquisición de Datos) es un concepto que se emplea para realizar un software para ordenadores que permite controlar y supervisar procesos industriales a distancia.
} 
pueda ser utilizado sin inconvenientes por un equipo pequeño. No debería ser un obstáculo la cantidad de personas involucradas. La pregunta 3 busca asegurar que el proceso pueda utilizarse independientemente de la ubicación geográfica en la que se encuentren cada uno de los desarrolladores involucrados. Finalmente, la pregunta 4 tiene como fin comprobar que el producto pueda desarrollarse con la mínima documentación necesaria. Como se explicó en la introducción, la documentación mínima se refiere a documentación que es clara, concisa, y completa y menor con respecto a la exigida por las metodologías de desarrollo clásicas. Quienes participen deben percibir que tienen lo necesario para completar cada entrega. A continuación, un resumen de los objetivos utilizando el modelo Objetivo-Pregunta-Métrica (del inglés Goal-Question-Metric (GQM)) (Solingen, 2002).

Analizar el proceso de desarrollo Klein con el propósito de evaluar la efectividad de su aplicación desde la perspectiva del investigador en el contexto de profesionales de la industria.

Finalmente, es necesario mencionar que forma parte en la naturaleza de los casos de estudio que las variables independientes no se puedan controlar (Runeson \& Höst, 2009). De este punto se habla en detalle en la sección "Limitaciones y Conclusiones".

\section{DISEÑO DEL CASO DE ESTUDIO}

En esta sección se describen el caso de estudio, el objetivo y las preguntas de la investigación, el procedimiento de obtención de los datos, los procedimientos de análisis y validación y los participantes.

\subsection{DESCRIPCIÓN DEL CASO DE ESTUDIO}

El caso de estudio consiste en dos proyectos: el primero tiene como objetivo modelar, diseñar e implementar una nueva funcionalidad en un sistema de telesupervisión de pozos y, el segundo, cambiar la arquitectura de la aplicación de monolítica a microservicios. Para tener una idea de la complejidad del sistema hay que tener en cuenta los siguientes puntos:

- En ambos casos se trabajará sobre un sistema en tiempo real.

- El sistema debe funcionar 24/7, por lo que cualquier modificación no debe interrumpir el funcionamiento del sistema.

- La situación que se presenta en el campo no es posible de replicar en un ambiente de pruebas, teniendo en cuenta que, como promedio, hay más de 12.000 equipos reportando simultáneamente con su propia configuración, tiempo de espera, protocolo de comunicación y comportamiento.

\subsection{CONTEXTO DE APLICACIÓN}

El sistema de telesupervisión consta de equipos de hardware y aplicaciones de software que funcionan de la siguiente manera: en cada pozo se implementa una red local inalámbrica compuesta por un dispositivo maestro y diversos sensores esclavos distribuidos en la locación. Cada dispositivo reporta la información de su red local en forma periódica y por eventos a través de repetidores distribuidos en el yacimiento. La información 
se recibe y guarda en servidores ubicados en la base operativa del yacimiento monitoreado. El usuario visualiza a través de una aplicación web el funcionamiento de los pozos y alarmas por situaciones anormales. La información se procesa y presenta a los usuarios a través de un portal web de reportes y diagnóstico. La arquitectura de la solución se ve en la Figura 5.1.

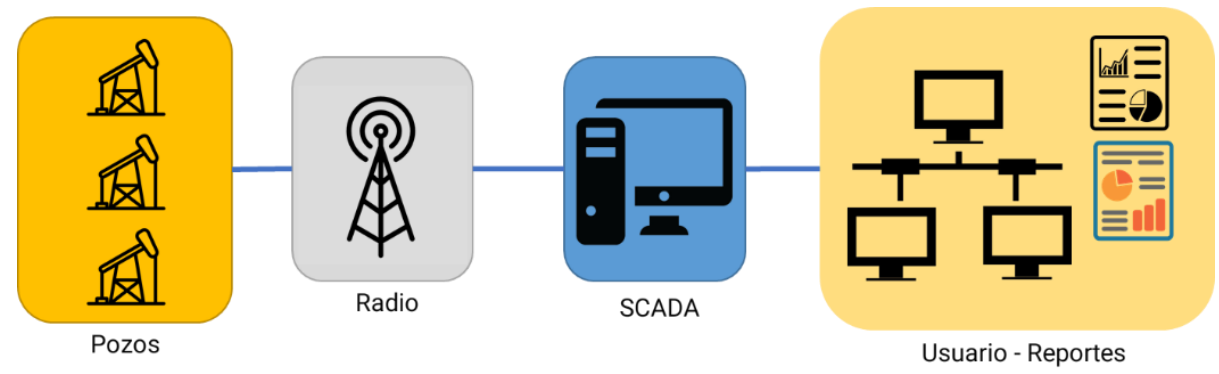

FIGURA 5.1 - Arquitectura de la solución

La arquitectura monolítica consiste en empaquetar a todos los componentes del negocio, distribuirlos e implementarlos como un todo (Zhongshan \& Wei, 2018). Cuando la aplicación se encuentra con un cuello de botella en el rendimiento, generalmente es por una limitación en uno de los módulos en lugar del conjunto de los componentes del sistema. En este tipo de arquitectura, no es posible replicar solo un componente o módulo para mejorar el desempeño. La arquitectura de microservicios es un modo de desarrollo y operación ligero y miniaturizado. Cada microservicio se implementa de manera independiente y sigue el principio de responsabilidad única (Martin, 2003), diferentes microservicios pueden utilizar diferentes tecnologías y actualizarse de forma independiente. La arquitectura de microservicios proporciona una solución efectiva para resolver los problemas de mantenimiento y desempeño propios de la arquitectura monolítica (Mazlami \& Cito, 2017).

A continuación, el caso de estudio se informa de acuerdo con las pautas propuestas por Runeson y Höst (Runeson \& Höst, 2012). El objetivo al utilizar un caso de estudio es doble: por un lado, comunicar los resultados del estudio y por otro, utilizarlo como fuente de información para evaluar la calidad del proceso. Con este doble objetivo, a continuación, se describe el caso de estudio.

\subsection{DESCRIPCIÓN DE LOS PARTICIPANTES}

En total, 7 desarrolladores participaron del caso de estudio y 2 clientes. Es importante comentar que los desarrolladores llevan trabajando sobre el sistema de telesupervisión, como promedio, más de 15 años, creando nueva funcionalidad y realizando mantenimiento regular. El equipo al inicio del caso de estudio tenía 2 años de experiencia utilizando Scrum en el desarrollo de software y 1 año utilizando tableros Kanban. Antes de utilizar dichos frameworks, no había un estándar de desarrollo.

A los participantes se les dio una capacitación de 2 horas sobre las características del proceso de desarrollo Klein y se les compartió un breve documento que explicaba cada etapa. 


\subsection{DESCRIPCIÓN DE LOS PROYECTOS}

A continuación, se describen brevemente en qué consisten los dos proyectos que formaron parte del caso de estudio. Si bien son dos proyectos independientes, algunos integrantes del equipo participaron en los dos en algún momento del desarrollo.

Desarrollo de interfaz entre sistema de telesupervisión y sistema $S C A D A$. El sistema de telesupervisión no contaba con una interfaz para consultar los datos que no sea a través de la interfaz de usuario o un sistema de reportes propietario. El cliente necesitaba contar con una nueva interfaz que utilice un protocolo de comunicación estándar que envíe la información recibida de los equipos del campo directamente a los servidores corporativos para ser mostrados en los sistemas $S C A D A$. El protocolo de comunicación que se utilizó fue Open Platform Communications (OPC). OPC es el estándar para el intercambio seguro y confiable de datos en el espacio de automatización industrial y en otras industrias. Es independiente de la plataforma y garantiza el flujo continuo de información entre dispositivos de múltiples proveedores. OPC Fundation ${ }^{5}$ es la responsable del desarrollo y mantenimiento de este estándar ( OPC Foundation, 2020). El equipo de desarrollo no tenía experiencia en la utilización del protocolo $O P C$ y trabajó en este proyecto por un periodo de 18 meses.

Migración de arquitectura monolítica a microservicios. El sistema de telesupervisión tiene más de 20 años de desarrollo y a medida que fue creciendo en funcionalidad, los módulos fueron integrándose en una misma solución. Esto tuvo como consecuencia que el sistema tenga una arquitectura monolítica, donde el mantenimiento y la incorporación de nuevas funcionalidades es cada vez más costoso. La empresa tomó la decisión de migrar el sistema a una arquitectura de microservicios para solucionar estos problemas. El desafío es que, mientras se migraran los módulos, el sistema anterior debería seguir funcionando de manera transparente para los usuarios. El equipo no tenía experiencia en la arquitectura de microservicios y está involucrado en el proyecto desde hace más de 18 meses.

\subsection{PROCEDIMIENTO DE RECOLECCIÓN DE DATOS}

En el caso de estudio, se reunieron datos tanto cuantitativos como cualitativos. Los métodos de recolección que se han utilizado son los siguientes:

- Observación. El autor estuvo presente en reuniones de los participantes. Las reuniones fueron transcritas y analizadas utilizando codificación descriptiva recomendada por Saldaña (Saldaña, 2009) para datos cualitativos.

- Análisis de documentación. El autor tuvo a su disposición los documentos generados durante las etapas de desarrollo de los dos proyectos.

- Cuestionarios y entrevistas. Los miembros del equipo y los clientes fueron entrevistados siguiendo un cuestionario abierto a discusión. Estas entrevistas fueron transcritas y analizadas utilizando codificación descriptiva recomendada por Saldaña (Saldaña, 2009) para datos cualitativos.

- Encuesta SUS (System Usability Scale) (Lewis \& Sauro, 2009) a los participantes. Este método fue desarrollado en 1986 por John Brooke como una herramienta para medir la usabilidad de un sistema a través de 10 preguntas

\footnotetext{
${ }^{5}$ https://opcfoundation.org/
} 
estandarizadas, cada una de las cuales es puntuada de 1 a 5 , donde 1 significa

Total Desacuerdo y 5 Total Acuerdo.

La codificación descriptiva, en esta investigación, implica asignar una palabra corta o una frase para representar simbólicamente el significado más amplio de una frase o declaración. La herramienta de análisis de datos Atlas.ti ${ }^{6}$ fue utilizada para registrar y formalizar el proceso de codificación.

\subsection{PROCEDIMIENTO DE ANÁLISIS Y VALIDACIÓN}

En este caso de estudio, se utilizaron análisis cuantitativos y cualitativos para examinar los datos recopilados. Para datos cuantitativos, se utilizó una encuesta SUS y luego se analizaron los resultados de acuerdo con el estándar. Para los datos cualitativos, se realizó el siguiente procedimiento: las entrevistas y reuniones se registraron, transcribieron, agruparon por frases y codificaron. La codificación implica que las partes del texto reciben uno o varios códigos que representan un determinado tema de interés: un código generalmente se asigna a muchos fragmentos de texto, y a un fragmento de texto se le puede asignar más de un código (Saldaña, 2009). A partir de este material, es posible identificar evidencia que responda las preguntas que plantea esta investigación. Además, se incluyen las opiniones del gerente de la empresa, el líder de proyectos y uno de los clientes.

\section{EJECUCIÓN}

Esta sección describe la ejecución de 28 iteraciones de los dos proyectos en un periodo de tiempo de 18 meses, donde los participantes fueron rotando. En el primer proyecto se realizaron 13 iteraciones y en el segundo 15. En cada una de las iteraciones, se aplicaron las 6 etapas del proceso de desarrollo propuesto. En primer lugar, se describe el proyecto de desarrollo de la interfaz entre el sistema de telesupervisión y el sistema $S C A D A$ y luego el proyecto de migración de arquitectura de monolítica a microservicios.

\subsection{DESARROLLO DE INTERFAZ ENTRE SISTEMA DE TELESUPERVISIÓN Y SISTEMA SCADA}

El proyecto, hasta el momento de la redacción de este trabajo, tuvo 13 iteraciones durante un periodo de 18 meses. Dos miembros del equipo estuvieron involucrados en el proyecto, uno de los cuales trabajó de manera remota. Para la elaboración de los documentos, se utilizó Google Docs. El tablero Kanban se alojó en fira ${ }^{7}$. Como medio de comunicación se utilizó el chat y videoconferencias de Google Hangouts. En la TABLA 5.1 se muestra el detalle de las iteraciones.

Durante la ejecución de las iteraciones que darían lugar a versiones ejecutables de la aplicación, se presentaron varias situaciones. Como la Tabla 5.1 muestra, en algunos casos no se logró cumplir con la estimación inicial. Analizando la documentación y lo que se conversó en las reuniones, las razones por las cuales no se logró el objetivo responden a "falta de conocimiento sobre OPC", "necesidad de mayor investigación",

\footnotetext{
${ }^{6}$ https://atlasti.com/

${ }^{7}$ https://www.atlassian.com/es/software/jira
} 
“diferencias entre producción y ambiente de pruebas”. Este patrón demostró que, a la hora de estimar no se tuvo presente que la investigación demandaría más tiempo del estimado. Por otro lado, la imposibilidad de replicar en un ambiente de pruebas lo que ocurría en producción tuvo un impacto significativo en el resultado.

TABLA 5.1 - Detalle de iteraciones proyecto Interfaz

\begin{tabular}{|c|c|c|c|c|c|}
\hline $\begin{array}{l}\text { Itera- } \\
\text { ción }\end{array}$ & $\begin{array}{c}\text { Participan- } \\
\text { tes }\end{array}$ & $\begin{array}{l}\text { Remo- } \\
\text { tos }\end{array}$ & $\begin{array}{l}\text { Estimación } \\
\text { Inicial } \\
\text { (días) }\end{array}$ & $\begin{array}{l}\text { ¿Se cumplió con } \\
\text { la estimación? }\end{array}$ & $\begin{array}{l}\text { Herramientas Utiliza- } \\
\text { das }\end{array}$ \\
\hline 1 & 2 & 1 & 5 & No & \multirow{13}{*}{$\begin{array}{c}\text { Google Hangouts } \\
\text { Google Docs } \\
\text { Fira } \\
\text { Microsoft Team Founda- } \\
\text { tion }\end{array}$} \\
\hline 2 & 2 & 1 & 5 & No & \\
\hline 3 & 2 & 1 & 10 & $\mathrm{Si}$ & \\
\hline 4 & 2 & 1 & 10 & $\mathrm{Si}$ & \\
\hline 5 & 2 & 1 & 10 & $\mathrm{Si}$ & \\
\hline 6 & 2 & 1 & 10 & No & \\
\hline 7 & 2 & 1 & 10 & $\mathrm{Si}$ & \\
\hline 8 & 2 & 1 & 10 & $\mathrm{Si}$ & \\
\hline 9 & 2 & 1 & 10 & $\mathrm{Si}$ & \\
\hline 10 & 2 & 1 & 10 & $\mathrm{Si}$ & \\
\hline 11 & 2 & 1 & 10 & $\mathrm{Si}$ & \\
\hline 12 & 2 & 1 & 10 & $\mathrm{Si}$ & \\
\hline 13 & 2 & 1 & 10 & $\mathrm{Si}$ & \\
\hline
\end{tabular}

Las primeras 5 versiones fueron utilizadas en un ambiente de pruebas preparado por el cliente, con datos reales, pero reducidos en volumen. El objetivo era evaluar que la interfaz funcionara y devolviera la información de manera correcta. A partir de la versión 6 , se comenzó a utilizar la aplicación en producción, con el volumen de datos real.

Con respecto a la utilización del proceso de desarrollo, del análisis de lo conversado en las reuniones se pudo observar que fue útil brindarles un template con ejemplos de lo que debería colocarse en cada punto. No se observó inconvenientes en la comunicación ni en la elaboración de la documentación porque las herramientas utilizadas, Google Docs, Fira y Google Hangouts facilitaban el trabajo distribuido. El equipo estableció como estándar mantener una correlación entre la versión de los documentos, la versión del tablero en fira y la versión del código fuente en Microsoft Team Foundation.

En los casos donde no se logró cumplir con los tiempos pactados con el cliente, se pudo observar que una razón fue que el equipo estaba confiado en que las tareas eran "sencillas", aún sin tener experiencia en las herramientas que iban a utilizar. Esto tenía como consecuencia agregar más tareas de las que podían completarse a la versión y finalmente no poder cumplir con lo pactado. En las últimas versiones se pudo ver un cambio de perspectiva y más cautela a la hora de planificar tareas. Por otro lado, se observó que las pruebas, que estaban a cargo del cliente, demoraron varios días debido a su poca disponibilidad. En una versión el cliente demoró 3 semanas en realizar la devolución. En ese caso particular, el equipo tuvo que corregir un problema que no se había detectado y la entrega final tardó más de 23 días de lo pactado. Es cierto que no era responsabilidad del equipo, pero el proyecto global se atrasó. 


\subsection{MIGRACIÓN DE ARQUITECTURA MONOLÍTICA A MICROSERVICIOS}

El proyecto, hasta el momento de la redacción de este trabajo, tuvo 15 iteraciones durante un periodo de 18 meses. Siete miembros del equipo estuvieron involucrados en el proyecto. Las versiones tuvieron diferentes combinaciones de equipos, no solo por la cantidad de participantes, sino por el nivel de distribución. Para la elaboración de los documentos, se utilizó Google Docs. El tablero Kanban se alojó en fira. Como medio de comunicación se utilizó el chat y videoconferencias de Google Hangouts, reuniones en persona y un grupo de WhatsApp. En la TABLA 5.2 se muestran el detalle de las iteraciones.

TABLA 5.2 - Detalle de iteraciones proyecto Microservicios

\begin{tabular}{|c|c|c|c|c|c|}
\hline $\begin{array}{l}\text { Itera- } \\
\text { ción }\end{array}$ & $\begin{array}{c}\text { Participan- } \\
\text { tes }\end{array}$ & $\begin{array}{l}\text { Remo- } \\
\text { tos }\end{array}$ & $\begin{array}{c}\text { Estimación } \\
\text { Inicial } \\
\text { (días) }\end{array}$ & $\begin{array}{c}\text { ¿Se cumplió con } \\
\text { la estimación? }\end{array}$ & $\begin{array}{l}\text { Herramientas Utiliza- } \\
\text { das }\end{array}$ \\
\hline 1 & 4 & 1 & 15 & No & \multirow{15}{*}{$\begin{array}{c}\text { Google Hangouts } \\
\text { Google Meet } \\
\text { Google Docs } \\
\text { Fira } \\
\text { Microsoft Team Founda- } \\
\text { tion } \\
\text { WhatsApp }\end{array}$} \\
\hline 2 & 4 & 1 & 15 & No & \\
\hline 3 & 3 & 1 & 15 & $\mathrm{Si}$ & \\
\hline 4 & 3 & 1 & 10 & $\mathrm{Si}$ & \\
\hline 5 & 3 & 1 & 10 & $\mathrm{Si}$ & \\
\hline 6 & 3 & 1 & 10 & $\mathrm{Si}$ & \\
\hline 7 & 3 & 1 & 10 & $\mathrm{Si}$ & \\
\hline 8 & 4 & 1 & 10 & No & \\
\hline 9 & 4 & 1 & 10 & No & \\
\hline 10 & 3 & 1 & 10 & $\mathrm{Si}$ & \\
\hline 11 & 3 & 1 & 10 & $\mathrm{Si}$ & \\
\hline 12 & 3 & 1 & 10 & $\mathrm{Si}$ & \\
\hline 13 & 2 & 2 & 10 & $\mathrm{Si}$ & \\
\hline 14 & 3 & 3 & 10 & $\mathrm{Si}$ & \\
\hline 15 & 3 & 3 & 10 & $\mathrm{Si}$ & \\
\hline
\end{tabular}

Durante la ejecución de las iteraciones que darían lugar a versiones ejecutables de la aplicación, se presentaron varias situaciones. Como la Tabla 5.2 muestra, en algunos casos no se logró cumplir con la estimación inicial. Analizando la documentación y lo que se conversó en las reuniones, las razones por las cuales no se logró el objetivo responden a "necesidad de mayor investigación" y "diferencias entre producción y ambiente de pruebas". Al igual que sucedió en el proyecto del desarrollo de la interfaz, este patrón demostró que, a la hora de estimar no se tuvo presente que la investigación demandaría más tiempo del estimado. Por otro lado, la imposibilidad de replicar en un ambiente de pruebas lo que ocurría en producción tuvo un impacto significativo en el resultado. Algo que llama la atención es que, en las iteraciones donde había mayor cantidad de desarrolladores, no se lograba cumplir con el objetivo. Luego de un análisis, la razón sería que, por ser un equipo más grande, existía la idea de "somos más, entonces tenemos que ser más productivos” por lo que se incluyeron más tareas de las que el equipo podía completar. Algunas tareas dependían de otras para su inicialización, generando un tiempo extra al estimado. Por ejemplo, en la iteración 2, un desarrollador estimó que realizaría una tarea en 8 horas, cuando la realidad fueron 18 , porque, además 
de tener que esperar que otro miembro del equipo terminara una tarea previa relacionada que demandó mayor investigación, encontró errores en la misma que demandaron tiempo extra.

A partir de la versión 2, se puso en producción la aplicación, la cual conviviría con la versión anterior hasta que todos los módulos fueran migrados. A medida que las versiones se iban entregando, la versión anterior tenía menos responsabilidades. Al momento de la redacción de este documento, ya se habían migrado todos los módulos a microservicios.

Con respecto a la utilización del proceso de desarrollo, del análisis de lo conversado en las reuniones se pudo observar que fue útil brindarles un template con ejemplos de lo que se debería colocarse en cada punto. No se observó inconvenientes en la comunicación ni en la elaboración de la documentación porque las herramientas utilizadas Google Docs, Fira, Google Hangouts, Google Meet y WhatsApp facilitaban el trabajo distribuido. El equipo estableció como estándar mantener una correlación entre la versión de los documentos, la versión del tablero en fira y la versión del código fuente en $\mathrm{Mi}$ crosoft Team Foundation. Por otro lado, se notó la importancia de la conversación sobre los puntos a desarrollar. Del análisis de las reuniones, se destaca que "conversar ahorra tiempo". Para resolver situaciones complejas, quienes participaban de la iteración tenían la costumbre de reunirse unos minutos para aclarar cualquier duda existente.

\subsection{DISCUSIÓN DE LA APLICACIÓN DEL PROCESO DURANTE LAS 28 ITE- RACIONES}

Durante la ejecución del proceso, surgieron situaciones para llevar a la práctica la teoría descrita en el proceso. A continuación, se comentan algunas de ellas, en qué etapa específica del proceso ocurrieron y cómo decidió el equipo resolverlas.

Iniciación. Una situación que se presentó al comienzo de los proyectos era ¿qué se debería colocar en la sección "arquitectura" de la primera versión del producto en esta fase: solo el módulo de la solución que se desarrollará o colocar toda la arquitectura de lo que abarcaría la solución completa? Si se colocaba solo el módulo, no se sabría qué relación tendría con el resto de los módulos ya desarrollados o a desarrollar. Pero si se colocaba toda la arquitectura, podría confundir. Finalmente, el equipo decidió probar con colocar toda la arquitectura, pero resaltar el módulo que iba a ser desarrollado en cada versión. Por lo tanto, se colocó un gráfico general, que se iría modificando a medida que el conocimiento de la solución creciera. En la Figura 5.2 un ejemplo de lo que decidieron hacer.

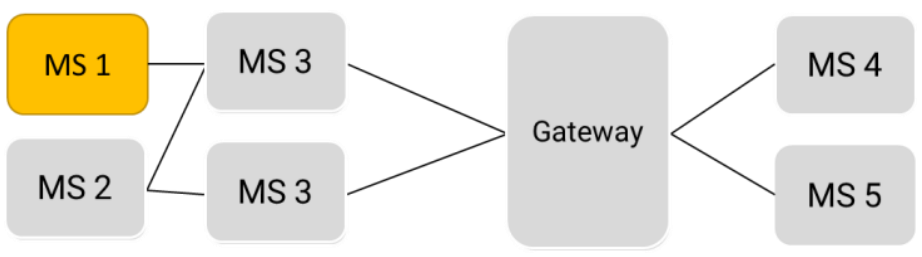

FIGURA 5.2 - Arquitectura de microservicios 
Definición preliminar. Una situación que fue recurrente en los dos proyectos fue la de cuántos requerimientos deberían incluirse en una versión particular. En varias iteraciones el equipo tendía a incluir gran cantidad de requerimientos que no podían completarse en el tiempo estimado. Quizás se llegaban a codificar, pero no se probaban correctamente por falta de tiempo y esto generaba problemas de implementación. El equipo tuvo que mentalizarse que incluir una o dos funcionalidades, bien probadas, era mejor que intentar planificar por fuera de sus posibilidades y entregar un producto sin terminar ni probar. Fue muy importante que conversaran entre ellos para focalizarse en un desarrollo de 10 días e incluir suficiente tiempo para hacer pruebas de calidad. Preguntas como: ¿tenemos experiencia en esa tecnología? ¿se puede hacer una prueba de calidad en la oficina? ¿hay otro proyecto al que debamos darle atención en estos días, que podría quitarnos tiempo de este proyecto? Luego de que las versiones fueron avanzando y el equipo veía las ventajas de una planificación criteriosa, se comenzó a establecer un estándar que se aplicaría durante el resto de los proyectos. Una "norma" que establecieron era: si el documento tiene más de dos páginas, hay que revisar los requerimientos incluidos porque es posible que haya un exceso.

Requerimientos a tareas. La primera pregunta que se hicieron los miembros del equipo fue ¿cómo pasamos los requerimientos del documento "Definición Preliminar” a las tareas en el tablero? ¿Uno a uno? Decidieron estandarizarlo de manera sencilla: los requerimientos se pasan "uno a uno" a tareas de tablero, para luego analizar si es necesario dividirlos en tareas más pequeñas o subtareas, algo que siempre terminaban realizando para dividir el trabajo de una manera más eficiente y poder establecer los criterios de aceptación correspondientes. La descripción de la tarea en el tablero era el requerimiento del documento "Definición preliminar".

Ejecución de tareas. En esta etapa era común que hubiera que modificar, cancelar o incluir tareas. ¿Cuál sería el criterio para seguir? Si el cliente solicitaba una nueva tarea o modifica lo que se debía hacer ¿qué haría el equipo? Decidieron que no podría estandarizarse el procedimiento y que lo mejor sería analizar cada caso particular y en la medida de lo posible adaptarse a lo solicitado. Eso podía hacerse agregando más tiempo a la entrega o cancelando alguna tarea y reasignando los recursos para satisfacer al cliente.

Entrega de la versión. La implementación es una tarea muy crítica dentro del desarrollo y el proceso no establece criterios de cómo hacerlo, por lo que el equipo tuvo que crear estándares de implementación que facilitaran la tarea. Por ejemplo, se estandarizó cómo nombrar las versiones dentro del código fuente y la estructura de carpetas. Por otro lado, se creó un documento que define qué archivos se deben incluir, cuáles reemplazar y cuáles eliminar. Si la implementación requiere scripts de base de datos, se debe explicar cuáles ejecutar y en qué orden. Este documento se fue mejorando con el pasar de las entregas para hacerle más fácil el trabajo al implementador.

Revisión. Cuando el equipo llegaba a este punto en la versión era cuando hacía el análisis de lo realizado y las mejoras a implementar a la posteridad. Como el proceso no tiene un documento de "lecciones aprendidas" el equipo lo agregó. No se hizo en todas las versiones, sino en aquella donde había información valiosa que escribir. 
Comunicación. Durante el desarrollo de los dos proyectos era muy importante la comunicación. Además de los medios empresariales estándar como Google Hangouts, Google Meet y correo electrónico, en uno de los proyectos se decidió utilizar un grupo de WhatsApp para compartir ideas y otros avances. El correo electrónico no era tan ágil como WhatsApp. Por ejemplo, enviar un correo con copia a todos no funcionaba ya que o el mensaje no se leía o se leía muy tarde. Los temas que se trataban eran nuevas versiones listas para prueba, resultados de las pruebas, nombres de los módulos, tecnologías a aplicar, entre otros. El equipo completo podía brindar su opinión, incluyendo aquellos que no estaban trabajando en esa versión en particular pero que lo habían hecho en versiones anteriores.

\section{RESULTADOS}

En este caso de estudio, se utilizaron análisis cualitativos y cuantitativos para examinar los datos recopilados. En primer lugar, se describe el análisis cualitativo, donde se utilizó Codificación Descriptiva. Luego se describe el análisis cuantitativo, donde se utilizó una encuesta SUS. Finalmente, se incluyen las opiniones del gerente de la empresa, el líder de proyectos y uno de los clientes.

\subsection{ANÁLISIS CUALITATIVO}

Luego de la ejecución de los dos proyectos, se realizó una encuesta cualitativa a los participantes. Dicha encuesta permitió obtener información muy valiosa. Para su análisis e interpretación se utilizó la Codificación Descriptiva recomendada por Saldaña (Saldaña, 2009). De acuerdo con el autor, esta codificación resume en una palabra o frase corta el tema básico de una porción de datos cualitativos. Es importante que estos códigos sean identificaciones del tema, no abreviaciones del contenido. Se eligió este tipo de codificación porque es especial para transcripciones de entrevistas, notas, documentos, correspondencia y video. Las preguntas que formaron parte de la encuesta se encuentran en el Apéndice 1.

Códigos. A partir de las respuestas a las encuestas, se obtuvieron los códigos descriptivos que se detallan a continuación. Estos códigos son la base del análisis e interpretación posterior. En la Tabla 5.3 se muestran los códigos y el grupo al que pertenecen. Los grupos fueron creados en línea con el objetivo de responder las preguntas de la investigación.

TABLA 5.3 - Códigos cualitativos

\begin{tabular}{|l|l|}
\hline \multicolumn{1}{|c|}{ Grupo } & \multicolumn{1}{c|}{ Código Descriptivo } \\
\hline \multirow{4}{*}{ Documentación Mínima } & Documentación contribuye al orden \\
\cline { 2 - 2 } & Documentación sencilla \\
\cline { 2 - 2 } & El uso de un template para documentos es una ventaja \\
\cline { 2 - 2 } & Sin problemas de adaptación \\
\hline \multirow{2}{*}{ Equipo Distribuido } & Herramientas en la nube contribuyen \\
\cline { 2 - 2 } & Puede usarse en un equipo distribuido \\
\hline Equipo Pequeño & Puede usarse en un equipo pequeño \\
\hline \multirow{2}{*}{ Trazabilidad de Requerimientos } & Ayuda a ordenar el proyecto \\
\cline { 2 - 2 } & El proceso es sencillo de entender \\
\hline
\end{tabular}




\begin{tabular}{|l|l|}
\hline \multicolumn{1}{|c|}{ Grupo } & \multicolumn{1}{c|}{ Código Descriptivo } \\
\hline \multirow{2}{*}{ Validar Entregas } & Permite trazar requerimientos \\
\cline { 2 - 2 } & Planificar pocas tareas es una ventaja \\
\cline { 2 - 2 } & Puede usarse en un proyecto complejo \\
\hline \multirow{2}{*}{ Oportunidad de Mejora } & Documentación contribuye a validar entregas \\
\cline { 2 - 2 } & Entregas cortas es una ventaja \\
\cline { 2 - 2 } & Planificar pocas tareas requiere tiempo de adaptación \\
\cline { 2 - 2 } & Incorporar lecciones aprendidas \\
\hline
\end{tabular}

Red de códigos. Una manera de ver la relación que existe entre los códigos que se han obtenido de las respuestas a los cuestionarios es a través de una red de nodos. Cada nodo es uno de los códigos obtenidos. Las relaciones pueden ser "es causa de", "está asociado a”, "contradice”, "es parte de", "es una”, "es una propiedad de” y "podría incluir”. En apéndice 3 se puede observar el diagrama de red de los códigos y sus relaciones.

Ocurrencia de Códigos. Una manera muy importante de analizar los datos cualitativos obtenidos de las encuestas es obtener las ocurrencias de los códigos y cuán representativos son con respecto al total (Vatansever \& Baltaci Goktalay, 2018), (Palamar \& Acosta, 2020). Las tablas que se muestran a continuación tienen un resumen con esta información. En la Tabla 5.4 se muestran los códigos descriptivos, la ocurrencia absoluta y el porcentaje de ocurrencias de cada uno con respecto al total de ocurrencias en las encuestas realizadas a los participantes. En las columnas E1, E2, etc. son las encuestas realizadas a cada participante. La información de la tabla permite conocer cuáles son los temas más recurrentes en las respuestas.

TABLA 5.4 - Ocurrencia de códigos cualitativos

\begin{tabular}{|l|c|c|c|c|c|c|c|c|c|}
\hline \multicolumn{1}{|c|}{ CÓDIGO } & E1 & E2 & E3 & E4 & E5 & E6 & E7 & Total & $\mathbf{\%}$ \\
\hline El proceso es sencillo de entender & 3 & 1 & 1 & 2 & 2 & 1 & 1 & $\mathbf{1 1}$ & 15.28 \\
\hline Puede usarse en equipos distribuidos & 2 & 1 & 1 & 1 & 1 & 1 & 1 & $\mathbf{8}$ & 11.11 \\
\hline Permite trazar requerimientos & 1 & 1 & 1 & 1 & 1 & 1 & 1 & $\mathbf{7}$ & 9.72 \\
\hline Puede usarse con un equipo pequeño & 1 & 1 & 1 & 1 & 1 & 1 & 1 & $\mathbf{7}$ & 9.72 \\
\hline Puede usarse en un proyecto complejo & 1 & 1 & 1 & 1 & 1 & 1 & 1 & $\mathbf{7}$ & 9.72 \\
\hline Incorporar lecciones aprendidas & 1 & 1 & 1 & 1 & 0 & 0 & 1 & $\mathbf{5}$ & 6.94 \\
\hline Ayuda a ordenar el proyecto & 0 & 0 & 0 & 1 & 1 & 0 & 2 & $\mathbf{4}$ & 5.56 \\
\hline Documentación sencilla & 1 & 1 & 1 & 0 & 0 & 0 & 1 & $\mathbf{4}$ & 5.56 \\
\hline $\begin{array}{l}\text { El uso de un template para documentos es una } \\
\text { ventaja }\end{array}$ & 2 & 1 & 1 & 0 & 0 & 0 & 0 & $\mathbf{4}$ & 5.56 \\
\hline Entregas cortas es una ventaja & 0 & 0 & 1 & 1 & 0 & 0 & 2 & $\mathbf{4}$ & 5.56 \\
\hline Herramientas en la nube contribuyen & 1 & 0 & 0 & 1 & 1 & 0 & 1 & $\mathbf{4}$ & 5.56 \\
\hline Sin problemas de adaptación & 0 & 0 & 1 & 1 & 1 & 1 & 0 & $\mathbf{4}$ & 5.56 \\
\hline $\begin{array}{l}\text { Planificar pocas tareas requiere tiempo de adap- } \\
\text { tación }\end{array}$ & 1 & 1 & 0 & 0 & 0 & 0 & 1 & $\mathbf{3}$ & 4.29 \\
\hline Documentación contribuye a validar entregas & 0 & 0 & 0 & 0 & 1 & 0 & 1 & $\mathbf{2}$ & 2.78 \\
\hline Planificar pocas tareas es una ventaja & 1 & 0 & 0 & 0 & 0 & 0 & 1 & $\mathbf{2}$ & 2.78 \\
\hline Documentación contribuye al orden & 0 & 0 & 0 & 1 & 0 & 0 & 0 & $\mathbf{1}$ & 1.39 \\
\hline
\end{tabular}


La Tabla 5.5 muestra la ocurrencia binaria de los códigos, lo que permite conocer qué participantes mencionaron el código en sus respuestas y conocer el grado de acuerdo en las mismas.

TABLA 5.5 - Ocurrencia binaria de códigos cualitativos

\begin{tabular}{|l|c|c|c|c|c|c|c|c|c|}
\hline \multicolumn{1}{|c|}{ CÓDIGO } & E1 & E2 & E3 & E4 & E5 & E6 & E7 & Total & $\mathbf{\%}$ \\
\hline El proceso es sencillo de entender & $*$ & $*$ & $*$ & $*$ & $*$ & $*$ & $*$ & $\mathbf{7}$ & 100.00 \\
\hline Permite trazar requerimientos & $*$ & $*$ & $*$ & $*$ & $*$ & $*$ & $*$ & $\mathbf{7}$ & 100.00 \\
\hline Puede usarse con un equipo pequeño & $*$ & $*$ & $*$ & $*$ & $*$ & $*$ & $*$ & $\mathbf{7}$ & 100.00 \\
\hline Puede usarse en equipos distribuidos & $*$ & $*$ & $*$ & $*$ & $*$ & $*$ & $*$ & $\mathbf{7}$ & 100.00 \\
\hline Puede usarse en un proyecto complejo & $*$ & $*$ & $*$ & $*$ & $*$ & $*$ & $*$ & $\mathbf{7}$ & 100.00 \\
\hline Incorporar lecciones aprendidas & $*$ & $*$ & $*$ & $*$ & & & $*$ & $\mathbf{5}$ & 71.42 \\
\hline Documentación sencilla & $*$ & $*$ & $*$ & & & & $*$ & $\mathbf{4}$ & 57.14 \\
\hline Herramientas en la nube contribuyen & $*$ & & & $*$ & $*$ & & $*$ & $\mathbf{4}$ & 57.14 \\
\hline Sin problemas de adaptación & & & $*$ & $*$ & $*$ & $*$ & & $\mathbf{4}$ & 57.14 \\
\hline Ayuda a ordenar el proyecto & & & & $*$ & $*$ & & $*$ & $\mathbf{3}$ & 42.85 \\
\hline $\begin{array}{l}\text { El uso de un template para documentos es una } \\
\text { ventaja }\end{array}$ & $*$ & $*$ & $*$ & & & & & $\mathbf{3}$ & 42.85 \\
\hline Entregas cortas es una ventaja & & & $*$ & $*$ & & & $*$ & $\mathbf{3}$ & 42.85 \\
\hline $\begin{array}{l}\text { Planificar pocas tareas requiere tiempo de adap- } \\
\text { tación }\end{array}$ & $*$ & $*$ & & & & & $*$ & $\mathbf{3}$ & 42.85 \\
\hline Documentación contribuye a validar entregas & & & & & $*$ & & $*$ & $\mathbf{2}$ & 28.57 \\
\hline Planificar pocas tareas es una ventaja & $*$ & & & & & & $*$ & $\mathbf{2}$ & 28.57 \\
\hline Documentación contribuye al orden & & & & $*$ & & & & $\mathbf{1}$ & 14.28 \\
\hline
\end{tabular}

De acuerdo con lo expuesto en las Tablas 4.4 y 4.5, se puede llegar a las siguientes conclusiones:

- Los participantes mencionaron en el $100 \%$ de las encuestas que el proceso es sencillo de entender. En términos de ocurrencias, representa el $15.28 \%$ sobre el total, por lo que es el tema más comentado por los participantes. Algunas respuestas explican las razones: "No es necesario leer un libro para saber cómo usarlo", "Cada etapa es fácil de comprender" y "Me gustó que sea claro por qué hay que completar ciertas cosas”. Los códigos relacionados que contribuyeron a este resultado son:

○ Documentación sencilla: se mencionan en el 57.14\% de las encuestas.

- Sin problemas de adaptación: mencionado en 4 encuestas.

- El uso de templates para documentos: mencionado en 3 encuestas.

Es evidente que, desde el punto de vista de los desarrolladores, lo que hace sencillo al proceso es no necesitar leer mucha documentación, que se explique qué se tiene que poner y en qué lugar y explicar las razones del por qué se escribe algo.

- El $100 \%$ de las respuestas concordaron en que el proceso permite realizar la trazabilidad de los requerimientos, por lo que es posible conocer lo que solicitaba el cliente desde el comienzo y validarlo al final de cada iteración. Entre las respuestas, los participantes comentaron que "los documentos antes de comenzar el desarrollo se firman por el cliente y luego de probarlo, el cliente 
firma un documento donde dice que está de acuerdo" y "durante toda la versión mantenemos contacto con el cliente".

- Por las respuestas de los participantes, se puede concluir que el proceso puede usarse en equipos distribuidos. El 100\% de las encuestas concuerdan en eso. Los participantes mencionaron este tema en el $11.43 \%$ del total de ocurrencias. Entre las respuestas al cuestionario, los participantes mencionaron que "el proceso fue utilizado durante la cuarentena y todos estaban en sus casas", "siempre había un integrante que trabajaba de manera remota". Por otro lado, de las respuestas obtenidas se concluye que las herramientas en la nube como Google Docs, Google Hangouts y fira contribuyeron en este punto, ya que el $57.14 \%$ de los encuestados las mencionó puntualmente.

- El $100 \%$ de las encuestas concuerda con que el proceso puede utilizarse por equipos pequeños. Los participantes expresaron que "lo utilizaron con 2, 3 y 4 personas sin problemas”.

- Todos los participantes concordaron en que el proceso de desarrollo puede utilizarse para proyectos complejos. Por proyectos “complejos", de acuerdo con lo entendido por el equipo, se hace referencia a proyectos donde hay un gran nivel de incertidumbre sobre la solución, la tecnología y la manera de hacer pruebas de campo. En palabras de los mismos participantes se utilizó Klein en proyectos donde "la tecnología era totalmente nueva" y "el equipo no tenía experiencia sobre el tema”.

- Con respecto a las oportunidades de mejora, 5 encuestas revelaron que los participantes opinaron que sería bueno incorporar al proceso una etapa opcional de "lecciones aprendidas", donde el equipo pueda reflexionar sobre las mejoras a poner en práctica en nuevas versiones, corregir tendencias negativas o mejorar la comunicación. Por otro lado, se puede observar que al equipo le costó poner en práctica el principio de desarrollar pocas funcionalidades, bien probadas. En las reuniones se podía notar que, en un principio, los participantes tenían el concepto de que, poner pocas tareas a realizar, era un indicador de baja productividad.

\subsection{ANÁLISIS CUANTITATIVO}

Para obtener información cuantitativa del caso de estudio se utilizó un cuestionario SUS (System Usability Scale, en español Escala de Usabilidad del Sistema) que fue desarrollado en 1986 por John Brooke como una herramienta para medir la usabilidad de un sistema a través de 10 preguntas estandarizadas, cada una de las cuales es puntuada de 1 a 5, donde 1 significa Total Desacuerdo y 5 Total Acuerdo. En el apéndice 4 se encuentra la encuesta realizada.

Una vez realizadas las encuestas a los usuarios involucrados, se aplica un proceso estándar para medir el resultado. Las preguntas impares tomarán el valor asignado por el usuario y se le restará 1 . Para las preguntas pares, será de 5 menos el valor asignado por el encuestado. Una vez obtenido el número final, se lo multiplica por 2.5. El número final es el puntaje SUS del sistema analizado, que será un valor entre 0 y 100 (Lewis \& 
Sauro, 2009). Cuanto mayor sea el número mejor será el resultado. Para medir el rating SUS del sistema se utiliza la escala de la Tabla $5.6^{8}$.

TABLA 5.6 - Rating SUS

\begin{tabular}{|c|c|c|}
\hline Resultado $\boldsymbol{S U S}$ & Grado & Rating \\
\hline$>80.3$ & $\mathrm{~A}$ & Excelente \\
\hline $68-80.3$ & $\mathrm{~B}$ & Bueno \\
\hline 68 & $\mathrm{C}$ & Promedio \\
\hline $51-68$ & $\mathrm{D}$ & Pobre \\
\hline$<51$ & $\mathrm{~F}$ & Malo \\
\hline
\end{tabular}

En el caso particular se solicitó a los 7 involucrados en el caso de estudio que contesten una encuesta SUS luego de utilizar el proceso. Según Nielsen (Nielsen, 1994) (Nilsen \& Norman, 2000), para tener resultados válidos que permitan determinar el $80 \%$ de los problemas de usabilidad el tamaño de la muestra debe ser de $4 \pm 1$. Uno de los factores que determinan el número correcto es la experiencia de los participantes en el uso del sistema a ser evaluado. En la Tabla 4.7 los resultados de la encuesta. Como se puede concluir a partir de los resultados el proceso tuvo una recepción excelente por parte de los participantes.

TABLA 5.7 - Resultados de la encuesta SUS

\begin{tabular}{|c|c|c|}
\cline { 2 - 3 } \multicolumn{1}{c|}{} & Escalas & \multicolumn{1}{c|}{} \\
\hline Participante & Resultado SUS (/100) & Grado \\
\hline 1 & $\mathbf{9 2 . 5}$ & $\mathrm{A}$ \\
\hline 2 & $\mathbf{6 7 . 5}$ & $\mathrm{D}$ \\
\hline 3 & $\mathbf{1 0 0}$ & $\mathrm{A}$ \\
\hline 4 & $\mathbf{1 0 0}$ & $\mathrm{A}$ \\
\hline 5 & $\mathbf{9 2 . 5}$ & $\mathrm{A}$ \\
\hline 6 & $\mathbf{9 2 . 5}$ & $\mathrm{A}$ \\
\hline 7 & $\mathbf{9 2 . 5}$ & $\mathrm{A}$ \\
\hline Resultado & $\mathbf{9 1 . 0 7}$ & $\mathrm{A}$ \\
\hline
\end{tabular}

\subsection{OPINIONES}

Además de las encuestas cualitativas y la encuesta SUS cuantitativa, se solicitó a tres de los participantes que expliquen en sus palabras si existió alguna mejora en el desarrollo con la utilización de Klein en comparación con el proceso que tenían previamente. A continuación, sus apreciaciones.

Gerente de la empresa de Desarrollo. "Por muchos años estuvimos llevando adelante proyectos de desarrollo sin un proceso específico. En los últimos años nos decidimos por incorporar Scrum como estándar. Si bien al principio nos fue muy útil, porque introdujo al equipo al desarrollo ágil, lo cierto es que, de acuerdo con nuestras características de desarrollo, mantenimiento e investigación, se hicieron comunes las situaciones donde en cada proyecto intervenía 1, 2 o 3 desarrolladores, los cuales tenían que forzar la utilización de Scrum para cumplir con sus requerimientos de aplicación. Entre las alternativas estaba

\footnotetext{
${ }^{8}$ https://uiuxtrend.com/measuring-system-usability-scale-sus/
} 
utilizar XP, sin embargo, para su adopción el equipo era reticente a leer instructivos técnicos. Al poco tiempo surgió la posibilidad de utilizar Klein, un proceso que, desde el principio, parecía resolver algunos problemas que estábamos enfrentando. El equipo estuvo de acuerdo en adoptarlo y probarlo para determinar si podríamos utilizarlo como estándar de desarrollo. Luego de algunos proyectos, pudimos confirmar que Klein tenía mucho potencial. Nos ayudó a organizarnos, avanzar, aunque existirán aspectos inciertos en algunos casos, porque sabíamos que en su debido momento se aclararían. Antes tendíamos a demorar el inicio de los proyectos por este motivo. Por otro lado, luego de usarlo por casi 2 años, logramos pasar la auditoría de calidad de desarrollo con el proceso Klein. Actualmente, es nuestro estándar de desarrollo y la adopción por parte del equipo ha sido muy buena, no solo porque es sencillo de utilizar, sino porque la documentación que nos anima a utilizar es útil. El único detalle, en nuestro caso, es que incorporamos "lecciones aprendidas" a la etapa de Revisión".

Líder de Proyectos de la empresa de Desarrollo. "El proceso Klein nos ha ayudado a organizarnos muy bien como equipo de desarrollo. Algo que rescato es la trazabilidad que existe entre las diferentes versiones de cada proyecto. Por ejemplo, la versión 1 comienza con el documento "Iniciación" y puede trazarse hasta la carpeta en el control de código fuente. Esto nunca lo habíamos podido hacer con otros procesos de desarrollo. Durante la auditoría de calidad, el auditor pudo notar la trazabilidad y le pareció muy bueno lo que vio. En cuanto a la calidad del producto, Klein nos ha ayudado a mantener el orden entre lo solicitado y lo entregado a los clientes. Como el proceso es sencillo de entender, con ponerlo en práctica en un proyecto, ya supimos cómo utilizarlo en los siguientes. Creo que Klein va a seguir siendo nuestro proceso por mucho tiempo más. Incluso lo estamos utilizando actualmente en un proyecto de gran incertidumbre y complejidad. Al ser tan flexible, nos permite adaptarnos con facilidad a proyectos de desarrollo e investigación."

Cliente. "Como cliente noté que los documentos que me mostraron se entendieron con facilidad. La mayoría de las cosas que quería que el sistema haga las charlábamos y luego se escribían en un documento sencillo. Con respecto a la calidad de lo entregado, podía ver qué era lo que había pedido y probar si era así antes de firmar. No es difícil entender lo que se hizo. En cuanto al producto entregado en general cumplía con lo pedido. A veces no podía probar en producción lo que me entregaban, pero no era problema del equipo, más que nada otros asuntos de la empresa o externos impedían cumplir con los tiempos pactados. Estaba claro que cada "versión" del producto era la base de una próxima versión más completa. Me gustó tener disponible para probar el producto cada poco tiempo"

\subsection{CERTIFICACIÓN DE NORMA ISO 9001.2015}

En el año 2019 la empresa que formó parte del caso de estudio logró certificar la norma de calidad ISO $9001.2015^{9}$ para desarrollo de software utilizando como base para su procedimiento el proceso Klein. Por lo tanto, a partir de ese momento, Klein es el proceso estándar de todos los proyectos de desarrollo que realizan. Se incluye una versión simplificada del procedimiento en el apéndice 5.

\footnotetext{
${ }^{9}$ https://www.iso.org/home.html
} 


\section{EVALUACIÓN DE VALIDEZ}

Los casos de estudio son por naturaleza cualitativos. Por esta razón, la información recolectada suele ser muy difícil de juzgar objetivamente (Yin, 2008). Para mejorar la validez interna de los resultados presentados, las variables independientes que podrían influir en este caso de estudio se han identificado de acuerdo con lo establecido por (Díaz \& Pérez, 2014):

- Experiencia del equipo: en este sentido se distinguen dos tipos de experiencia del equipo de desarrollo: la referida al conocimiento en el uso previo de la tecnología a implementar en los proyectos, que fue muy poca, y a la referida a la consolidación como equipo de trabajo, que es de más de 12 años.

- Complejidad de los proyectos: otra variable que influye es la complejidad de los proyectos involucrados en el caso de estudio. Si fueran demasiado sencillos, podría objetarse que el caso de estudio no es válido. Sin embargo, en los dos proyectos, la complejidad fue alta. A pesar de trabajar sobre un sistema que se conocía, los dos proyectos eran totalmente nuevos, sin precedentes en la empresa.

- Influencia entre los participantes: la interacción grupal puede dar paso a respuestas diferentes de los individuos debido a la influencia que pueden tener otros participantes. Para mejorar la validez interna de los resultados, las entrevistas se realizaron individualmente con los desarrolladores sin que se crucen entre ellos antes o después de cada entrevista individual

Sin embargo, la principal limitación en la investigación con casos de estudio se refiere a la validez externa, es decir, "la generalidad de los resultados con respecto a una población específica" (van Heesch \& Avgeriou, 2012), ya que solo se estudia un caso. No obstante, los casos de estudio permiten evaluar un fenómeno, un modelo o un proceso en un entorno real. Esto es algo importante en la ingeniería de software en el que una multitud de factores externos pueden afectar los resultados de la validación, y que otras técnicas, como los experimentos formales, aunque permiten la replicación y la generalización, no tienen en cuenta ya que se llevan a cabo en entornos controlados (Díaz \& Pérez, 2014).

La confiabilidad tiene que ver con la replicación, es decir, con el hecho de que se encontrarán los mismos resultados si se rehace el análisis. Es por eso por lo que todas las interpretaciones incluidas en este caso de estudio fueron validadas con los participantes para evitar la influencia del autor sobre los resultados.

\section{LIMITACIONES Y CONCLUSIONES}

Los resultados observados durante el caso de estudio son alentadores. No obstante, el caso de estudio tiene algunas limitaciones que se exponen a continuación.

- El número de participantes $(\mathrm{n}=7)$ es reducido y todos pertenecen a la misma empresa. Haría falta probarlo con mayor cantidad de equipos en diferentes empresas. 
- Si bien la pandemia obligó a desarrollar en un entorno completamente distribuido, la mayor parte del tiempo que demandó el caso de estudio los miembros del equipo podían verse y tratar personalmente.

- El análisis cualitativo tiene un nivel de subjetividad. Cuán involucrado se esté como observador o como miembro externo durante el trabajo, influirá en cómo se perciban, documenten y codifiquen los datos (Adler \& Adler, 1987). También lo hacen los tipos de preguntas que se realizan y los tipos de respuestas que se reciben durante las entrevistas (Kvale, 1996) y el detalle y la estructura de las notas. Merriam (Merriam, 1998) afirma que "nuestro análisis e interpretación reflejarán los conceptos, lenguaje, modelos y teorías que estructuraron la idea inicial del estudio". Y no es solo el enfoque de la investigación cualitativa lo que influye y afecta las decisiones de codificación, sino que, como dicen Sipe y Ghiso (Sipe \& Ghiso, 2004) "Toda codificación es cuestión de criterio" ya que traemos "nuestras subjetividades, nuestras personalidades, nuestras predisposiciones, [y] nuestras peculiaridades" al proceso.

Finalmente, se analizarán las respuestas a las preguntas planteadas al inicio de este trabajo y ver hasta qué punto el proceso de desarrollo ha sido efectivo en este caso particular.

\section{1) ¿Puede utilizarse el proceso de desarrollo con hasta cinco desarrolla- dores?}

La evidencia empírica obtenida del caso de estudio ha demostrado que el proceso puede utilizarse con 2, 3, 4 y hasta 5 desarrolladores. No se probó utilizarlo de manera individual. Sin embargo, no habría razón para creer que no, ya que el proceso no limita la cantidad de desarrolladores que pueden participar. Sin embargo, para confirmar dicha hipótesis, debería realizarse un caso de estudio.

2) ¿Es viable su utilización en un equipo distribuido geográficamente?

El caso de estudio demostró que es posible utilizar el proceso en un equipo distribuido geográficamente. Incluso demostró su efectividad cuando todos los miembros del equipo estaban trabajando de manera remota. Las herramientas en la nube jugaron un papel muy importante en este punto.

\section{3) ¿Puede asegurar la trazabilidad de los requerimientos?}

La evidencia obtenida ha demostrado que se puede asegurar la trazabilidad de los requerimientos desde el inicio al fin de cada versión del producto entregado. Los documentos de "Iniciación" y "Definición preliminar" permiten que el cliente expresamente apruebe lo que se va a realizar y el documento "Revisión" sirve como validación de que se realizó lo que se esperaba.

\section{4) ¿Reduce la cantidad de documentación?}

De acuerdo con los datos obtenidos por el caso de estudio, el proceso reduce la cantidad de documentación al tener templates de documentación fijos, entregas en pocos días y al apuntar a incrementos funcionales pequeños por versión. De hecho, entre las encuestas el $57.14 \%$ de los participantes concordó en que "la documentación era sencilla". 
Por lo analizado en este capítulo, hay buenas razones para creer que el proceso de desarrollo Klein es un proceso que garantiza la trazabilidad de los requerimientos, puede aplicarse a equipos pequeños y distribuidos y con documentación mínima.

\section{RECAPITULACIÓN}

En este capítulo se ha descrito el caso de estudio llevado a cabo para demostrar que el proceso Klein pueda cumplir con los objetivos planteados en la introducción de este trabajo. 1) Que asegure la trazabilidad de los requerimientos, 2) Que pueda aplicarse a un equipo pequeño, 3) Que sea posible tener el equipo distribuido y 4) que su foco sea la documentación mínima. Los resultados han sido alentadores, ya que las 28 iteraciones en un periodo de 18 meses han demostrado que Klein cumple con las 4 premisas. Por otro lado, la empresa que participó del caso de estudio certificó la norma de calidad ISO 9001.2015 en 2019 para el diseño y desarrollo de software utilizando como estándar el proceso Klein. 


\section{Capítulo 6 Conclusiones}

En la actualidad es común encontrar empresas con equipos pequeños de desarrollo de software y con miembros distribuidos geográficamente. En relación con el producto que genera el equipo de desarrollo por un lado está la necesidad de brindarle a sus clientes documentación mínima y clara para facilitar su lectura y, por otro lado, lograr la trazabilidad de requerimientos debido a la importancia de certificar normas de calidad. Esta tesis se enfocó en un proceso de desarrollo en ese marco.

Este trabajo analizó diferentes propuestas de desarrollo de software que van desde las clásicas hasta las ágiles con el objetivo de identificar insuficiencias para su aplicación en: equipos pequeños, distribuidos geográficamente, en proyectos que requieran trazabilidad de los requerimientos y documentación mínima. Además, determinó el impacto de internet, las redes sociales y los smartphones en los hábitos de lectura de las personas y su relación con la documentación de los proyectos de desarrollo de software.

El resultado de este trabajo es un proceso de desarrollo de software con trazabilidad de requerimientos, documentación mínima, aplicable con equipos pequeños, distribuidos. El proceso presentado en este trabajo le permitió a la empresa que participó del caso de estudio certificar la norma ISO 9001.2015 de calidad de software en 2019. A partir de dicha certificación, Klein es el proceso estándar de todos los desarrollos de la empresa.

El proceso se aplicó en un trabajo experimental de 18 meses de duración donde se ejecutaron 28 iteraciones. El caso de estudio se realizó en una empresa especializada en software y hardware para la industria de hidrocarburos y telemetría. Específicamente, se realizó con dos proyectos tecnológicos para la industria petrolera involucrando a 7 profesionales. Para analizar su efectividad se reunieron datos tanto cuantitativos como cualitativos. En el caso de la evaluación cualitativa, los métodos utilizados fueron: observación, análisis de documentación, cuestionarios y entrevistas. Toda esta información fue transcrita y analizada utilizando la codificación descriptiva para datos cualitativos recomendada por Saldaña (Saldaña, 2009). Para la evaluación cuantitativa, se utilizó una encuesta System Usability Scale (SUS) a los participantes (Lewis \& Sauro, 2009).

Cuando se presentó el proceso al equipo de desarrollo fue necesario no solo explicar sus bondades sino dar tiempo para que cada uno se convenza de su utilidad. Algo que ayudó fue aceptar sus sugerencias. Eso permitió que vean al proceso como "suyo" y no solo como algo que la gerencia deseaba poner en marcha. Por supuesto, al intentar implementar algo nuevo, fue necesario dar las justificaciones pertinentes y las razones por las que el proceso iba a ser una mejora en el desarrollo. Los aspectos que favorecieron su adopción fueron: que el proceso sea sencillo de entender, que no requiera leer documentación extensa, y que los momentos donde había que escribir fueran pocos y puntuales. Por otro lado, jugó a favor que el proceso incluya aspectos de frameworks con los que el equipo estaba familiarizado como Scrum y Kanban. El que se incluyeran documentos especialmente focalizados en la trazabilidad de los requerimientos le dio seguridad al equipo de que el proceso permitiría cumplir con la auditoría de calidad. 
Una situación que fue recurrente en los dos proyectos fue la de cuántos requerimientos deberían incluirse en una versión particular. En varias iteraciones el equipo tendía a incluir gran cantidad de requerimientos que no podían completarse en el tiempo estimado. Quizás se llegaban a codificar, pero no se probaban correctamente por falta de tiempo y esto generaba problemas de implementación. El equipo tuvo que mentalizarse que incluir una o dos funcionalidades, bien probadas, era mejor que intentar planificar por fuera de sus posibilidades y entregar un producto sin terminar ni probar. Fue muy importante que conversaran entre ellos para focalizarse en un desarrollo de 10 días e incluir suficiente tiempo para hacer pruebas de calidad. Preguntas como: ¿tenemos experiencia en esa tecnología? ¿se puede hacer una prueba de calidad en la oficina? ¿hay otro proyecto al que debamos darle atención en estos días, que podría quitarnos tiempo de este proyecto? Luego de que las versiones fueron avanzando y el equipo veía las ventajas de una planificación criteriosa, se comenzó a establecer un estándar que se aplicaría durante el resto de los proyectos.

La implementación es una tarea muy crítica dentro del desarrollo y el proceso no establece criterios de cómo hacerlo, por lo que el equipo tuvo que crear estándares de implementación que facilitaran la tarea. Por ejemplo, se estandarizó cómo nombrar las versiones dentro del código fuente y la estructura de carpetas. Por otro lado, se creó un documento que define qué archivos se deben incluir, cuáles reemplazar y cuáles eliminar. Si la implementación requiere scripts de base de datos, se debe explicar cuáles ejecutar y en qué orden. Este documento se fue mejorando con el pasar de las entregas para hacerle más fácil el trabajo al implementador.

Durante el desarrollo de los dos proyectos fue muy importante la comunicación. Además de los medios empresariales estándar como Google Hangouts, Google Meet y correo electrónico, en uno de los proyectos se decidió utilizar un grupo de WhatsApp para compartir ideas y otros avances. El correo electrónico no era tan ágil como WhatsApp. Por ejemplo, enviar un correo con copia a todos no funcionaba ya que o el mensaje no se leía o se leía muy tarde. Los temas que se trataban eran nuevas versiones listas para prueba, resultados de las pruebas, nombres de los módulos, tecnologías a aplicar, entre otros. El equipo completo podía brindar su opinión, incluyendo aquellos que no estaban trabajando en esa versión en particular pero que lo habían hecho en versiones anteriores.

La adopción de Klein como proceso de desarrollo estándar logró un cambio en la mentalidad del equipo, a tal punto que se volvieron defensores de su aplicación. Cualquier miembro que se olvidara de cargar alguna tarea, cambiarle el estado o hacer alguna prueba sin documentar era objeto de llamadas de atención por parte de otros miembros. Desarrollar algo sin tener algún documento que lo respalde se volvió inimaginable. Por otro lado, la discusión de "si hay que crear una nueva versión o no" fue tema de debate, hasta definir un estándar. Es normal preguntar: ¿Es una nueva funcionalidad o es una corrección menor? La respuesta determina si se crea una nueva versión con sus documentos correspondientes, o si se continúa con los mismos documentos, pero se crea una versión "menor".

Por otro lado, hay algunos aspectos en los que el proceso podría mejorar. Por ejemplo, un elemento que sería positivo incluir sería un documento opcional de "lecciones aprendidas". Esto animaría al equipo a mejorar de manera continua a través de las 
diferentes iteraciones. Otro punto para tener presente es que escribir documentación de manera simple depende en gran medida de la capacidad de los desarrolladores. En caso de que no se tenga esa habilidad, la escritura de la documentación podría no tener los resultados esperados. Por otro lado, el éxito de la aplicación del proceso depende de planificar tareas que puedan completarse en 10 días cómo máximo. Si el equipo está acostumbrado a planificar gran cantidad de tareas, puede llevar tiempo acostumbrarse a esa nueva forma de pensar.

La validación del proceso ha sido muy positiva, pero sería importante probarlo con otros equipos y bajo otras condiciones. Por ejemplo, equipos de desarrollo sin experiencia trabajando juntos, con grandes diferencias horarias, culturares o lingüísticas. Sería muy positivo realizar experimentos que permitan comparar los resultados de un mismo proyecto utilizando Klein y algún otro proceso. Esto brindaría mucha información y permitiría determinar el verdadero impacto en su adopción. Finalmente, de acuerdo con lo observado durante el caso de estudio, es muy importante para el equipo contar con una plataforma distribuida y colaborativa que centralice todo lo necesario durante el proyecto: documentos, tablero y código. En los proyectos que se analizaron en este trabajo, se tenía en Google Docs los documentos, en fira el tablero y en Visual Studio y Microsoft Team Foundation el código. Quizás el desarrollo de una herramienta CASE que tenga todo junto podría ser una opción. 


\section{Referencias}

\section{INTRODUCCIÓN}

Agile Alliance. (2001). Manifesto for Agile Software Development. Obtenido de Manifesto for Agile Software Development: https://agilemanifesto.org/

Anderson, D. \&. (2016). Essential Kanban Condensed. Lean-Kanban University.

Beck, K. \&. (2004). Extreme Programming Explained: Embrace Change. Addison-Wesley Professional.

Carr, N. (2011). The Shallows: What the Internet Is Doing to Our Brains. W. W. Norton \& Company.

Cerqueira, M., \& Magalhães, A. P. (2018). A Software Development Process for Super Agile Projects. Proceedings of the XIV Brazilian Symposium on Information Systems - SBSI'18, 400-407.

Department of Defense. (29 de 02 de 1988). Defense System Software Development. DOD-STD-2167A. Washington DC, Estados Unidos.

Gazzaley, A. \&. (2016). The Distracted Mind: Ancient Brains in a High-Tech World. MIT Press.

Jacobson, I. \&. (1999). Unified Software Development Process. . Addison-Wesley Professional.

Johnsson, B., \& Magnusson, B. (2019). Live GUI development for service-based systems. Proceedings of the Conference Companion of the 3rd International Conference on Art, Science, and Engineering of Programming (Programming '19) (págs. 1-4). New York, NY, USA: Association for Computing Machinery.

Lewis, J., \& Sauro, J. (2009). The Factor Structure of the System Usability Scale. Lecture Notes in Computer Science, 94-103.

Monteiro, P., \& Borges, P. (2012). A reduced set of RUP roles to small software development teams. International Conference on Software and System Process (ICSSP), 190-199.

Robinson, P. T. (2019). Communication Network in an Agile Distributed Software Development Team. ACM/IEEE 14th International Conference on Global Software Engineering (ICGSE)., 100-104.

Royce, W. (1970). Managing the Development of Large Software Systems. . Proceedings of IEEE WESCON, 328-388.

Saldaña, J. (2009). The coding manual for cualitative researchers. London: Sage Publications Ltd.

Sutherland, J., \& Schwaber, K. (2017). www.scrumguides.org. Obtenido de The Scrum Guide: http://www.scrumguides.org/docs/scrumguide/v2017/2017-Scrum-GuideUS.pdf

Venson, E., \& Guo, X. (2019). Costing Secure Software Development: A Systematic Mapping Study. Proceedings of the 14th International Conference on Availability, Reliability and Security (ARES '19) (págs. 1-11). New York, NY, USA: Association for Computing Machinery. 
Wang, C., \& Luo, Z. (2017). ow to Reduce Software Development Cost with Personnel Assignment Optimization: Exemplary Improvement on the Hungarian Algorithm. Proceedings of the 21st International Conference on Evaluation and Assessment in Software Engineering (EASE'17) (págs. 270-279). New York, NY, USA: Association for Computing Machinery.

Zhi-peng, S., \& Guiming, C. (2019). Evaluation of Large-scale Complex Systems Effectiveness Based on Big Data. Proceedings of the 2019 4th International Conference on Big Data and Computing (ICBDC 2019) (págs. 72-76). New York, NY, USA: Association for Computing Machinery.

\section{BACKGROUND}

Agile Alliance. (2001). Manifesto for Agile Software Development. Obtenido de Manifesto for Agile Software Development: https://agilemanifesto.org/

Al-Maharmeh, M. (2010). A composite application software development process framework (CASDPF).

Anderson, D., \& Carmichael, A. (2016). Essential Kanban Condensed. Lean-Kanban University.

Barbalet, J. (1999). Boredom and social meaning. The British fournal of Sociology, vol. 50, no. 4, 631-646.

Beck, K., \& Andres, C. (2004). Extreme Programming Explained: Embrace Change. Addison-Wesley Professional.

Carr, N. (2011). The Shallows: What the Internet Is Doing to Our Brains. W. W. Norton \& Company.

Cerqueira, M., \& Magalhães, A. P. (2018). A Software Development Process for Super Agile Projects. Proceedings of the XIV Brazilian Symposium on Information Systems - SBSI'18, 400-407.

Charnov, E. (1976). Optimal foraging, the marginal value theorem. Theoretical Population Biology, vol. 9, no. 2, 129-136.

CIBER Comitee. (2008). Information Behaviour of the Researcher of the Future: A CIBER Briefing Paper.

Cowen, T. (2009). Create Your Own Economy: The Path to Prosperity in a Disordered World. Dutton Adult.

Department of Defense. (29 de 02 de 1988). Defense System Software Development. DOD-STD-2167A. Washington DC, Estados Unidos.

Doidge, N. (2008). The Brain That Changes Itself: Stories of Personal Triumph from the Frontiers of Brain Science. Penguin UK.

Eastwood, J., \& Fenske, M. (2012). The Unengaged Mind: Defining Boredom in Terms of Attention . Perspectives on Psychological Science, vol. 7, no. 5, 482-495.

Elghondakly, R., \& Moussa, S. (2015). Waterfall and agile requirements-based model for automated test cases generation. IEEE Seventh International Conference on Intelligent Computing and Information Systems (ICICIS), 607-612.

Flewelling, P. (2018). The Agile Developer's Handbook: Get more value from your software development: get the best out of the Agile methodology. . Packt Publishing Ltd.

Foerde, K., \& Knowlton, B. (2006). Modulation of competing memory systems by distraction. Proceedings of the National Academy of Sciences, 11778-11783. 
Gazzaley, A., \& Rosen, L. (2016). The Distracted Mind: Ancient Brains in a High-Tech World. MIT Press.

Jacobson, I. \&. (1999). Unified Software Development Process. . Addison-Wesley Professional.

Johnsson, B., \& Magnusson, B. (2019). Live GUI development for service-based systems. Proceedings of the Conference Companion of the 3rd International Conference on Art, Science, and Engineering of Programming (Programming '19) (págs. 1-4). New York, NY, USA: Association for Computing Machinery.

Kandel, E. (2007). In Search of Memory: The Emergence of a New Science of Mind. W. W. Norton \& Company.

Langer, A. (2016). Guide to Software Development: Designing and Managing the Life Cycle. New York: Springer.

Lawton, G. (2008). Is it worth going to the mind gym? The new scientist, vol. 197, no. 2638, 26-29.

Lewis, J., \& Sauro, J. (2009). The Factor Structure of the System Usability Scale. Lecture Notes in Computer Science, 94-103.

Liu, Z. (2003). Reading behavior in the digital environment: Changes in reading behavior over the past ten years. Journal of Documentation, vol. 61, no. 6, 700-712.

Monteiro, P., \& Borges, P. (2012). A reduced set of RUP roles to small software development teams. International Conference on Software and System Process (ICSSP), 190-199.

Nielsen Norman Group. (2006). F-Shaped Pattern For Reading Web Content (original eyetracking research). Obtenido de F-Shaped Pattern For Reading Web Content (original eyetracking research): https://www.nngroup.com/articles/f-shapedpattern-reading-web-content-discovered/

Nielsen Norman Group. (11 de 2017). How Users Read on the Web. Obtenido de How Users Read on the Web: https://www.nngroup.com/articles/how-users-read-onthe-web/

Ophir, E., \& Nass, C. (2009). Cognitive control in media multitaskers. Proceedings of the National Academy of Sciences U. S. A., vol. 106, no. 37, 15583-15587.

Pascual-Leone, A. (2005). The plastic human brain cortex. Annual Review of Neuroscience, vol. 28, 377-401.

Robinson, P. T. (2019). Communication Network in an Agile Distributed Software Development Team. . ACM/IEEE 14th International Conference on Global Software Engineering (ICGSE)., 100-104.

Rosen, L. (2013). Is Facebook creating 'iDisorders'? The link between clinical symptoms of psychiatric disorders and technology use, attitudes and anxiety. Computers in Human Behavior, vol. 29, no. 3, 1243-1254.

Rowlands, I. (2008). The Google generation: the information behaviour of the researcher of the future. Aslib Proceedings, 290-310.

Royce, W. (1970). Managing the Development of Large Software Systems. . Proceedings of IEEE WESCON, 328-388.

Saldaña, J. (2009). The coding manual for cualitative researchers. London: Sage Publications Ltd.

Schuh, G., \& Rebentisch, E. (2017). Agile-waterfall hybrid product development in the manufacturing industry - Introducing guidelines for implementation of parallel 
use of the two models. IEEE International Conference on Industrial Engineering and Engineering Management (IEEM), 725-729.

Stellman, A., \& Greene, J. (2014). Learning Agile: Understanding Scrum, XP, Lean, and Kanban. O’Reilly Media Inc.

Sutherland, J., \& Schwaber, K. (2017). www.scrumguides.org. Obtenido de The Scrum Guide: http://www.scrumguides.org/docs/scrumguide/v2017/2017-Scrum-GuideUS.pdf

Sweller, J. (1999). Instructional Design in Technical Areas. Australian Council for Educational.

The Department of Justice, U. (01 de 01 de 2003). Systems Development Life Cycle. Obtenido de Systems Development Life Cycle: https://www.justice.gov/archive/jmd/irm/lifecycle/ch1.htm

Venson, E., \& Guo, X. (2019). Costing Secure Software Development: A Systematic Mapping Study. Proceedings of the 14th International Conference on Availability, Reliability and Security (ARES '19) (págs. 1-11). New York, NY, USA: Association for Computing Machinery.

VersionOne Inc. (26 de 05 de 2020). 14th Annual State of Agile Report. Obtenido de 14th Annual State of Agile Report: https://stateofagile.com/\#ufh-i-615706098-14thannual-state-of-agile-report/7027494

Wang, C., \& Luo, Z. (2017). ow to Reduce Software Development Cost with Personnel Assignment Optimization: Exemplary Improvement on the Hungarian Algorithm. Proceedings of the 21st International Conference on Evaluation and Assessment in Software Engineering (EASE'17) (págs. 270-279). New York, NY, USA: Association for Computing Machinery.

Weinreich, E. O. (2008). Not quite the average: An empirical study of Web use. ACM Transactions on the Web, vol. 2.

Zhi-peng, S., \& Guiming, C. (2019). Evaluation of Large-scale Complex Systems Effectiveness Based on Big Data. Proceedings of the 2019 4th International Conference on Big Data and Computing (ICBDC 2019) (págs. 72-76). New York, NY, USA: Association for Computing Machinery.

\section{TRABAJOS RELACIONADOS}

Abrahamsson, P. (2004). Mobile-D: an agile approach for mobile application development. Companion to the 19th annual ACM SIGPLAN conference on Object-oriented programming systems, languages, and applications, 174-175.

Al-Maharmeh, M. (2010). A composite application software development process framework (CASDPF).

Al-Maharmeh, M., \& Unhelkar, B. (2009). Applying a Composite Process Framework $(\mathrm{CPF})$ in Real Life Software Development Project. . Sixth International Conference on Information Technology: New Generations., 1384-1389.

Bernabé, R., Navia, I., \& García-Peñalvo, F. (2015). Faat: freelance as a team. Proceedings of the 3rd International Conference on Technological Ecosystems for Enhancing Multiculturality, 687-694.

Cerqueira, M., \& Magalhães, A. (2018). A Software Development Process for Super Agile Projects. . Proceedings of the XIV Brazilian Symposium on Information Systems. 
Dos Santos, L., \& L'Erario, A. (2018). A scrum-based process to distributed projects in multidisciplinary teams. Proceedings of the 13th Conference on Global Software Engineering, 133-134.

Lin, L., \& Yang, W. (2012). A layer-based method for rapid software development. Computer and Mathematics with Applications, 1364-1375.

Losada, B., \& Urretavizcaya, M. (2013). A guide to agile development of interactive software with a "User Objectives"-driven methodology. Science of Computer Programming, 2268-2281.

Mandal, A. (2009). BRIDGE: A Model for Modern Software Development Process to Cater the Present Software Crisis. IEEE International Advance Computing Conference, $1617-1623$.

Monteiro, P., \& Borges, P. (2012). A reduced set of RUP roles to small software development teams. International Conference on Software and System Process (ICSSP), 190-199.

Rettig, M., \& Simons, G. (1993). A project planning and development process for small teams. ACM, 45-55.

Rizwan, J., \& Hussain, S. (2008). An adaptive software development process model. Advances in Engineering Software, 654-658.

Sampaio, A., \& Vasconcelos, A. (2004). Assessing agile methods: An empirical study. Journal of the Brazilian Computer Society, 21-48.

Vallon, R., \& Strobl, S. (2016). ADAPT: A Framework for Agile Distributed Software Development. IEEE Software, 106-111.

\section{KLEIN: PROCESO PROPUESTO}

Agile Alliance. (2001). Manifiesto por el Desarrollo Ágil de Software. Obtenido de Manifiesto por el Desarrollo Ágil de Software: http://agilemanifesto.org/ISO/es/manifesto.html

Beck, K. (2004). Extreme Programming Explained: Embrace Change. Addison-Wesley.

Brechner, E. (2015). Agile Project Management with Kanban (Developer Best Practices). Microsoft Press.

Flewelling, P. (2018). The Agile Developer's Handbook: Get more value from your software development: get the best out of the Agile methodology. Packt Publishing Ltd.

\section{CASO DE ESTUDIO}

OPC Foundation. (28 de 05 de 2020). OPC Foundation. Obtenido de OPC Foundation: https://opcfoundation.org/about/what-is-opc/

Adler, P., \& Adler, P. (1987). Membership roles in field research. Newbury Park: Sage.

Díaz, J., \& Pérez, J. (2014). A model for tracing variability from features to product-line architectures: a case study in smart grids. Requirements Engineering.

Kvale, S. (1996). Interviews: An introduction to qualitative research interviewing. Thousand. Thousand Oaks: Sage.

Lewis, J., \& Sauro, J. (2009). The Factor Structure of the System Usability Scale. Lecture Notes in Computer Science, 94-103.

Martin, R. C. (2003). Agile Software Development: Principles, Patterns, and Practices. Pearson Education. 
Mazlami, G., \& Cito, J. (2017). Extraction of Microservices from Monolithic Software Architectures. EEE 24th International Conference on Web Services, 524-531.

Merriam, S. (1998). Qualitative research and case study applications in education. San Francisco: Jossey-Bass.

Nielsen, J. (1994). Estimating the number of subjects needed for a thinking aloud test. International fournal of Human-Computer Studies, 385-397.

Nilsen, J., \& Norman. (18 de 3 de 2000). www.nngroup.com. Obtenido de www.nngroup.com: https://www.nngroup.com/articles/why-you-only-need-totest-with-5-users/

Palamar, J., \& Acosta, P. (2020). A qualitative descriptive analysis of effects of psychedelic phenethylamines and tryptamines. Human Psychopharmacology Clinical and Experimental, 35.

Runeson, P., \& Höst, M. (2009). Guidelines for conducting and reporting case study research in software engineering. Empirical Software Engineering, 131-164.

Runeson, P., \& Höst, M. (2012). Case study research in software engineering: guidelines and examples. Hoboken: Wiley.

Saldaña, J. (2009). The coding manual for cualitative researchers. London: Sage Publications Ltd.

Sipe, L. R., \& Ghiso, M. P. (2004). Developing conceptual categories in classroom descriptive research: Some problems and possibilities. Anthropology and Education Quarterly, 472-85.

Solingen, R. \&. (2002). Encyclopedia of Software Engineering. Wiley \& Sons.

van Heesch, U., \& Avgeriou, P. (2012). A documentation framework for architecture decisions. Journal of Software Systems, 795-820.

Vatansever, Ö., \& Baltaci Goktalay, S. (2018). How Does Teaching Programming through Scratch Affect Problem-solving Skills of 5th and 6th Grade Middle School Students? International fournal of Management and Social Sciences, 17781801.

Yin, R. (2008). Case study research. Design and methods. London: Sage.

Zhongshan, R., \& Wei, W. (2018). Migrating Web Applications from Monolithic Structure to Microservices Architecture. Proceedings of the Tenth Asia-Pacific Symposium on Internetware, ACM, 1-10.

\section{CONCLUSIONES}

Lewis, J., \& Sauro, J. (2009). The Factor Structure of the System Usability Scale. Lecture Notes in Computer Science, 94-103.

Saldaña, J. (2009). The coding manual for cualitative researchers. London: Sage Publications Ltd. 


\section{Apéndice}

\section{APÉNDICE 1 - ENCUESTA PARA OBTENER INFORMACIÓN CUALITATIVA}

A continuación, se muestra la encuesta que se utilizó en el caso de estudio para obtener la información cualitativa por parte de los participantes.

1) En términos generales ¿cuál fue tu experiencia utilizando el proceso?

2) ¿Crees que el proceso puede utilizarse en proyectos complejos?

3) ¿Crees que el proceso puede utilizarse en equipos distribuidos geográficamente?

4) Con respecto a la documentación del proceso ¿crees que contribuye al proyecto?

5) ¿Crees que puede utilizarse por una persona o un equipo pequeño?

6) Teniendo en cuenta tu experiencia con otros procesos ¿qué ventaja ves en Klein? ¿Alguna desventaja?

7) Al utilizar el proceso ¿qué fue lo que más te costó adoptar?

8) Con respecto a las etapas del proceso ¿crees que habría alguna que debería mejorarse? ¿Alguna que debería quitarse o agregarse?

9) ¿Crees que es posible hacer una trazabilidad entre lo que pide el cliente y lo que finalmente se le entrega? 


\section{APÉNDICE 2 - RESPUESTAS A LAS ENCUESTAS PARA OBTENER INFORMA- CIÓN CUALITATIVA}

En este apéndice se transcribieron las respuestas a las encuestas para obtener la información cualitativa de los participantes del caso de estudio.

\section{Encuesta 1}

En términos generales ¿cuál fue tu experiencia utilizando el proceso?

Muy buena. Lo vi bastante sencillo. Me gustó que sea claro por qué hay que completar ciertas cosas. No veo que tenga información redundante o que no se sepa para qué está. Las etapas son sencillas de entender. No es necesario leer un libro para saber cómo usarlo.

\section{¿Crees que el proceso puede utilizarse en proyectos complejos?}

Totalmente. El proyecto en el que utilizamos el proceso era complejo y con gran incertidumbre. La tecnología era totalmente nueva para nosotros y el proceso nos ayuda a ordenar el desarrollo.

¿Crees que el proceso puede utilizarse en equipos distribuidos geográficamente?

Si. Lo utilizamos durante la cuarentena y todos estábamos en nuestras casas. Como utilizamos herramientas de colaboración en línea, fue sencillo utilizar el proceso.

Con respecto a la documentación del proceso ¿crees que contribuye al proyecto? Si. Creo que el template con los títulos marcando qué hay que completar ayudan mucho en las reuniones. No estamos pensando demasiado qué completar o qué poner.

¿Crees que puede utilizarse por una persona o un equipo pequeño?

Sí. Lo utilizamos 2, 3 y 4 personas y anduvo muy bien. No veo por qué no podría usarlo una sola persona. A diferencia de Scrum, donde hay que cumplir ciertos roles, Klein no los pide. Es una ventaja desde mi punto de vista.

Teniendo en cuenta tu experiencia con otros procesos ¿qué ventaja ves en Klein? ¿Alguna desventaja?

Es fácil de usar. Permite que arranquemos con algo en vez de estar pensando en todo lo que el sistema debería o no hacer al futuro. No perdemos tiempo.

Al utilizar el proceso ¿qué fue lo que más te costó adoptar?

Creo que lo que más me costó fue acostumbrarme a planificar pocas tareas. Siempre pensé que la productividad depende de la cantidad de cosas que se hacen en una versión del producto, pero no es siempre así.

Con respecto a las etapas del proceso ¿crees que habría alguna que debería mejorarse? ¿Alguna que debería quitarse o agregarse?

Creo que las etapas están bien. Quizás, en algunas ocasiones, se podría agregar una etapa de "lecciones aprendidas". Creo que sería útil para no volver a cometer los mismos errores una y otra vez.

¿Crees que es posible hacer una trazabilidad entre lo que pide el cliente y lo que finalmente se le entrega?

Si. Los documentos antes de comenzar el desarrollo se firman por el cliente y luego de probarlo, el cliente firma un documento donde dice que está de acuerdo.

\section{Encuesta 2}


En términos generales ¿cuál fue tu experiencia utilizando el proceso?

Me gustó. Lo veo bastante flexible y no tenemos que escribir muchas cosas.

$¿$ Crees que el proceso puede utilizarse en proyectos complejos?

Si. Los proyectos que lo estamos usando son complejos y anda muy bien.

¿Crees que el proceso puede utilizarse en equipos distribuidos geográficamente?

Si. De hecho, siempre hay algún miembro del equipo que trabaja remoto.

¿Crees que puede utilizarse por una persona o un equipo pequeño?

Sí. Nos pasaba que cuando usábamos Scrum, teníamos que adaptarlo cuando éramos pocos o uno solo trabajando. No es el caso de Klein.

Con respecto a la documentación del proceso ¿crees que contribuye al proyecto? Si. No soy muy amigo de escribir documentación, así que un proceso que me pida escribir poco ya tiene mi aprobación. Me gustan los documentos estándar. Así en todas las etapas sabemos dónde buscar lo que necesitamos.

Teniendo en cuenta tu experiencia con otros procesos ¿qué ventaja ves en Klein? ¿Alguna desventaja?

Es fácil de usar y puede usarse con pocos desarrolladores. No se me ocurre una desventaja.

Al utilizar el proceso ¿qué fue lo que más te costó adoptar?

Acostumbrarme a no planificar tantas tareas. El periodo de entrega es de 10 días máximo y antes, cuando usábamos Scrum eran de 21 días.

Con respecto a las etapas del proceso ¿crees que habría alguna que debería mejorarse? ¿Alguna que debería quitarse o agregarse?

Las etapas las veo bien. Están bien definidas. Quizás podría incorporarse una retrospectiva, pero no en todas las iteraciones. En aquellas donde hubo un aprendizaje que valga la pena puntualizar. Scrum nos obligaba a hacer retrospectivas en todas las iteraciones y a veces no había nada significativo que decir.

¿Crees que es posible hacer una trazabilidad entre lo que pide el cliente y lo que finalmente se le entrega?

Si. El cliente firma al principio y al final de cada entrega.

\section{Encuesta 3}

En términos generales ¿cuál fue tu experiencia utilizando el proceso?

Bien, todo bien. Lo veo sencillo.

¿Crees que el proceso puede utilizarse en proyectos complejos?

$\mathrm{Si}$. En mi caso, que tuve que usar por primera vez la tecnología $O P C$ me fue útil el proceso.

¿Crees que el proceso puede utilizarse en equipos distribuidos geográficamente?

Si. Participé como remoto en varias versiones de los productos y no tuve ningún inconveniente.

¿Crees que puede utilizarse por una persona o un equipo pequeño?

Así es. En mi caso lo utilizamos entre 2 desarrolladores, algo que no podíamos hacer con Scrum.

Con respecto a la documentación del proceso ¿crees que contribuye al proyecto? 
Claro. Los documentos explican qué poner y dónde. No hay mucho que pensar. Y como son documentos cortos, de una página, son fáciles de leer para los clientes.

Teniendo en cuenta tu experiencia con otros procesos ¿qué ventaja ves en Klein? ¿Alguna desventaja?

Puede utilizarse con un equipo reducido, no hay que escribir mucho y permite hacer entregas funcionales en poco tiempo. No veo desventajas en usarlo.

Al utilizar el proceso ¿qué fue lo que más te costó adoptar?

No me costó adaptarme. Varias cosas que incluye el proceso, ya las utilizaba en otros procesos como Scrum o Kanban.

Con respecto a las etapas del proceso ¿crees que habría alguna que debería mejorarse? ¿Alguna que debería quitarse o agregarse?

Las etapas las veo bien. En una de esas agregar lecciones aprendidas. En proyectos donde se aprende mucho en cada iteración creo que una etapa de ese tipo ayudaría.

$¿$ Crees que es posible hacer una trazabilidad entre lo que pide el cliente y lo que finalmente se le entrega?

Si. Hay dos formularios que se firman al principio y otro al final de cada versión del producto.

\section{Encuesta 4}

En términos generales ¿cuál fue tu experiencia utilizando el proceso?

Muy buena. Creo que fue el proceso que necesitábamos para ordenarnos como equipo. Nos permite mantener la trazabilidad entre la idea, el desarrollo y el código.

¿Crees que el proceso puede utilizarse en proyectos complejos?

Si. Los últimos proyectos en los que lo utilizamos eran complejos. Nadie del equipo de desarrollo tenía experiencia en las tecnologías que utilizamos.

¿Crees que el proceso puede utilizarse en equipos distribuidos geográficamente?

Si. Como usamos herramientas en la nube como Google Docs, Fira y Hangouts es bastante sencillo colaborar, aunque alguno esté trabajando de manera remota.

Con respecto a la documentación del proceso ¿crees que contribuye al proyecto? Si. Lo que escribimos es suficiente para conocer lo que hay que hacer. Muchas de las dudas las resolvemos conversando. Incluso en algunas etapas, en las que tuvimos que ver la documentación de etapas anteriores, nos fue sencillo encontrar lo que buscábamos.

¿Crees que puede utilizarse por una persona o un equipo pequeño?

Sí, creo que es una de las ventajas del proceso. En nuestro caso fue utilizado por entre 2 y 5 personas.

Teniendo en cuenta tu experiencia con otros procesos ¿qué ventaja ves en Klein? ¿Alguna desventaja?

No se me ocurre una desventaja. Algo que me parece positivo es la idea de hacer entregas cortas. Antes acostumbrábamos a pensar en todo lo que podía presentarse y eso hacía que tardemos mucho en arrancar. Klein nos ayudó a eliminar ese obstáculo.

Al utilizar el proceso ¿qué fue lo que más te costó adoptar?

No se me ocurre algo que me haya costado.

Con respecto a las etapas del proceso ¿crees que habría alguna que debería mejorarse? ¿Alguna que debería quitarse o agregarse? 
Creo que incluir lecciones aprendidas sería algo positivo.

¿Crees que es posible hacer una trazabilidad entre lo que pide el cliente y lo que finalmente se le entrega?

Si. Durante toda la versión mantenemos contacto con el cliente. Se firman los documentos.

\section{Encuesta 5}

En términos generales ¿cuál fue tu experiencia utilizando el proceso?

Me gustó. Tenía experiencia con Scrum y Kanban. Klein usa cosas de esos procesos y los otros documentos permiten ordenar el desarrollo desde el inicio de la versión hasta el final.

¿Crees que el proceso puede utilizarse en proyectos complejos?

Los proyectos en los que lo usamos tenían un gran nivel de incertidumbre. Así que sí, considero que se puede usar en proyectos complejos.

$¿$ Crees que el proceso puede utilizarse en equipos distribuidos geográficamente?

Si. Hoy está todo preparado para trabajar desde casa. Es cuestión de acostumbrarse a utilizarlas. En nuestro caso usamos Google Hangouts, Google Docs, Fira, Microsoft Team Foundation. Creo que esas herramientas nos hicieron fácil trabajar de manera remota.

Con respecto a la documentación del proceso ¿crees que contribuye al proyecto?

Si. Para validar el proceso de desarrollo necesitábamos contar con documentos oficiales que expliquen lo que el cliente quería y al final del proyecto o entrega, que el mismo cliente valide que lo que se hizo era lo que pidió. Klein nos ayudó con eso.

¿Crees que puede utilizarse por una persona o un equipo pequeño?

Sí, creo que es una de las ventajas del proceso. Cuando usábamos Scrum y éramos 2 los que trabajábamos en el proyecto, teníamos que asumir varios roles para "cumplir" con lo pedido. Pero no era Scrum. Klein nos fue útil al no exigir un mínimo de participantes. Teniendo en cuenta tu experiencia con otros procesos ¿qué ventaja ves en Klein? ¿Alguna desventaja?

Nos permitió ordenar el proceso de desarrollo de la empresa. Una vez que todos nos acostumbramos al estándar, después intercambiar de proyectos era sencillo porque todos hacíamos lo mismo.

Al utilizar el proceso ¿qué fue lo que más te costó adoptar?

Nada.

Con respecto a las etapas del proceso ¿crees que habría alguna que debería mejorarse? ¿Alguna que debería quitarse o agregarse?

Cuando trabajamos con proyectos grandes, donde hay varios componentes, tuvimos que adaptar la documentación para que refleje el "proyecto padre" y los "hijos". Pero no creo que sea una "mejora", sería una adaptación que el proceso nos permitía hacer.

¿Crees que es posible hacer una trazabilidad entre lo que pide el cliente y lo que finalmente se le entrega?

Así es. Hay 2 documentos que se firman por el cliente al inicio. Después de la entrega el cliente nos firma un documento donde dice que está conforme o no.

\section{Encuesta 6}


En términos generales ¿cuál fue tu experiencia utilizando el proceso?

Buena. Creo que es fácil de usar.

¿Crees que el proceso puede utilizarse en proyectos complejos?

$\mathrm{Si}$.

¿Crees que el proceso puede utilizarse en equipos distribuidos geográficamente?

Si.

Con respecto a la documentación del proceso ¿crees que contribuye al proyecto? Si.

¿Crees que puede utilizarse por una persona o un equipo pequeño?

Sí.

Teniendo en cuenta tu experiencia con otros procesos ¿qué ventaja ves en Klein? ¿Alguna desventaja?

No veo desventaja.

Al utilizar el proceso ¿qué fue lo que más te costó adoptar?

Nada.

Con respecto a las etapas del proceso ¿crees que habría alguna que debería mejorarse? ¿Alguna que debería quitarse o agregarse?

Está bien así.

¿Crees que es posible hacer una trazabilidad entre lo que pide el cliente y lo que finalmente se le entrega?

Si.

\section{Encuesta 7}

En términos generales ¿cuál fue tu experiencia utilizando el proceso?

Excelente. Nos ordenó el proceso de desarrollo. Cada etapa es fácil de entender y nos permite avanzar. Creo que la idea de encarar una sola funcionalidad, bien probada, es muy buena. Antes solíamos encarar muchas tareas, que dejábamos a medio terminar o mal probadas y pasábamos mucho tiempo corrigiendo problemas. La implementación era muy complicada. Ahora eso se redujo mucho.

$¿$ Crees que el proceso puede utilizarse en proyectos complejos?

Si. Probamos el proceso durante casi dos años con proyectos de tecnología nuevos, donde el equipo de desarrollo no tenía experiencia y funcionó muy bien.

¿Crees que el proceso puede utilizarse en equipos distribuidos geográficamente?

Si. Hubo etapas donde solo había un desarrollador remoto, pero durante la pandemia todos estábamos en nuestras casas trabajando y se pudo trabajar con normalidad. Estar acostumbrados a usar herramientas en la nube es una ventaja.

Con respecto a la documentación del proceso ¿crees que contribuye al proyecto? Totalmente. Cada documento nos permite tener una visión de lo que hay que hacer y lo que finalmente se hizo. Se le hace fácil a los clientes entender lo que hicimos. Con Scrum era más complicado de mostrar. Al no tener que escribir mucho, sino pensar en ideas globales nos permite comenzar a trabajar y, si surgen dudas, los charlamos con el resto. ¿Crees que puede utilizarse por una persona o un equipo pequeño?

Sí. Lo usamos de manera individual y con 2 a 5 desarrolladores sin problemas. 
Teniendo en cuenta tu experiencia con otros procesos ¿qué ventaja ves en Klein? ¿Alguna desventaja?

No veo desventaja. El proceso nos ordenó el proceso de desarrollo. De hecho, certificamos calidad de software con el proceso. Estamos muy contentos y ya es un estándar en el equipo. Al ser un proceso flexible, podemos adaptarlo a lo que vayamos necesitando. Al utilizar el proceso ¿qué fue lo que más te costó adoptar?

Como toda cosa "nueva", hay que ir descartando viejas ideas que no van en sintonía. Por ejemplo, acostumbrábamos a pensar en todo lo que podría englobar el proyecto, aunque faltaran meses para implementarlo. Ahora pensamos en 10 días. Eso nos ayudó a "arrancar" y no estar dando vueltas en situaciones que quizás no se presenten nunca o el mismo conocimiento gradual dictamine que no era necesario contemplar.

Con respecto a las etapas del proceso ¿crees que habría alguna que debería mejorarse? ¿Alguna que debería quitarse o agregarse?

Me gustan las etapas. Quizás agregar "lecciones aprendidas" podría servir en ciertos casos. Actualmente lo hacemos de manera implícita, pero contar con un documento estándar estaría bueno.

$¿$ Crees que es posible hacer una trazabilidad entre lo que pide el cliente y lo que finalmente se le entrega?

Así es. Creo que es una ventaja importante para la calidad. El cliente firma el documento de "fase 1" y "fase 2" como lo llamamos nosotros, donde especifica qué quiere que hagamos. Al final, firma el documento de "fase 3" donde se deja en claro qué se hizo y qué no. Esto nos permite trazar los requisitos durante todo el proceso. 


\section{APÉNDICE 3 - RED DE CÓDIGOS CUALITATIVOS}

En este apéndice se incluye un gráfico con la red de códigos cualitativos que son el resultado del análisis de las respuestas a las encuestas cualitativas realizadas a los participantes del caso de estudio. El mismo fue generado por Atlas.ti.

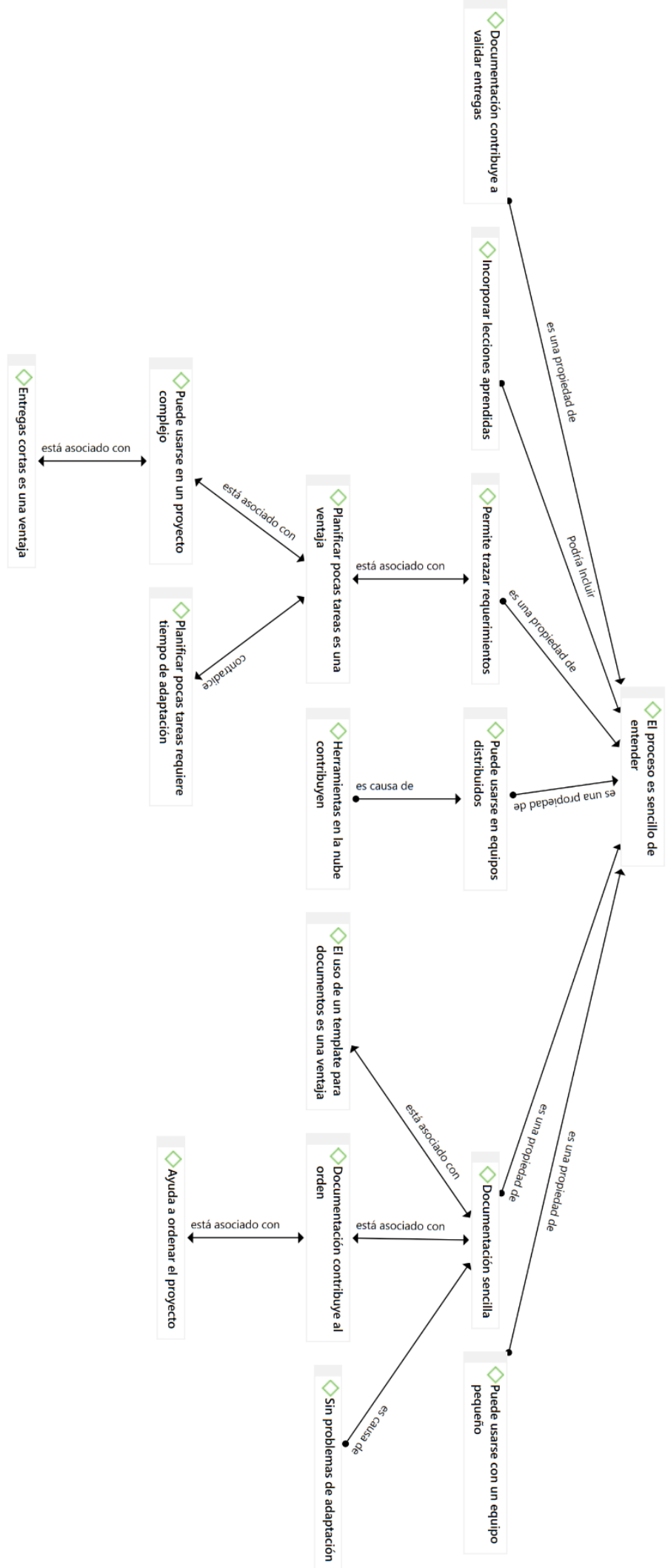




\section{APÉNDICE 4 - PROCESO DE DESARROLLO KLEIN: SYSTEM USABILITY SCALE}

A continuación, se transcribe la encuesta SUS que se utilizó para obtener información cuantitativa a los participantes del caso de estudio.

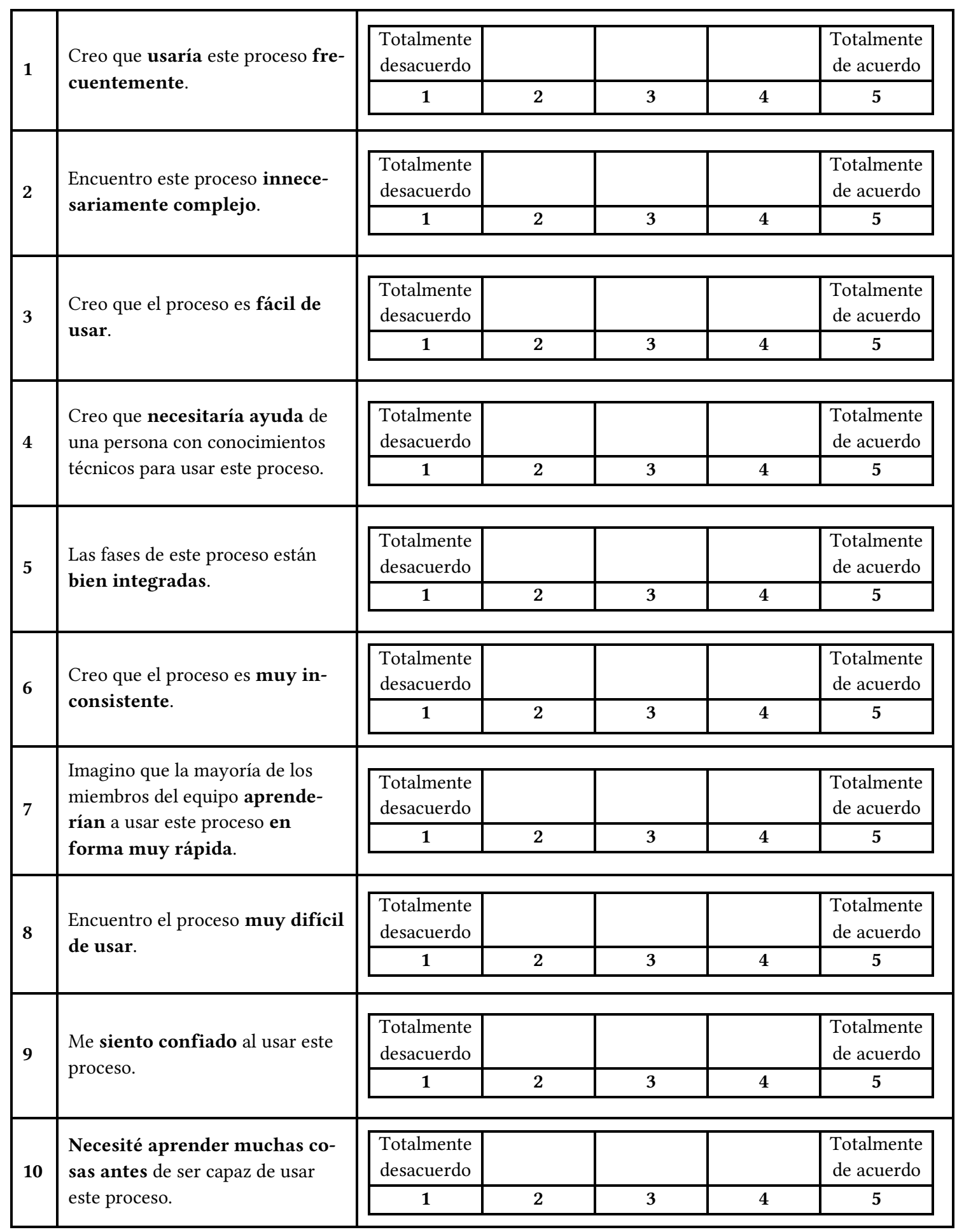




\section{APÉNDICE 5 - DOCUMENTO DEL ESTÁNDAR DE DISEÑO Y DESARROLLO DE SOFTWARE CERTIFICADO CON LA NORMA ISO 9001.2015}

ISO 9000 es una familia de estándares, establecidos por la Organización Internacional de Normalización (ISO). Se pueden aplicar en cualquier tipo de organización o actividad orientada a la producción de bienes o servicios. Las normas recogen tanto el contenido mínimo como las guías y herramientas específicas de implementación como los métodos de auditoría. ISO 9000 es un marco de trabajo que permite gestionar, controlar y mejorar una organización con el objetivo de mejorar la calidad de los productos y servicios que produce. Las organizaciones dependen de sus clientes, por lo que se deben entender sus necesidades, cumplir con sus requisitos y esforzarse por superar sus expectativas. En particular la ISO 9001.2015 se enfoca en sistemas de gestión de calidad que apliquen procesos para la mejora del sistema y el aseguramiento de la conformidad con los requisitos del cliente. El sistema se basa en 4 pilares fundamentales: planificar y establecer los objetivos del sistema y sus procesos, y los recursos necesarios para generar y proporcionar resultados de acuerdo con los requisitos del cliente y las políticas de la organización, e identificar y abordar los riesgos y las oportunidades. Hacer: implementar lo planificado. Verificar: realizar el seguimiento y (cuando sea aplicable) la medición de los procesos y los productos y servicios resultantes respecto a las políticas, los objetivos, los requisitos y las actividades planificadas, e informar sobre los resultados. Actuar: tomar acciones para mejorar el desempeño, cuando sea necesario. Entre los requisitos de productos y servicios, la norma establece en el artículo 8.2.3.2 que "la organización debe conservar la información documentada sobre cualquier requisito nuevo para los productos o servicios". Por otro lado, el artículo 8.2.4, sobre "Cambios en los requisitos para los productos o servicios", establece que "la organización debe asegurarse de que, cuando se cambien los requisitos para los productos y servicios, la información documentada pertinente sea modificada y de que las personas pertinentes sean conscientes de los requisitos modificados".

El siguiente documento es una versión simplificada y modificada para mantener el secreto profesional de la empresa que participó del caso de estudio. Los documentos "Fase 1", "Fase 2" y "Fase 3" son los nombres de los documentos del proceso Klein correspondientes a "Iniciación", "Definición Preliminar" y "Revisión”. El tablero Kanban de las etapas "Requerimientos a Tareas" y "Ejecución de Tareas" se alojan en fira.

\section{DISEÑO Y DESARROLLO DE SOFTWARE}

\section{PROCEDIMIENTO}

\section{Diseño y Desarrollo de software:}

A partir de un requerimiento de un cliente, analizamos la idea para darle forma y entender lo que se requiere para determinar, por un lado, su factibilidad y por el otro, evaluar si tenemos la capacidad para dar respuesta a esa solicitud.

Luego, antes de dar lugar a la propuesta al cliente, se tiene en cuenta el alcance, el costo beneficio, los diferentes participantes (externos e internos), la gestión, la planificación, y los riesgos.

A partir de la propuesta aceptada por el cliente, se diseña la solución y se desarrolla a partir de lo diseñado con el fin de crear un producto que satisfaga las necesidades del cliente. 
Desde: Requerimiento (Viene de Gestión de las Relaciones con los Clientes) Entregable: Documentos Fase I Iniciación (Ver modelo) y Fase II Definición Preliminar (Ver modelo)

Hasta: Producto final y Documento Fase III (Va al proceso de implementación)

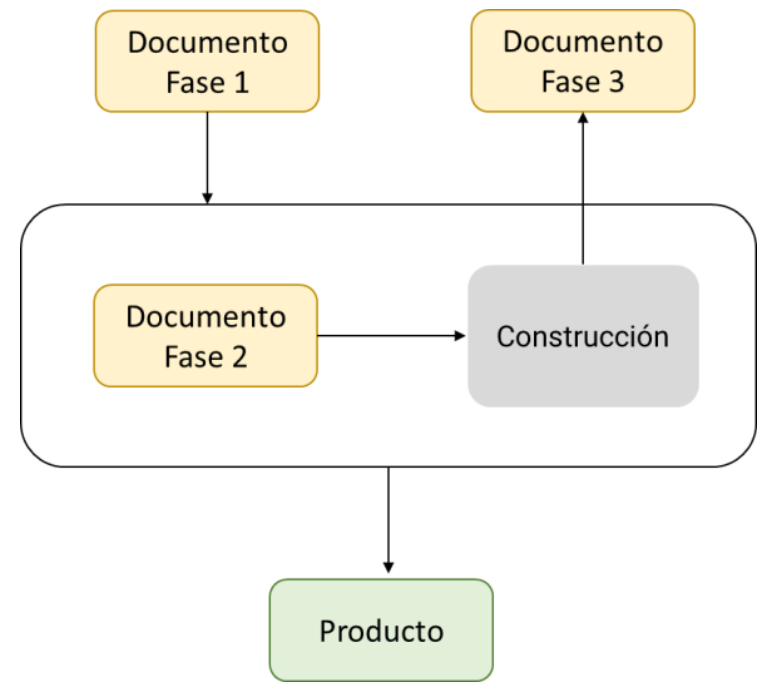

El proceso de diseño y desarrollo garantiza la calidad del producto teniendo en cuenta el siguiente esquema de trabajo.
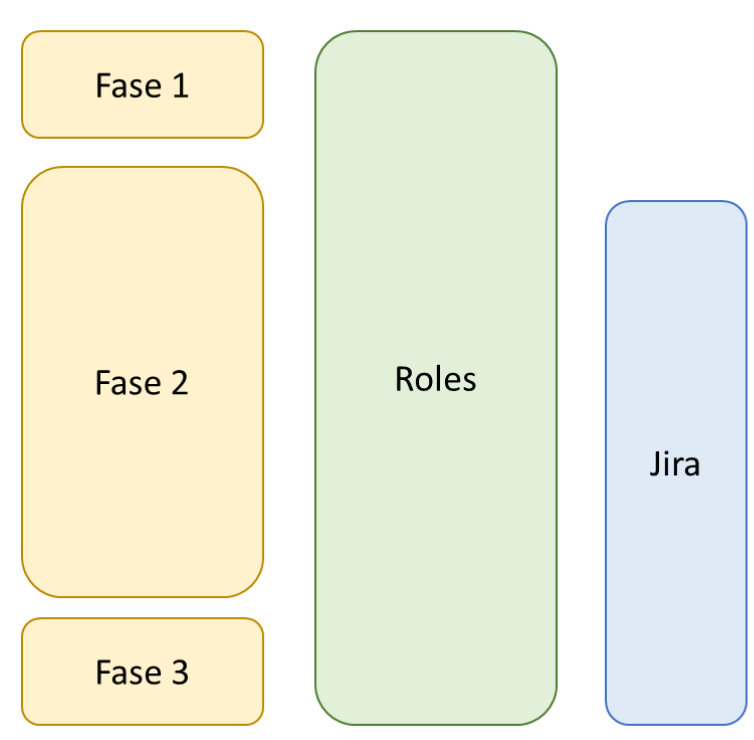

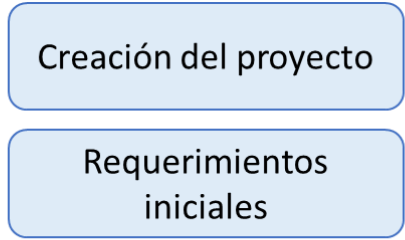

Tareas para la iteración

Asignación de tareas

Ejecución de tareas

Entrega de versión del producto

Una vez definida la visión y comprensión de los requerimientos en la fase 1 y que ha sido compartida y aceptada por todos (Cliente y Proveedor)

1. Crear el proyecto en una herramienta. (Por ejemplo, Jira)

2. Se genera la lista inicial de requerimientos funcionales.

3. Se genera la lista inicial de tareas priorizadas (Backlog de tareas)

4. Se definen la iteración (Versión entregables), la fecha de inicio y fin definidas en Fase 2

5. Definir y asignar los roles y las responsabilidades.

6. Se incluyen las acciones de Revisión, Verificación, y Validación que se consideren necesarias.

7. Se asignan las tareas.

8. Se ejecutan las tareas. 
9. Ejecutar y dejar registros de las pruebas definidas.

10. Ejecutar y dejar registro de las pruebas definidas.

11. Se obtiene el producto final.

Cada requerimiento funcional definido en el Documento Fase 2 será clasificado por su tipo (historia, tarea o error) y agregados al Backlog en JIRA. Sobre estos requerimientos se define la estimación de tiempo de desarrollo y los criterios de aceptación.

Cada iteración tiene una fecha de inicio y fin sobre la cual se medirá la eficacia del desarrollo.

El tiempo estimado es el que corresponde de la sumatoria de las estimaciones realizadas en cada requerimiento funcional.

Si ocurriese un error o surgiera una mejora en la versión productiva del software se deberá generar una revisión de dicha versión. En el Documento Fase 2 se detalla el error a solucionar o el requerimiento. Allí queda registrado en que versión /revisión del software está solucionado dicho error.

El responsable de desarrollar cualquier tipo requerimiento agrega todas las tareas en JIRA que son necesarias para lograr el resultado, allí no es necesario definir tiempo de desarrollo porque ese tiempo está definido en el requerimiento funcional.

No se mide la eficacia de cada tarea sino la eficacia de cada iteración.

\section{Definición y ejecución de las iteraciones}

- Cada iteración tiene fecha de inicio y fecha de fin acordada (por todas las partes involucradas)

- Como parte de las verificaciones que se aplican, cada tarea es sometida a las pruebas que se hayan definido para dicha tarea. De esta manera aseguramos que el resultado obtenido nos dará un producto que cumple con los requisitos preestablecidos en el documento de Fase 1.

- Cada una de las tareas, involucradas en la iteración, deberá ser entregada con el detalle de las pruebas realizadas y el resultado obtenido, lo cual se toma como evidencia de que han pasado las pruebas correspondientes, y que la tarea se ha finalizado correctamente.

- El $100 \%$ de las tareas involucradas en una iteración se consideran finalizadas, sólo si se han pasado satisfactoriamente las pruebas definidas.

- Al final de cada iteración parcial, se debe documentar el cumplimiento del alcance correspondiente a dicha iteración.

- Se debe medir si hay un desvío entre la cantidad de días consumidos y los planificados (Advertir el impacto por diferencia con el presupuesto)

- Cualquier acción que se realice, y tenga un impacto en la fecha estimada de entrega final, debe ser debidamente documentada e informada al proceso de relaciones con el cliente, y pactada con el cliente, evaluando los costos que ello implique. Se debe medir la cantidad de días de desvíos y la diferencia del valor acordado.

\section{Producto liberado para su implementación}

La calidad del producto liberado a producción estará dada por las validaciones aplicadas, asegurando que el producto desarrollado está acorde a su especificación y cumpla las necesidades de los clientes, dichas validaciones quedarán registradas en el Documento Fase 3.

Al finalizar, se creará un documento de implementación donde se especificarán las versiones de cada componente a instalar o actualizar, los scripts a ejecutar y cualquier consideración que sea necesaria para la implementación.

\section{Gestión del proyecto}


Toda la documentación que se genere para un proyecto determinado debe ser generada y alojada en una carpeta creada en el disco compartido de desarrollo, donde se agregará una nueva carpeta con el nombre del proyecto correspondiente. 